\title{
A Universal Porous Adsorbent for the Selective Capture of Carbon Dioxide
}

\author{
Omid T. Qazvini and Shane G. Telfer* \\ MacDiarmid Institute for Advanced Materials and Nanotechnology, School of Fundamental Sciences, \\ Massey University, Palmerston North, New Zealand. \\ Email: s.telfer@massey.ac.nz
}

\begin{abstract}
Efficient and sustainable methods for carbon dioxide $\left(\mathrm{CO}_{2}\right)$ capture are essential. Its atmospheric concentration must be reduced to meet climate change targets, and its removal from sources such as chemical feedstocks is vital. While mature technologies involving chemical reactions that absorb $\mathrm{CO}_{2}$ exist, they have many drawbacks. Porous materials with void spaces that are complementary in size and electrostatic potential to $\mathrm{CO}_{2}$ offer an alternative. In these materials, the molecular $\mathrm{CO}_{2}$ guests are trapped by noncovalent interactions, hence they can be recycled by releasing the $\mathrm{CO}_{2}$ with a low energy penalty. Capacity and selectivity are the twin challenges for such porous adsorbents. Here, we show how a metal-organic framework, termed MUF-16 (MUF = Massey University Framework), is a universal adsorbent for $\mathrm{CO}_{2}$ that sequesters large quantities of $\mathrm{CO}_{2}$ from a broad palette of gas streams with record selectivities over competing gases. The crystallographically-determined position of the $\mathrm{CO}_{2}$ molecules captured in the framework pores illustrate how complementary noncovalent interactions envelop $\mathrm{CO}_{2}$ while repelling other guest molecules. The low affinity of the pore environment for other gases underpins the strikingly high selectivity of MUF-16 for $\mathrm{CO}_{2}$ over methane, nitrogen, hydrogen, acetylene, ethylene, ethane, propylene and propane. Breakthrough gas separations under dynamic conditions benefit from short time lags in the elution of the weakly-adsorbed component to deliver a repertoire of high-purity products. MUF-16 is an inexpensive, robust, recyclable adsorbent that is universally applicable to the removal of $\mathrm{CO}_{2}$ from sources such as natural gas, syngas, flue gas and chemical feedstocks.
\end{abstract}




\section{Introduction}

Chemical separation processes consume vast quantities of energy. Economical and practical pathways to alleviating this burden are required. This is especially relevant to the capture of $\mathrm{CO}_{2}$. The release of $\mathrm{CO}_{2}$ into the atmosphere underlies the greenhouse effect and subsequent temperature increases. There is a pressing need to mitigate $\mathrm{CO}_{2}$ emissions, which can be achieved using a multifaceted approach involving an overall reduction in energy intensity coupled to the uptake of carbon-free fuels and enhanced $\mathrm{CO}_{2}$ sequestration techniques. Fossil fuels can be decarbonized by trapping $\mathrm{CO}_{2}$ from syngas prior to use, and emitted $\mathrm{CO}_{2}$ can be captured at point sources where its concentration is high. ${ }^{1}$ Negative emissions that accrue by capturing $\mathrm{CO}_{2}$ directly from air are also baked in to most future climate scenarios. ${ }^{2} \mathrm{CO}_{2}$ must be removed from gas streams in many other situations, for example from natural gas and biogas, and purify valuable hydrocarbons prior to polymerization or chemical derivatization. All of these processes are separations that rely on the selective capture of $\mathrm{CO}_{2}$ over other gases. The established technology for trapping $\mathrm{CO}_{2}$ involves chemical reactions with absorbents, typically amines, in solution. ${ }^{3}$ This incurs multiple drawbacks, including high energy penalties during regeneration, losses due to degradation and evaporation, and the corrosion of hardware and pipelines. ${ }^{4}$

The adsorption of $\mathrm{CO}_{2}$ in nanoporous materials is an attractive alternative to solution chemisorption. ${ }^{5}$ The weak, noncovalent bonding interactions that underlie physisorption rely on accessible pores that are structured on the molecular scale. They lower the energy requirements for driving off the trapped $\mathrm{CO}_{2}$ to deliver materials that are sustainable and recyclable. Effective physisorbents combine high uptake, rapid guest diffusion, and long-term stability with selectivity for $\mathrm{CO}_{2}$ over competing gases at relevant concentrations. In this context, metal-organic frameworks (MOFs) have risen to prominence. ${ }^{6-9} \mathrm{MOF}$ materials are built up from metal ions and organic ligands, and their pore shape, size and chemical environment can be systematically designed. This in turn leads tailors interactions between framework hosts and molecular guests. For example, the Ni-(4-pyridylcarboxylate) ${ }_{2}$ framework is able to capture large quantities of $\mathrm{CO}_{2}$ and exhibits an appreciable selectivity for $\mathrm{CO}_{2}$ over $\mathrm{H}_{2}$ at high pressures. This makes it amenable to the purification of syngas. ${ }^{10}$ While natural gas and biogas are primarily composed of methane (at high pressure and low pressure, respectively), contamination by $\mathrm{CO}_{2}$ can be considerable and cause pipeline corrosion and dry ice formation. MOFs such as SIFSIX-14-Cu-i and NbOFFIVE-1$\mathrm{Ni}$, however, offer a means of significantly reducing the $\mathrm{CO}_{2}$ concentration in the presence of dominant quantities of methane. ${ }^{6,11,12}$ Designing analogues of these MOFs by changing the metal ion or altering the interpenetration level has dramatic consequences for their adsorption behaviour. ${ }^{13}$ Despite these advances, challenges remain in identifying MOF adsorbents that combine a good separation performance with the other requisite characteristics. For example, Mg-MOF-74 is distinguished by its high $\mathrm{CO}_{2}$ uptake, but this arises from a high density of open metal sites that are irreversibly blocked by traces of water vapour and oxygen. ${ }^{14}$ Impregnation of the material with amines improves the stability and selectivity of the material, but high temperatures are required to recycle the material by $\mathrm{CO}_{2}$ desorption. ${ }^{15}$ 
The recent surge of interest in porous frameworks has largely focussed on the separation of specific gas pairs. ${ }^{6,8}$ However, a truly universal adsorbent that can capture $\mathrm{CO}_{2}$ from a diverse array of gas streams with various compositions and operating pressures is yet to emerge. Such a material would have many advantages, such as economies of scale in manufacturing, well understood adsorption metrics, industry acceptance, and facile deployment. Traditional adsorbents such as zeolites, silica gel and activated carbon approach this kind of universality for other gases, which highlights the opportunities for next-generation materials with improved selectivities and physicochemical characteristics.

Inspired by the superb properties of MOFs derived from straightforward and readily-available linkers, ${ }^{16,17}$ we sought to develop an adsorbent that could efficiently trap $\mathrm{CO}_{2}$. Our interest was captured by the MUF-16 (MUF = Massey University Framework) series of materials. These frameworks are prepared simply by combining 5-aminoisophthalic acid ( $\mathrm{H}_{2}$ aip), an inexpensive, commercially-available linker, with cobalt(II), nickel(II), or manganese(II) salts in alcoholic solvent (Figure 2a). This delivers a family of compounds with the general formula $\left[\mathrm{M}(\mathrm{Haip})_{2}\right],{ }^{18,19}$ referred to as MUF-16 (M =Co), MUF16(Ni) and MUF-16(Mn), respectively. These crystalline materials are high yielding on multi-gram scales and tolerant to typical laboratory atmospheres. Their crystal structures were determined by single crystal X-ray diffraction (Table S4). The three frameworks are isostructural, belonging to the I2/a space group. Individually, the metal ions adopt an octahedral geometry with four carboxylate and two amino donors, arranged trans to one another, from six different Haip ligands. These ions are aligned into onedimensional chains along the crystallographic $b$ axis supported on each side by $\mu_{2}$-bridging carboxylate groups (Figure 1b). Adjacent chains are connected into two-dimensional sheets by Haip ligands that extend across the bc plane by coordinating to the metal centres with both their amino and carboxylate donors (Figure 1b). Only one of the two carboxyl groups of each Haip ligand coordinates to the metal. The other remains protonated and engages in hydrogen-bonding with a partner extending from an adjacent layer (Figure 1c). These interactions link the layers into three-dimensional frameworks. The frameworks support one-dimensional channels running along a crystallographic axis with dimensions of approximately $3.3 \times 6.5 \AA$ (Figure 1d). In their as-synthesized form the pores contain occluded water, which can be easily removed by heating in vacuo.

MUF-16 frameworks are obtained in high purity, as established by both elemental analysis and the match between the powder X-ray diffraction patterns recorded on bulk material and those simulated from the single-crystal X-ray diffraction structures (Figure S7). Thermogravimetric analysis demonstrated their thermal stability beyond $330{ }^{\circ} \mathrm{C}$ under nitrogen (Figure S4). The frameworks are chemically robust, being unaffected by soaking in water or exposure to air for prolonged periods, as confirmed by powder X-ray diffraction and gas adsorption analysis (vide infra). 

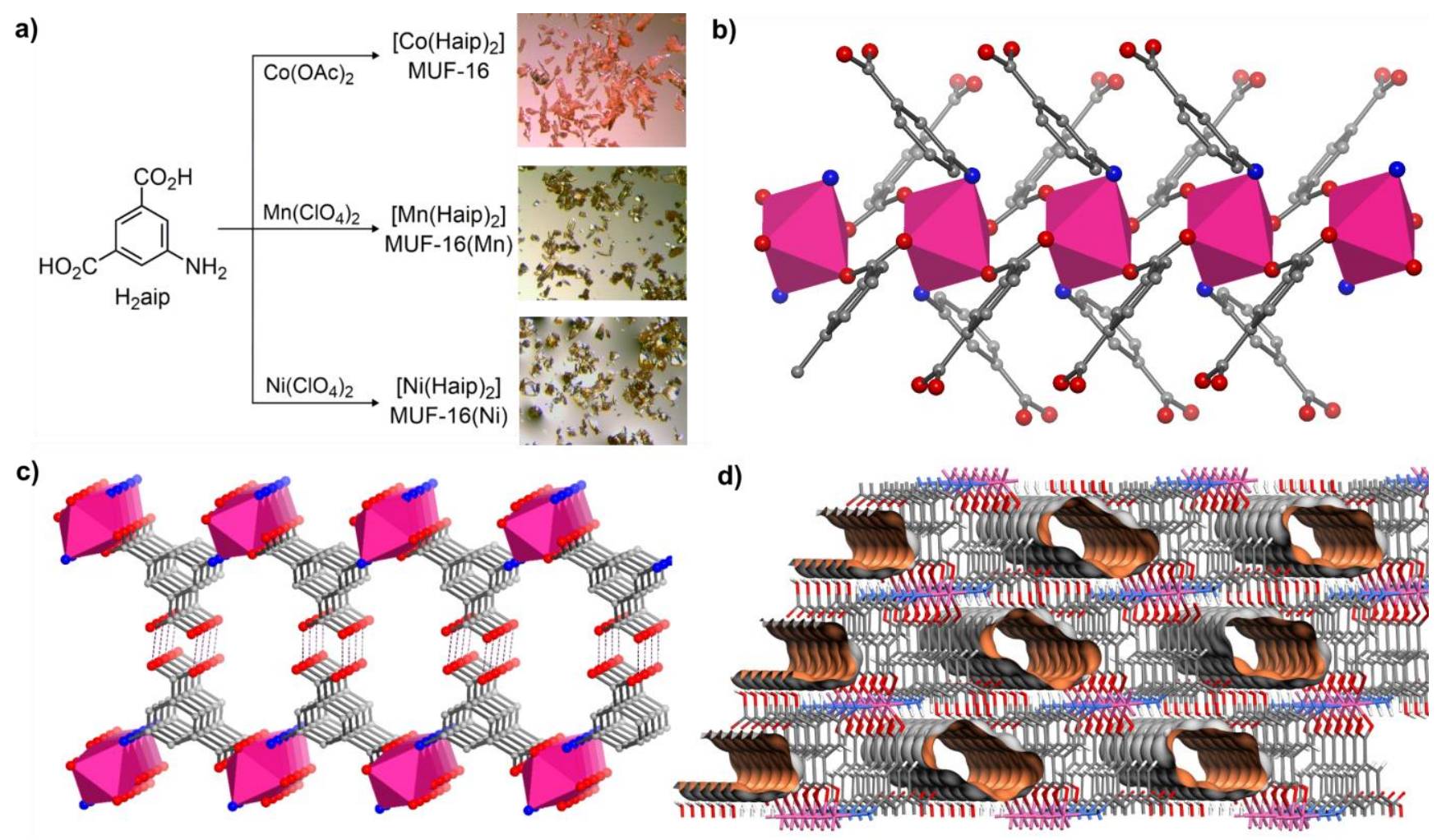

Figure 1. (a) Synthetic routes to the MUF-16 family and optical micrographs of the reaction products. (b) Infinite secondary building units (iSBUs) in MUF-16 comprise one-dimensional cobalt(II) chains connected by $\mu_{2}$-bridging carboxylate groups of the Haip ligands $\left(\mathrm{H}_{2}\right.$ aip $=5$-aminoisophthalic acid).

The cobalt(II) ions are depicted as filled octahedra. (c) The iSBUs are linked into planar twodimensional sheets by the Haip ligands and further connected into a three-dimensional framework by

hydrogen bonding (depicted as dashed lines) between adjacent sheets. (d) MUF-16 features onedimensional channels that propagate through the framework. The Connolly surface of the framework is shown in orange and defined with a probe of diameter $1.0 \AA$. Colour code: cobalt = magenta; oxygen = red; carbon = grey; hydrogen $($ where shown $)=$ white .

As suggested by SCXRD, the MUF-16 frameworks are accessible to a range of incoming gases. Activation to give permanently porous materials is straightforward, and nitrogen adsorption isotherms measured at $77 \mathrm{~K}$ gave BET surface areas of 215, 209 and $238 \mathrm{~m}^{2} / \mathrm{g}$ for MUF-16, MUF-16(Mn), and MUF-16(Ni), respectively (Figures S18-S20). Total pore volumes of $0.11 \mathrm{~cm}^{3} / \mathrm{g}$ were measured for all three frameworks (Table S1). These values are comparable with the geometric surface areas and pore volumes calculated from the crystallographic coordinates. $\mathrm{CO}_{2}$ adsorption isotherms were collected at $293 \mathrm{~K}$ (Figure 2a). These isotherms rise steeply at low pressures and nearly plateau towards 1 bar, which indicates a strong affinity of the frameworks for the $\mathrm{CO}_{2}$ guests. The capacities of these materials to host $\mathrm{CO}_{2}$ is considerable: both MUF-16 and MUF-16(Ni) take up $2.13 \mathrm{mmol} / \mathrm{g}\left(48 \mathrm{~cm}^{3} / \mathrm{g}\right)$ at $1 \mathrm{bar}$, and MUF$16(\mathrm{Mn})$ adsorbs $2.25 \mathrm{mmol} / \mathrm{g}\left(50.5 \mathrm{~cm}^{3} / \mathrm{g}\right)$. This equates to approximately 0.9 molecules of $\mathrm{CO}_{2}$ per metal site (Table S6). Since the framework pores are nearly saturated at $293 \mathrm{~K}$ and 1 bar, $\mathrm{CO}_{2}$ uptake is only marginally higher at $273 \mathrm{~K}$ (Figure S11). The isosteric heat of adsorption $\left(Q_{s t}\right)$ at zero-coverage was calculated to be around $33-37 \mathrm{~kJ} / \mathrm{mol}$ (Figure $2 \mathrm{~b}$ ). The $Q_{s t}$ increases at higher loadings, which can be attributed to intermolecular interactions between the adsorbates when the framework pores approach saturation. These interactions were experimentally verified by SCXRD (vide infra). Since $Q_{s t}$ values 
remain moderate even at high $\mathrm{CO}_{2}$ loading, and well below values observed for MOFs with open metal sites, the energy required to regenerate the frameworks by $\mathrm{CO}_{2}$ desorption is likely to be low. Furthermore, the risk of irreversible poisoning by traces of pernicious contaminants is minor.
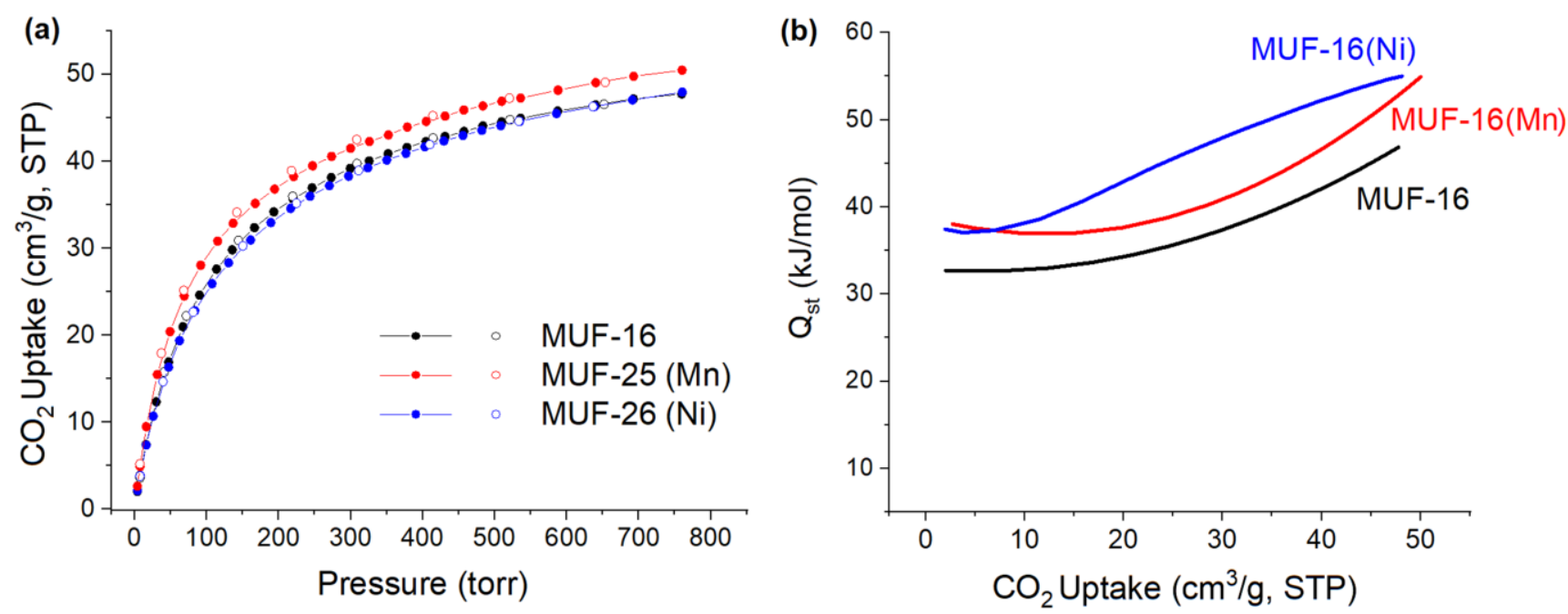

Figure 2. (a) Volumetric adsorption (filled circles) and desorption (open circles) isotherms of $\mathrm{CO}_{2}$ measured at $293 \mathrm{~K}$ and for MUF-16 (black), MUF-16(Mn) (red), and MUF-16(Ni) (blue). (b) Heats of adsorption $\left(\mathrm{Q}_{\mathrm{st}}\right.$ ) calculated for $\mathrm{CO}_{2}$ binding to MUF-16 (black), MUF-16(Mn) (red), and MUF-16(Ni) (blue) as a function of $\mathrm{CO}_{2}$ uptake. A high affinity for $\mathrm{CO}_{2}$ coupled to a moderate heat of adsorption promise an adsorbent that takes up significant quantities of gas yet is easily recycled.

Single-crystal X-ray diffraction was used to identify the $\mathrm{CO}_{2}$ binding sites in these frameworks. MUF-16(Mn) was selected for this study since its darker colour streamlined crystal handling, but the results are applicable to the other members of the MUF-16 family. After transferring a MUF-16(Mn) single crystal into a capillary, it was activated in vacuo and the capillary flame-sealed. This allowed the guest-free structure of MUF-16(Mn) to be crystallographically determined under a vacuum (Table S5). We then filled $\mathrm{CO}_{2}$ into the capillary to a pressure of 1.1 bar to determine the structure of the $\mathrm{CO}_{2}$-loaded framework. We noted only minor changes to the framework itself upon either evacuation or filling with $\mathrm{CO}_{2}$. A clear picture of the affinity of MUF-16 for $\mathrm{CO}_{2}$ was revealed by the $\mathrm{CO}_{2}$-loaded SCXRD structure. First, the dimensions of the framework pores match the size of the $\mathrm{CO}_{2}$ molecules, which allows these guests to be enveloped by multiple non-covalent contacts (Figure 3a). Second, these contacts are favourable since the electric quadrupole of the $\mathrm{CO}_{2}$ is complementary to the polarization of the MUF-16 pore surface. For example, one of the electronegative oxygen atoms of the $\mathrm{CO}_{2}$ molecule engages in $\mathrm{N}-\mathrm{H} \cdots \mathrm{O}$ and $\mathrm{C}-\mathrm{H} \cdots \mathrm{O}$ interactions with hydrogen atoms of amino and phenyl groups at distances of 2.55 and $2.81 \AA$, respectively. Similarly, the electropositive carbon atom of the $\mathrm{CO}_{2}$ molecule contacts an oxygen atom of a non-coordinated carboxylate group with a distance of $2.87 \AA$. Two sites, which are related by crystallographic symmetry and share a common location for one of the oxygen atoms, are available to the $\mathrm{CO}_{2}$ guests. They are occupied with a 50/50 ratio to give one $\mathrm{CO}_{2}$ molecule per Mn centre overall. The $\mathrm{CO}_{2}$ guest molecules are aligned along the pore axis in a tilted 
fashion (Figure 3b). These arrays take advantage of short attractive $\mathrm{C} \cdots \mathrm{O}$ intermolecular interactions between adjacent molecules at $3.78 \AA$, which underlie the observed increase in $Q_{s t}$ as a function of gas loading observed in the adsorption isotherms.
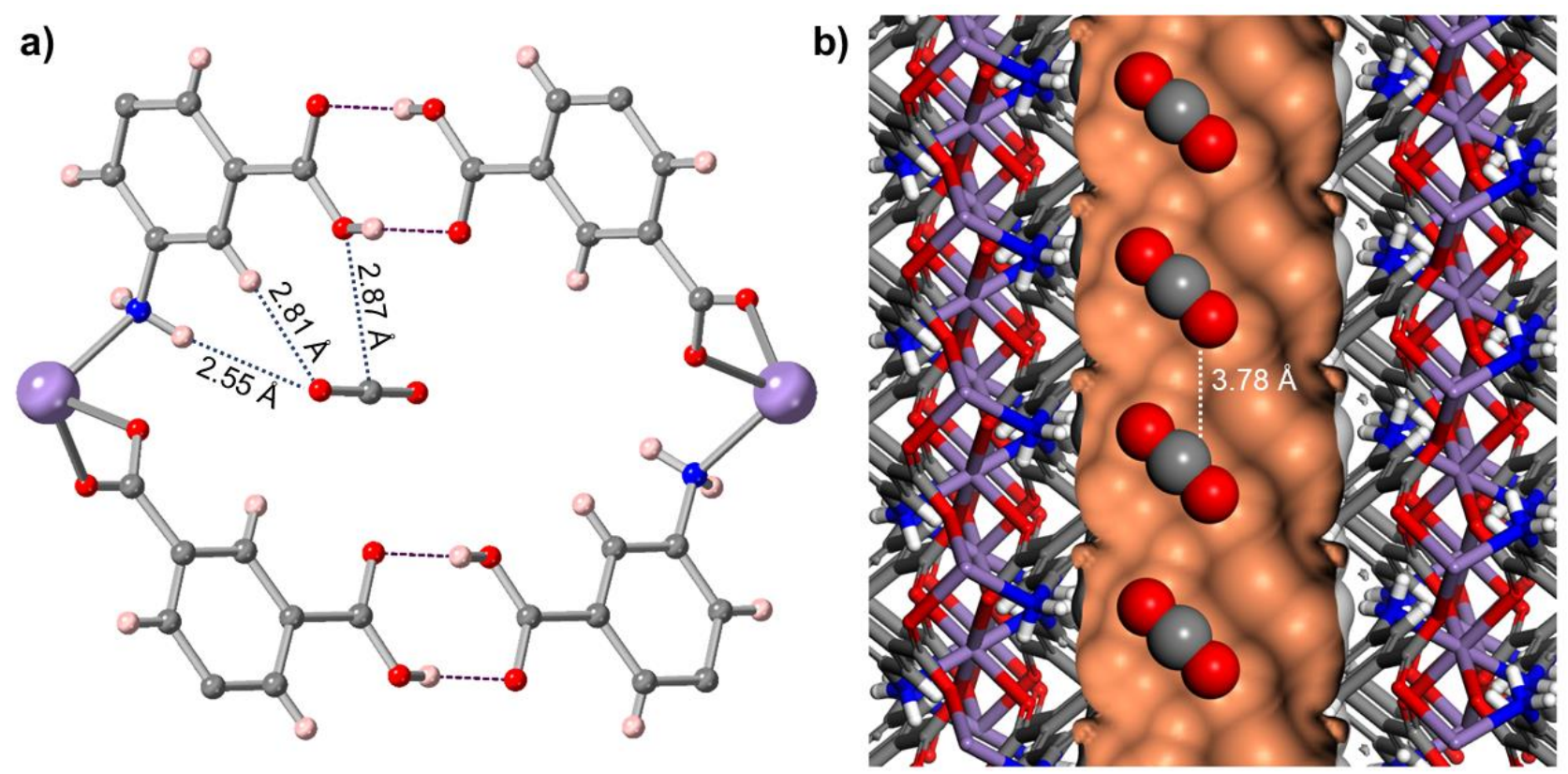

Figure 3. (a) The adsorption sites of $\mathrm{CO}_{2}$ molecules in the pores MUF-16(Mn) as determined by single-crystal X-ray diffraction. A view down the long axis of the channel is depicted. A second, symmetry-equivalent $\mathrm{CO}_{2}$ adsorption site is present. (b) Arrays of adsorbed $\mathrm{CO}_{2}$ molecules observed in the channels of MUF-16(Mn) highlighting potential attractive noncovalent interactions between adjacent guests. The $\mathrm{CO}_{2}$ molecules in are shown in representative orientations that correspond to one of the two symmetry-related crystallographic orientations. Colour code: manganese = light purple; nitrogen $=$ blue; oxygen $=$ red; carbon $=$ grey; hydrogen $=$ white; pore Connolly surface $=$ orange .

\section{Selectivity of MUF-16 for $\mathrm{CO}_{2}$ and gas separations}

The high uptake of $\mathrm{CO}_{2}$ by MUF-16 stands in contrast to other gases. Adsorption isotherms of $\mathrm{H}_{2}$, $\mathrm{Ar}, \mathrm{N}_{2}, \mathrm{CH}_{4}, \mathrm{O}_{2}, \mathrm{C}_{2} \mathrm{H}_{2}, \mathrm{C}_{2} \mathrm{H}_{4}, \mathrm{C}_{2} \mathrm{H}_{6}, \mathrm{C}_{3} \mathrm{H}_{6}$ and $\mathrm{C}_{3} \mathrm{H}_{8}$ were measured on MUF-16 at $293 \mathrm{~K}^{20}$ Only modest quantities of these gases are adsorbed, and care was taken to ensure the accuracy of these measurements (Figure 4a and Table S1). For example, MUF-16 takes up just 1.32 and $1.20 \mathrm{~cm}^{3} / \mathrm{g}$ of $\mathrm{N}_{2}$ and $\mathrm{CH}_{4}$ at 1 bar and $293 \mathrm{~K}$, respectively, which rises to the highest value amongst the measured adsorbates of 5.35 $\mathrm{cm}^{3} / \mathrm{g}$ for $\mathrm{C}_{3} \mathrm{H}_{6}$. While the low uptake of the monatomic and diatomic gases is a well-established function of their small polarizabilities and small (or zero) quadrupole moments, the diminished affinity for the larger hydrocarbon guests is notable. Electropositive regions around their termini (Figure S1) leads to repulsive interactions with the framework pore surface, as illustrated by the hypothetical loading of $\mathrm{C}_{2} \mathrm{H}_{2}$ in MUF-16 (Figure S2).

The observed uptake ratios for $\mathrm{CO}_{2} / \mathrm{N}_{2}, \mathrm{CO}_{2} / \mathrm{CH}_{4}$ and $\mathrm{CO}_{2} / \mathrm{H}_{2}$ are 36.2, 39.8 and 74.6, respectively, at $293 \mathrm{~K}$ and 1 bar. The preferential uptake of $\mathrm{CO}_{2}$ over $\mathrm{N}_{2}$ is comparable to the benchmark physisorbent $\left[\mathrm{Cd}_{2} \mathrm{~L}\left(\mathrm{H}_{2} \mathrm{O}\right)\right]^{21}$ (36.3), and elevated beyond materials such as SIFSIX-2-Cu-i (34), ${ }^{22}$ DICRO-3-Ni-i (20), ${ }^{23}$ and zeolite $13 \mathrm{X}$ (18.7) (Table S10). While some materials that trap $\mathrm{CO}_{2}$ by chemisorption show 
higher uptake ratios, including amine-functionalised frameworks en-Mg-dobpdc (47), ${ }^{15} \mathrm{mmen}-\mathrm{Cu}$ BTTri (38.3) ${ }^{24}$ and Mg-mmen-dobpdc (36.7), ${ }^{25}$ they require significant energy input to desorb the captured $\mathrm{CO}_{2}$. With respect to $\mathrm{CO}_{2} / \mathrm{CH}_{4}$, the uptake ratio of MUF-16 is comparable to that of $\left[\mathrm{Cd}_{2} \mathrm{~L}\left(\mathrm{H}_{2} \mathrm{O}\right)\right](42.9),{ }^{21}$ and is exceeded by only one other reported material (SIFSIX-14-Cu-i, 116). ${ }^{26}$

MUF-16 adsorbs more $\mathrm{CO}_{2}$ than $\mathrm{C} 2$ and $\mathrm{C} 3$ hydrocarbons with uptake ratios of between 9.0 and 15.9 at $293 \mathrm{~K}$ and 1 bar (Table 1). This contrasts with typical physisorbents, which show a preference for unsaturated hydrocarbons especially when bonding between the guest's $\pi$ electrons and open metal sites can occur. ${ }^{27-34}$ The inverted selectivity for $\mathrm{CO}_{2}$ over $\mathrm{C} 2$ and $\mathrm{C} 3$ hydrocarbons exhibited by MUF-16 has seldom been reported, ${ }^{34-42}$ and, to the best of our knowledge, there are not any MOFs reported in the literature that preferentially adsorb $\mathrm{CO}_{2}$ with this degree of generality. It is notable that energy efficiency gains may stem from MUF-16 since high-purity hydrocarbon products can be obtained in a single step by capturing $\mathrm{CO}_{2}$ from crude gas streams. On the other hand, hydrocarbon-selective MOFs require additional processing and purification since $\mathrm{CO}_{2}$ is co-adsorbed by the adsorbent. ${ }^{34,43,44}$ MUF-16 has a particularly high affinity for $\mathrm{CO}_{2}$ relative to $\mathrm{C}_{2} \mathrm{H}_{2}$, which is elevated beyond earlier reported $\mathrm{CO}_{2}$ selective materials including SIFSIX-3-Ni (1.2 at $298 \mathrm{~K}$ and $0.1 \mathrm{bar})^{34}$, CD-MOF (1.3 at $298 \mathrm{~K}$ and 1 bar $)^{42}, \mathrm{~K}_{2}\left[\mathrm{Cr}_{3} \mathrm{O}(\mathrm{OOCH})_{6}(4 \text {-ethylpyridine })_{3}\right]_{2}\left[\alpha-\mathrm{SiW}_{12} \mathrm{O}_{40}\right]\left(4.5\right.$ at $278 \mathrm{~K}$ and 1 bar) ${ }^{38}$ and [Mn(bdc)(dpe)] $\left(6.4\right.$ at $273 \mathrm{~K}$ and 1 bar) ${ }^{39}$ (Table S11).
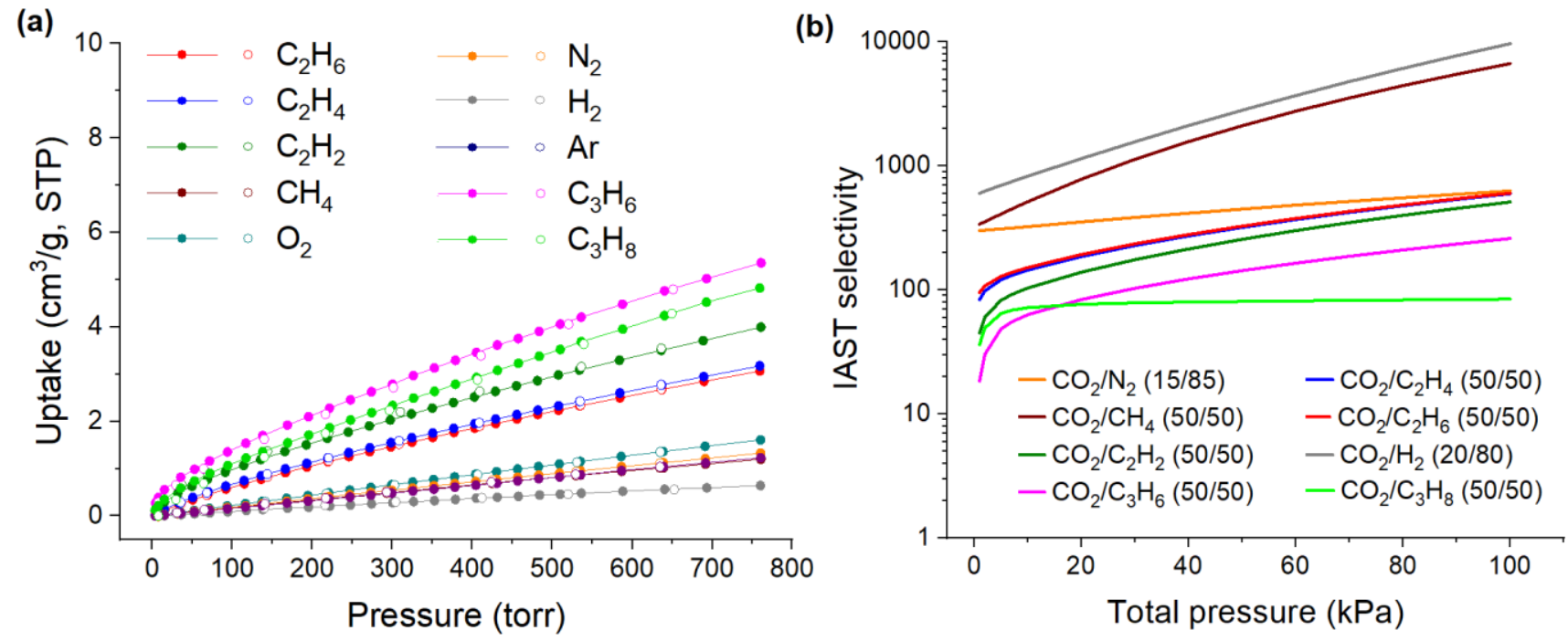

Figure 4. (a) Experimental $\mathrm{H}_{2}, \mathrm{Ar}, \mathrm{N}_{2}, \mathrm{CH}_{4}, \mathrm{O}_{2}, \mathrm{C}_{2} \mathrm{H}_{2}, \mathrm{C}_{2} \mathrm{H}_{4}, \mathrm{C}_{2} \mathrm{H}_{6}, \mathrm{C}_{3} \mathrm{H}_{6}$ and $\mathrm{C}_{3} \mathrm{H}_{8}$ adsorption (solid spheres) and desorption (open spheres) isotherms of MUF-16 measured at $293 \mathrm{~K}$. (b) Predicted IAST selectivities, displayed with a log scale, of MUF-16 for various gas mixtures at $293 \mathrm{~K}$. 
Table 1. Summary of gas adsorption data and IAST-calculated selectivities for the MUF-16 family at 1 bar and $293 \mathrm{~K}$.

\begin{tabular}{|c|c|c|c|c|}
\hline & Gas(es) & MUF-16 & MUF-16(Mn) & MUF-16(Ni) \\
\hline \multirow{9}{*}{ 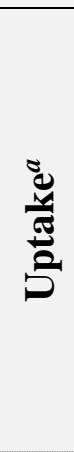 } & $\mathrm{CO}_{2}$ & 47.78 & 50.5 & 47.97 \\
\hline & $\mathrm{N}_{2}$ & 1.32 & 2.86 & 2.30 \\
\hline & $\mathrm{CH}_{4}$ & 1.20 & 3.10 & 2.77 \\
\hline & $\mathrm{H}_{2}$ & 0.64 & 1.10 & 0.78 \\
\hline & $\mathrm{C}_{2} \mathrm{H}_{2}$ & 3.99 & 9.69 & 7.53 \\
\hline & $\mathrm{C}_{2} \mathrm{H}_{4}$ & 3.17 & 8.31 & 5.42 \\
\hline & $\mathrm{C}_{2} \mathrm{H}_{6}$ & 3.06 & 8.81 & 5.67 \\
\hline & $\mathrm{C}_{3} \mathrm{H}_{6}$ & 5.35 & - & - \\
\hline & $\mathrm{C}_{3} \mathrm{H}_{8}$ & 4.82 & - & - \\
\hline \multirow{8}{*}{ : } & $\mathrm{CO}_{2} / \mathrm{N}_{2}{ }^{b}$ & 630 & 260 & 280 \\
\hline & $\mathrm{CO}_{2} / \mathrm{CH}_{4}{ }^{c}$ & 6690 & 470 & 1220 \\
\hline & $\mathrm{CO}_{2} / \mathrm{H}_{2}{ }^{d}$ & 9690 & 300 & 6830 \\
\hline & $\mathrm{CO}_{2} / \mathrm{C}_{2} \mathrm{H}_{2}{ }^{c}$ & 510 & 31 & 46 \\
\hline & $\mathrm{CO}_{2} / \mathrm{C}_{2} \mathrm{H}_{4}{ }^{c}$ & 600 & 150 & 130 \\
\hline & $\mathrm{CO}_{2} / \mathrm{C}_{2} \mathrm{H}_{6}{ }^{c}$ & 600 & 55 & 110 \\
\hline & $\mathrm{CO}_{2} / \mathrm{C}_{3} \mathrm{H}_{6}{ }^{c}$ & 260 & - & - \\
\hline & $\mathrm{CO}_{2} / \mathrm{C}_{3} \mathrm{H}_{8}{ }^{c}$ & 84 & - & - \\
\hline
\end{tabular}

${ }^{a} \mathrm{In} \mathrm{cm}^{3} / \mathrm{g} .{ }^{b} 15 / 85$ ratio at 1 bar and $293 \mathrm{~K}$ as calculated by IAST. ${ }^{c} 50 / 50$ ratio at 1 bar and $293 \mathrm{~K}$ as calculated by IAST. ${ }^{\mathrm{d}} 20 / 80$ ratio at 1 bar and $293 \mathrm{~K}$ as calculated by IAST.

While uptake ratios provide an excellent indication of preferential affinity, the selectivity for a particular component of a gas mixture can be quantified by Ideal Adsorbed Solution Theory (IAST) calculations. At $293 \mathrm{~K}$ and 1 bar, the IAST selectivity of MUF-16 for $\mathrm{CO}_{2}$ in the presence of $\mathrm{N}_{2}(15 / 85$ $\mathrm{CO}_{2} / \mathrm{N}_{2}$ mixture) is 630 (Figure $4 \mathrm{~b}$ ). This exceptional preference for $\mathrm{CO}_{2}$ surpasses the majority of reported materials and positions MUF-16 as a remarkably good adsorbent for this key separation (Figure 5 and Table S10). For 50/50 $\mathrm{CO}_{2} / \mathrm{CH}_{4}$ mixtures, the IAST selectivity of MUF-16 is 6690 , which represents a new selectivity benchmark (Figures $4 \mathrm{~b}$ and 5, Tables 1 and S10). Similarly high selectivities were calculated for the separation of $\mathrm{CO}_{2}$ and $\mathrm{H}_{2}$. For equimolar mixtures of $\mathrm{CO}_{2}$ and $\mathrm{C} 2$ hydrocarbons, the IAST-calculated selectivities range between 510 and 600 at $293 \mathrm{~K}$ and 1 bar (Figure 4b, Table 1). MUF-16 thus marks a significant new yardstick for separating $\mathrm{CO}_{2}$ from these gases, which is a difficult and relevant challenge. The substantial improvements compared with previously-reported materials in the case of acetylene are highlighted in Figure 5 (see also Table S11). Further, MUF-16 efficiently captures $\mathrm{CO}_{2}$ from both propane and propylene (Figure $4 \mathrm{~b}$, Table 1). 


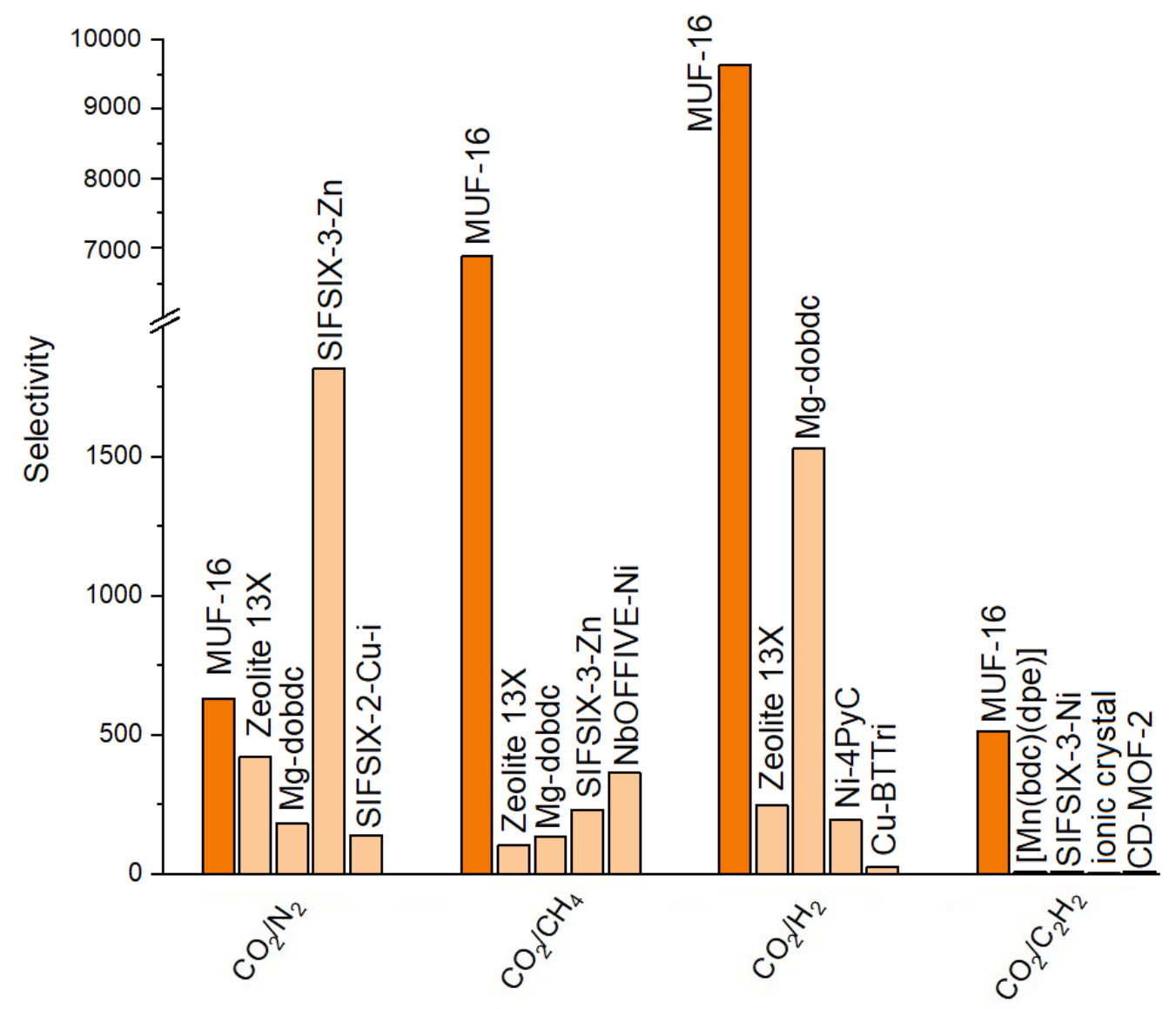

Figure 5. IAST selectivity of MUF-16 in comparison to top-performing physisorbents for $\mathrm{CO}_{2} / \mathrm{N}_{2}$ (15/85), $\mathrm{CO}_{2} / \mathrm{CH}_{4}(15 / 85), \mathrm{CO}_{2} / \mathrm{H}_{2}(20 / 80)$ and $\mathrm{CO}_{2} / \mathrm{C}_{2} \mathrm{H}_{2}(50 / 50)$ mixtures at ambient temperature and 1 bar. For clarity, the y axis is broken in two parts with different scales. The formula of the 'ionic crystal' is $\left.\mathrm{K}_{2}\left[\mathrm{Cr}_{3} \mathrm{O}(\mathrm{OOCH})_{6} \text { (4-ethylpyridine }\right)_{3}\right]_{2}\left[\alpha-\mathrm{SiW}_{12} \mathrm{O}_{40}\right]$.

While the pore characteristics of MUF-16 clearly favour the uptake of $\mathrm{CO}_{2}$ over other gases, its selectivity mechanism could potentially rely on molecular sieving if the larger adsorbates are excluded from the framework on the basis of their size. This was ruled out by measuring gas adsorption isotherms at $195 \mathrm{~K}$, which revealed that MUF-16 is able to take up significant amounts of $\mathrm{C}_{2} \mathrm{H}_{6}$ (Figure $\mathrm{S} 14$ ). Thus, these molecules can freely enter the pore network of MUF-16 but their interactions with the framework are weak so their uptake is low at ambient temperatures. Further, the kinetics of adsorption of several guest molecules were measured (Figure S15). All gases reach their equilibrium uptake in well under one minute and the uptake rates are similar for all gases. Therefore, thermodynamic - rather than kinetic effects have the most decisive impact on the differential affinity of these gases for MUF-16.

Next, we applied MUF-16 to the separation of gas mixtures under dynamic conditions using an adsorption bed. While the IAST calculations indicated that MUF-16 has impressive separation capabilities, experimental data from breakthrough measurements yield data under real operating conditions. We initially focussed on the separation of $\mathrm{CO}_{2}$ and $\mathrm{N}_{2}$, and employed gas feeds with 50/50, 15/85, 1/99 and 0.4/99.6 compositions. MUF-16 efficiently retained $\mathrm{CO}_{2}$ and delivered pure $\mathrm{N}_{2}$ with a short time lag in all four cases even with low amounts of $\mathrm{CO}_{2}$ in the mixture (Figures 6a and S52-S54). 
The dynamic capacities of MUF-16 for $\mathrm{CO}_{2}$ derived from these breakthrough measurements (up to 1.57 $\mathrm{mmol} / \mathrm{g}$ ) are nearly identical to the equilibrium capacities at the corresponding partial pressures (Table S7). This indicates that MUF-16 is an excellent adsorbent under dynamic conditions, which stems from a combination of (i) differential affinity for the two gases, (ii) the short time delay for the appearance of the non-adsorbed $\mathrm{N}_{2}$ and its near-vertical elution profile. This implies that intra- and intercrystalline gas diffusion in the adsorption bed is unimpeded.
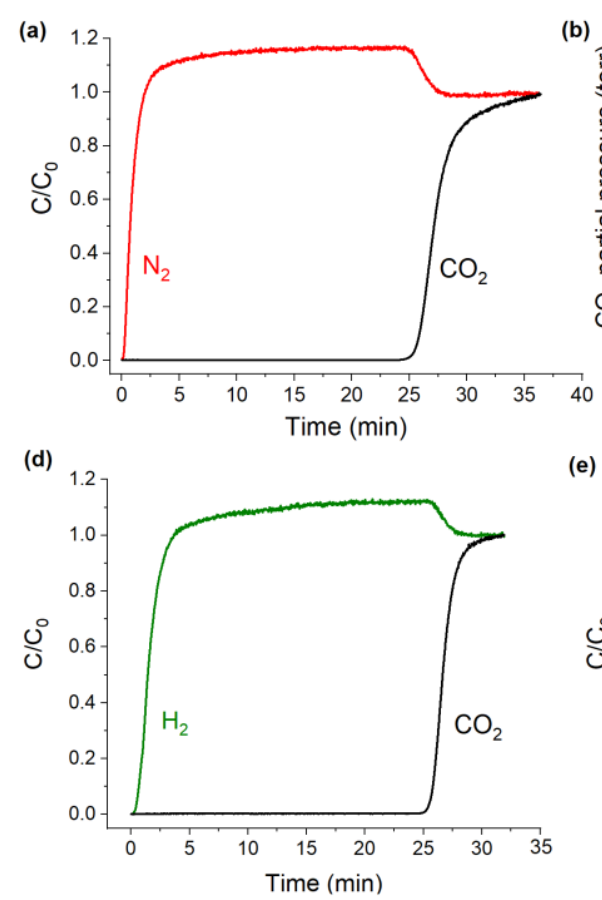
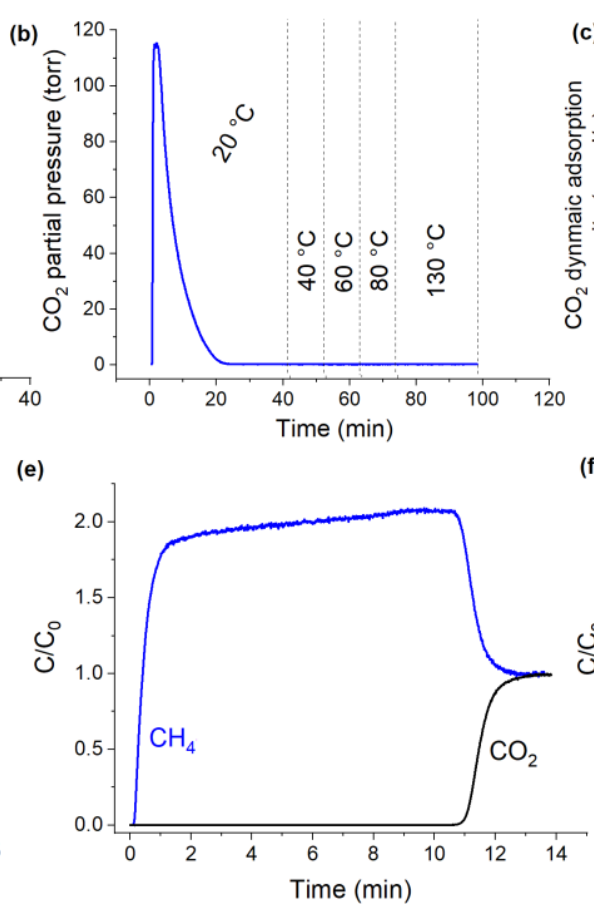
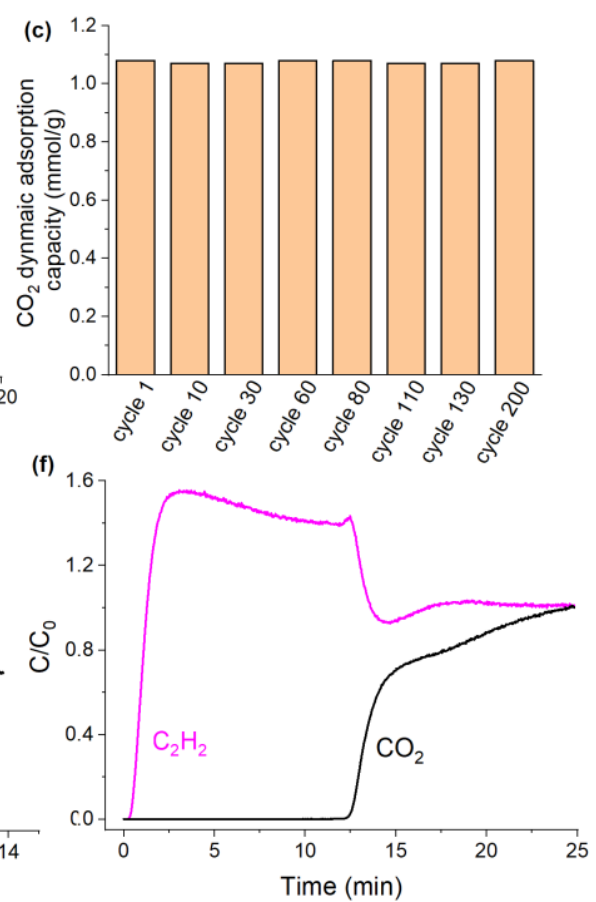

Figure 6. Experimental breakthrough curves for a (a) $15 / 85$ mixture of $\mathrm{CO}_{2} / \mathrm{N}_{2}$ at $293 \mathrm{~K}$ and 1.1 bar in an adsorption column packed with MUF-16. (b) $\mathrm{CO}_{2}$ concentration profile during regeneration with dry air at flowrates of $20 \mathrm{~mL} / \mathrm{min}$ at 1.1 bar. All of the $\mathrm{CO}_{2}$ was removed at $20{ }^{\circ} \mathrm{C}$ over a period of around 25 minutes, with no further loss of $\mathrm{CO}_{2}$ observed at $40,60,80$ or $130{ }^{\circ} \mathrm{C}$. (c) The $\mathrm{CO}_{2}$ dynamic adsorption capacity of MUF-16 obtained from the repeated breakthrough separation of $\mathrm{CO}_{2} / \mathrm{N}_{2}(15 / 85)$ followed by adsorbent regeneration. A total of 200 breakthrough cycles were measured. Experimental breakthrough curves for (d) a $15 / 85$ mixture of $\mathrm{CO}_{2} / \mathrm{H}_{2}$ (e) a $50 / 50$ mixture of $\mathrm{CO}_{2} / \mathrm{CH}_{4}$ and (f) a 50/50 mixture of $\mathrm{CO}_{2} / \mathrm{C}_{2} \mathrm{H}_{2}$.

MUF-16 can be fully regenerated and recycled for $\mathrm{CO}_{2}$ capture. Complete $\mathrm{CO}_{2}$ desorption was achieved by placing it under a dynamic vacuum or by purging with a flow of dry air $\left(\mathrm{CO}_{2}\right.$ content $<200$ ppm) at room temperature and 1 bar. The $\mathrm{CO}_{2}$ profile in the eluent from the adsorption bed was measured to show the $\mathrm{CO}_{2}$ is released within 25 minutes (Figure 6b). No further loss of $\mathrm{CO}_{2}$ was observed upon heating. Regenerating MUF-16 is simpler than typical adsorbents, ${ }^{45}$ which is advantageous from energy efficiency and economic standpoints. The recyclability of MUF-16 was then established by more than 200 breakthrough-regeneration cycles for the separation of $\mathrm{CO}_{2} / \mathrm{N}_{2}$ (Figure 6c). In line with its high stability, MUF-16 maintains its separation performance and uptake capacity over this period. With a raw materials cost of less than \$29 USD per kilogram, MUF-16 presents a sustainable and economical 
solution to $\mathrm{CO}_{2}$ capture. As an additional measure to render MUF-16 more compatible with typical largescale gas separation processes, we combined MUF-16 with a small quantity of polyvinylidene fluoride (PVDF) to make composite pellets (Figure S74). The PXRD pattern (Figure S75) and $\mathrm{CO}_{2}$ adsorption isotherm (Figure S76) of these easily-handled granules exhibit the same profile as MUF-16, indicating that the structure and gas adsorption characteristics are unchanged. Furthermore, the pellets maintain their $\mathrm{CO}_{2} / \mathrm{N}_{2}$ separation performance even after boiling in water (Figure S77).

Invigorated by these results, we applied MUF-16 to the separation of other gas mixtures where its low affinity non- $\mathrm{CO}_{2}$ gas components translates into rapid separations and high dynamic selectivities. While only a few nanoporous materials have been reported for the stripping of $\mathrm{CO}_{2}$ from $\mathrm{H}_{2} / \mathrm{CO}_{2}$ feedstocks, ${ }^{46,47}$ as required during the purification of syngas, this has been identified as a high priority. ${ }^{48,49}$ In this light, we conducted breakthrough studies for a $15 / 85$ mixture of $\mathrm{CO}_{2} / \mathrm{H}_{2}$ at $293 \mathrm{~K}$ and 1.1 bar to show that MUF-16 is able to efficiently separate $\mathrm{CO}_{2}$ from $\mathrm{H}_{2} . \mathrm{CO}_{2}$ was retained on the MUF-16 bed while the $\mathrm{H}_{2}$ component eluted immediately in a high purity stream (Figure 6d). Experimental breakthrough curves for gas compositions involving methane, ethane and propane were also measured with feed compositions of $\mathrm{CO}_{2} / \mathrm{CH}_{4}(50 / 50,15 / 85)$ and $\mathrm{CO}_{2} / \mathrm{CH}_{4} / \mathrm{C}_{2} \mathrm{H}_{6} / \mathrm{C}_{3} \mathrm{H}_{8}(15 / 80 / 4 / 1)$. We observed complete $\mathrm{CO}_{2}$ capture by MUF-16, whereby $\mathrm{CH}_{4}, \mathrm{C}_{2} \mathrm{H}_{6}$ and $\mathrm{C}_{3} \mathrm{H}_{8}$ broke through quickly with steep elution profiles (Figures 6e and S58). The dynamic uptake capacity of $\mathrm{CO}_{2}$ obtained from these breakthrough curves equates to 1.53 and $1.13 \mathrm{mmol} / \mathrm{g}$, which is nearly identical to the equilibrium capacity at the relevant partial pressures of $\mathrm{CO}_{2}$ (Table S7). These results demonstrate that the presence of the heavier adsorbates $\mathrm{C}_{2} \mathrm{H}_{6}$ and $\mathrm{C}_{3} \mathrm{H}_{8}$ does not impede the $\mathrm{CO}_{2}$ capture capabilities of MUF-16. This is an important observation for the removal of $\mathrm{CO}_{2}$ from both biogas and natural gas. ${ }^{50}$ To further demonstrate its applicability to natural gas sweeting, we conducted breakthrough measurements at higher pressure (9 bar), and observed that $\mathrm{CO}_{2}$ was cleanly removed from the gas stream (Figures S59$\mathrm{S} 60$ ). The dynamic uptake capacity for $\mathrm{CO}_{2}$ is higher than that measured at 1 bar. Extrapolation of these data to pressures relevant to natural gas processing ( 40-60 bar) predicts that MUF-16 can efficiently sequester $\mathrm{CO}_{2}$ from raw natural gas streams (Figure S64).

To test the ability of MUF-16 to separate $\mathrm{CO}_{2}$ from $\mathrm{C} 2$ hydrocarbons in a dynamic process, individual breakthrough curves for $\mathrm{CO}_{2} / \mathrm{C}_{2} \mathrm{H}_{6}(50 / 50), \mathrm{CO}_{2} / \mathrm{C}_{2} \mathrm{H}_{4}(50 / 50)$ and $\mathrm{CO}_{2} / \mathrm{C}_{2} \mathrm{H}_{2}(50 / 50$ and 5/95) mixtures were measured at $293 \mathrm{~K}$ and 1.1 bar. Complete separation was realized, and the $\mathrm{C} 2$ hydrocarbons were delivered in a single, direct adsorption step with a dynamic adsorption capacity for $\mathrm{CO}_{2}$ of around $1.22 \mathrm{mmol} / \mathrm{g}$ (Figures $6 \mathrm{f}$ and S65-S67, Table S7). This underscores the advantages conferred by the inverted selectivity of MUF-16 for producing high-value gases. The productivity of MUF-16 is high, with $1 \mathrm{~kg}$ producing $27 \mathrm{~L}$ of the $\mathrm{C} 2$ hydrocarbons from an equimolar mixture at $293 \mathrm{~K}$ and 1 bar. Extending these experimental results with simulated breakthrough profiles demonstrated that MUF-16 is capable of eliminating trace quantities of $\mathrm{CO}_{2}$ from $\mathrm{C}_{2} \mathrm{H}_{2}$ to produce a stream of high-purity $\mathrm{C}_{2} \mathrm{H}_{2}$ (Figure S70), which elutes after only a short time lag. In literature reports to date, the capture of 
$\mathrm{CO}_{2}$ over $\mathrm{C} 2$ hydrocarbons has so far largely been restricted to cryogenic temperatures and/or static conditions. ${ }^{35-40}$ With respect to $\mathrm{CO}_{2} / \mathrm{C}_{2} \mathrm{H}_{2}$ mixtures at ambient temperatures, we are aware of only three reported materials, CD-MOF-1 ${ }^{42}$, CD-MOF- $2^{42}$ and SIFSIX-3-Ni, ${ }^{34}$ for which inverse $\mathrm{CO}_{2}$ trapping has been verified by experimental breakthrough measurements. Since these MOFs adsorb $\mathrm{C}_{2} \mathrm{H}_{2}$ strongly at moderate pressures (in addition to $\mathrm{CO}_{2}$ ), their uptake ratios are modest, however, and they are limited to very low partial pressures of $\mathrm{CO}_{2}$ and suffer from low productivity. In contrast, MUF-16 operates efficiently across range of $\mathrm{CO}_{2} / \mathrm{C}_{2} \mathrm{H}_{2}$ mixtures and benefits from near-total rejection of $\mathrm{C}_{2} \mathrm{H}_{2}$ from the framework pores.

MUF-16 is a nanoporous adsorbent with universal selectivity for $\mathrm{CO}_{2}$. It combines attractive noncovalent contacts between guest $\mathrm{CO}_{2}$ molecules and the pore surface with rapid diffusion kinetics, robustness and recyclability. The selectivity of MUF-16 for $\mathrm{CO}_{2}$ is elevated beyond conventional materials and relevant to contexts as diverse as natural gas, syngas and chemical feedstocks. As a lowcost material with broad applicability and abundant technical and practical advantages, MUF-16 has the potential to be deployed universally for the capture of $\mathrm{CO}_{2}$ using pressure- or temperature-swing adsorption processes.

\section{Acknowledgements}

We are grateful to the MacDiarmid Institute for Advanced Materials and Nanotechnology and the RSNZ Marsden Fund for financial support. The data reported in the paper are presented in the supplementary information. Crystal structures of MUF-16 family collected at pristine form, under vacuum and loaded with $\mathrm{CO}_{2}$ are available free of charge from the Cambridge Crystallographic Data Centre under reference nos. CCDC 1948901-1948905. A provisional patent has been filed with IP Australia (Application number 2018904882). 


\section{References}

1. Abbasi, T. \& Abbasi, S. A. Decarbonization of fossil fuels as a strategy to control global warming. Renew. Sus. Energ. Rev. 15, 1828-1834, doi:doi.org/10.1016/j.rser.2010.11.049 (2011).

2. Masson-Delmotte, V. et al. Global Warming of $1.5^{\circ}$ C. An IPCC Special Report on the impacts of global warming of $1.5^{\circ} \mathrm{C}$ above pre-industrial levels and related global greenhouse gas emission pathways, in the context of strengthening the global response to the threat of climate change, sustainable development, and efforts to eradicate poverty. (Geneva, Switzerland, 2018).

3. Rochelle, G. T. Amine scrubbing for $\mathrm{CO}_{2}$ capture. Science 325, 1652-1654 (2009).

4. Yu, C.-H., Huang, C.-H. \& Tan, C.-S. A review of $\mathrm{CO}_{2}$ capture by absorption and adsorption. Aerosol Air Qual. Res. 12, 745-769 (2012).

5. Oschatz, M. \& Antonietti, M. A search for selectivity to enable $\mathrm{CO}_{2}$ capture with porous adsorbents. Energ. Environ. Sci. 11, 57-70, doi:10.1039/C7EE02110K (2018).

6. Lin, R.-B., Xiang, S., Xing, H., Zhou, W. \& Chen, B. Exploration of porous metal-organic frameworks for gas separation and purification. Coord. Chem. Rev. 378, 87-103 (2019).

7. Li, H. et al. Porous metal-organic frameworks for gas storage and separation: Status and challenges. EnergyChem 1, 100006, doi:doi.org/10.1016/j.enchem.2019.100006 (2019).

8. Ding, M., Flaig, R. W., Jiang, H.-L. \& Yaghi, O. M. Carbon capture and conversion using metalorganic frameworks and MOF-based materials. Chem. Soc. Rev. 48, 2783-2828, doi:10.1039/C8CS00829A (2019).

9. Mukherjee, S., Kumar, A. \& Zaworotko, M. J. in Metal-Organic Frameworks (MOFs) for Environmental Applications (ed Sujit K. Ghosh) 5-61 (Elsevier, 2019).

10. Nandi, S. et al. A single-ligand ultra-microporous MOF for precombustion $\mathrm{CO}_{2}$ capture and hydrogen purification. Science Advances 1, e1500421, doi:10.1126/sciadv.1500421 (2015).

11. Madden, D. G. et al. Highly selective $\mathrm{CO}_{2}$ removal for one-step liquefied natural gas processing by physisorbents. Chem. Commun. 55, 3219-3222 (2019).

12. Belmabkhout, Y. et al. Natural gas upgrading using a fluorinated MOF with tuned $\mathrm{H} 2 \mathrm{~S}$ and $\mathrm{CO} 2$ adsorption selectivity. Nature Energy 3, 1059-1066, doi:10.1038/s41560-018-0267-0 (2018).

13. Kumar, A. et al. Hybrid ultramicroporous materials (HUMs) with enhanced stability and trace carbon capture performance. Chem. Commun. 53, 5946-5949 (2017).

14. Remy, T. et al. Selective dynamic $\mathrm{CO}_{2}$ separations on Mg-MOF-74 at low pressures: a detailed comparison with 13X. J. Phys. Chem. C 117, 9301-9310 (2013).

15. McDonald, T. M. et al. Capture of Carbon Dioxide from Air and Flue Gas in the AlkylamineAppended Metal-Organic Framework mmen-Mg $\mathrm{Mg}_{2}$ (dobpdc). J. Am. Chem. Soc. 134, 7056-7065, doi:10.1021/ja300034j (2012).

16. Qazvini, O. T., Babarao, R., Shi, Z.-L., Zhang, Y.-B. \& Telfer, S. G. A Robust Ethane-Trapping Metal-Organic Framework with a High Capacity for Ethylene Purification. J. Am. Chem. Soc. 141, 5014-5020, doi:10.1021/jacs.9b00913 (2019).

17. Qazvini, O. T., Babarao, R. \& Telfer, S. G. Multipurpose Metal-Organic Framework for the Adsorption of Acetylene: Ethylene Purification and Carbon Dioxide Removal. Chem. Mater. 31, 4919-4926, doi:10.1021/acs.chemmater.9b01691 (2019). 
18. Tang, E. et al. Two Cobalt(II) 5-Aminoisophthalate Complexes and Their Stable Supramolecular Microporous Frameworks. Inorg. Chem. 45, 6276-6281, doi:10.1021/ic0602244 (2006).

19. Tian, C.-B. et al. Four New MnII Inorganic-Organic Hybrid Frameworks with Diverse Inorganic Magnetic Chain's Sequences: Syntheses, Structures, Magnetic, NLO, and Dielectric Properties. Inorg. Chem. 54, 2560-2571, doi:10.1021/ic502664e (2015).

20. While the CO2 adsorption properties of MUF-16(Mn) and MUF-16(Ni) are similar to that of MUF-16, we hereafter exclusively focus on gas capture by MUF-16 itself.

21. Hou, L. et al. A rod packing microporous metal-organic framework: unprecedented ukv topology, high sorption selectivity and affinity for $\mathrm{CO}_{2}$. Chem. Commun. 47, 5464-5466, doi:10.1039/C1CC10990A (2011).

22. Nugent, P. et al. Porous materials with optimal adsorption thermodynamics and kinetics for $\mathrm{CO} 2$ separation. Nature 495, 80-84 (2013).

23. Scott, H. S. et al. Crystal engineering of a family of hybrid ultramicroporous materials based upon interpenetration and dichromate linkers. Chem. Sci. 7, 5470-5476, doi:10.1039/C6SC01385F (2016).

24. McDonald, T. M., D'Alessandro, D. M., Krishna, R. \& Long, J. R. Enhanced carbon dioxide capture upon incorporation of N,N'-dimethylethylenediamine in the metal-organic framework CuBTTri. Chem. Sci. 2, 2022, doi:10.1039/c1sc00354b (2011).

25. Lee, W. R. et al. Diamine-functionalized metal-organic framework: exceptionally high $\mathrm{CO}_{2}$ capacities from ambient air and flue gas, ultrafast $\mathrm{CO}_{2}$ uptake rate, and adsorption mechanism. Energy Env. Sci. 7, 744-751, doi:10.1039/C3EE42328J (2014).

26. Jiang, M. et al. Controlling Pore Shape and Size of Interpenetrated Anion-Pillared Ultramicroporous Materials Enables Molecular Sieving of $\mathrm{CO}_{2}$ Combined with Ultrahigh Uptake Capacity. ACS Appl. Mater. Interfaces 10, 16628-16635, doi:10.1021/acsami.8b03358 (2018).

27. Moreau, F. et al. Unravelling exceptional acetylene and carbon dioxide adsorption within a tetraamide functionalized metal-organic framework. Nat. Commun. 8, 14085 (2017).

28. Xiang, S., Zhou, W., Gallegos, J. M., Liu, Y. \& Chen, B. Exceptionally High Acetylene Uptake in a Microporous Metal-Organic Framework with Open Metal Sites. J. Am. Chem. Soc. 131, 12415-12419, doi:10.1021/ja904782h (2009).

29. Li, P. et al. A Rod-Packing Microporous Hydrogen-Bonded Organic Framework for Highly Selective Separation of $\mathrm{C}_{2} \mathrm{H}_{2} / \mathrm{CO}_{2}$ at Room Temperature. Angew. Chem., Int. Ed. 54, 574-577, doi:doi:10.1002/anie.201410077 (2015).

30. Lee, J. et al. Separation of Acetylene from Carbon Dioxide and Ethylene by a Water-Stable Microporous Metal-Organic Framework with Aligned Imidazolium Groups inside the Channels. Angew. Chem., Int. Ed. 57, 7869-7873, doi:doi:10.1002/anie.201804442 (2018).

31. Luo, F. et al. UTSA-74: A MOF-74 Isomer with Two Accessible Binding Sites per Metal Center for Highly Selective Gas Separation. J. Am. Chem. Soc. 138, 5678-5684, doi:10.1021/jacs.6b02030 (2016).

32. Zhang, L. et al. Efficient separation of $\mathrm{C}_{2} \mathrm{H}_{2}$ from $\mathrm{C}_{2} \mathrm{H}_{2} / \mathrm{CO}_{2}$ mixtures in an acid-base resistant metal-organic framework. Chem. Commun. 54, 4846-4849, doi:10.1039/C8CC02235F (2018). 
33. Peng, Y.-L. et al. Robust Ultramicroporous Metal-Organic Frameworks with Benchmark Affinity for Acetylene. Angew. Chem., Int. Ed. 57, 10971-10975, doi:doi:10.1002/anie.201806732 (2018).

34. Chen, K.-J. et al. Benchmark $\mathrm{C}_{2} \mathrm{H}_{2} / \mathrm{CO}_{2}$ and $\mathrm{CO}_{2} / \mathrm{C}_{2} \mathrm{H}_{2}$ Separation by Two Closely Related $\begin{array}{llll}\text { Hybrid Ultramicroporous } & \text { Materials. }\end{array}$ doi:doi.org/10.1016/j.chempr.2016.10.009 (2016).

35. Yang, W. et al. Selective $\mathrm{CO}_{2}$ uptake and inverse $\mathrm{CO}_{2} / \mathrm{C}_{2} \mathrm{H}_{2}$ selectivity in a dynamic bifunctional metal-organic framework. Chem. Sci. 3, 2993, doi:10.1039/c2sc20443f (2012).

36. Noro, S.-i. et al. Selective Gas Adsorption in One-Dimensional, Flexible CuII Coordination Polymers with Polar Units. Chem. Mater. 21, 3346-3355, doi:10.1021/cm9012969 (2009).

37. Yanai, N. et al. Gas detection by structural variations of fluorescent guest molecules in a flexible porous coordination polymer. Nat. Mater. 10, 787 (2011).

38. Eguchi, R., Uchida, S. \& Mizuno, N. Inverse and High $\mathrm{CO}_{2} / \mathrm{C}_{2} \mathrm{H}_{2}$ Sorption Selectivity in Flexible Organic-Inorganic Ionic Crystals. Angew. Chem., Int. Ed. 51, 1635-1639, doi:doi:10.1002/anie.201107906 (2012).

39. Foo, M. L. et al. An Adsorbate Discriminatory Gate Effect in a Flexible Porous Coordination Polymer for Selective Adsorption of $\mathrm{CO}_{2}$ over $\mathrm{C}_{2} \mathrm{H}_{2}$. J. Am. Chem. Soc. 138, 3022-3030, doi:10.1021/jacs.5b10491 (2016).

40. Duan, J. et al. A Family of Rare Earth Porous Coordination Polymers with Different Flexibility for $\mathrm{CO}_{2} / \mathrm{C}_{2} \mathrm{H}_{4}$ and $\mathrm{CO}_{2} / \mathrm{C}_{2} \mathrm{H}_{6}$ Separation. Inorg. Chem. 52, 8244-8249, doi:10.1021/ic401157n (2013).

41. Horike, S. et al. Dense coordination network capable of selective $\mathrm{CO}_{2}$ capture from $\mathrm{C} 1$ and $\mathrm{C} 2$ hydrocarbons. J. Am. Chem. Soc. 134, 9852-9855, doi:10.1021/ja302043u (2012).

42. Li, L. et al. Inverse Adsorption Separation of $\mathrm{CO}_{2} / \mathrm{C}_{2} \mathrm{H}_{2}$ Mixture in Cyclodextrin-Based MetalOrganic Frameworks. ACS Appl. Mater. Interfaces 11, 2543-2550, doi:10.1021/acsami.8b19590 (2019).

43. Krishna, R. Methodologies for evaluation of metal-organic frameworks in separation applications. RSC Adv. 5, 52269-52295, doi:10.1039/C5RA07830J (2015).

44. Silva, F. A. D. \& Rodrigues, A. E. Propylene/propane separation by vacuum swing adsorption using 13X zeolite. AIChE J. 47, 341-357, doi:doi:10.1002/aic.690470212 (2001).

45. Tlili, N., Grévillot, G. \& Vallières, C. Carbon dioxide capture and recovery by means of TSA and/or VSA. Int. J. Greenh. Gas Con. 3, 519-527, doi:doi.org/10.1016/j.ijggc.2009.04.005 (2009).

46. Belmabkhout, Y., Pirngruber, G., Jolimaitre, E. \& Methivier, A. A complete experimental approach for synthesis gas separation studies using static gravimetric and column breakthrough experiments. Adsorption 13, 341-349 (2007).

47. Liu, K., Song, C. \& Subramani, V. Hydrogen and Syngas Production and Purification Technologies. (John Wiley \& Sons, 2010).

48. Sumida, K. et al. Carbon Dioxide Capture in Metal-Organic Frameworks. Chem. Rev. 112, 724781, doi:10.1021/cr2003272 (2012). 
49. Herm, Z. R., Swisher, J. A., Smit, B., Krishna, R. \& Long, J. R. Metal-organic frameworks as adsorbents for hydrogen purification and precombustion carbon dioxide capture. J. Am. Chem. Soc. 133, 5664-5667, doi:10.1021/ja111411q (2011).

50. Rufford, T. E. et al. The removal of $\mathrm{CO}_{2}$ and $\mathrm{N}_{2}$ from natural gas: A review of conventional and emerging process technologies. J. Petrol. Sci. Eng. 94, 123-154 (2012). 


\title{
Electronic Supplementary Information for:
}

\section{A Universal Porous Adsorbent for the Selective Capture of Carbon Dioxide}

\author{
Omid T. Qazvini and Shane G. Telfer* \\ MacDiarmid Institute for Advanced Materials and Nanotechnology, School of Fundamental Sciences, \\ Massey University, Palmerston North, New Zealand.
}

Electronic Supplementary Information for:

\section{Contents}

1. General procedures and information .1

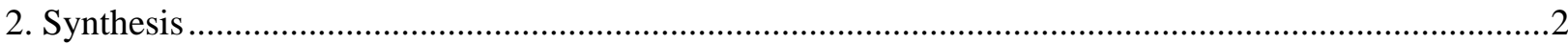

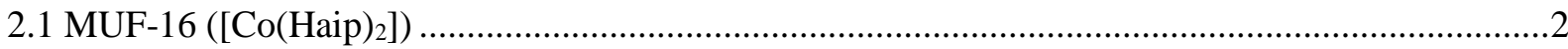

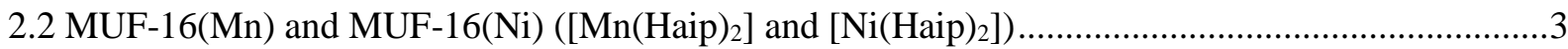

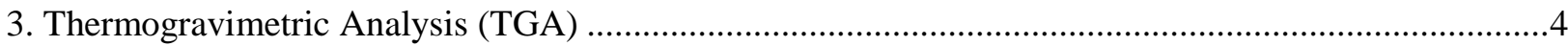

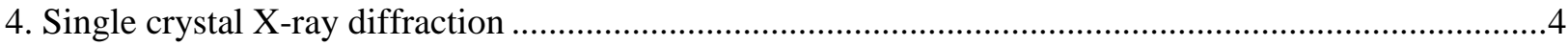

4.1 As-synthesized MUF-16, MUF-16(Ni) and MUF-16(Mn) ….....................................................

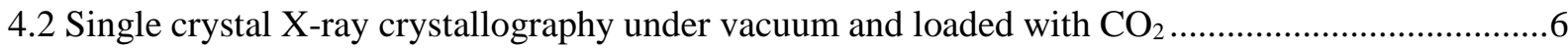

4.3 Refinement details for guest-free and $\mathrm{CO}_{2}$-loaded MUF-16(Mn) ..................................................

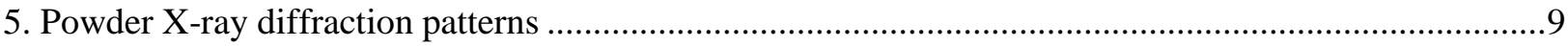

6. Low-pressure gas adsorption measurements ....................................................................................11

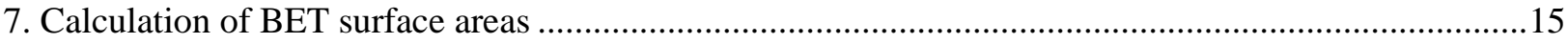

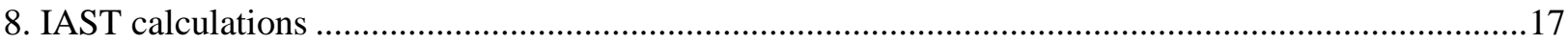

9. Breakthrough separation experiments and simulations ……...............................................................34

9.1 $\mathrm{CO}_{2} / \mathrm{N}_{2}, \mathrm{CO}_{2} / \mathrm{CH}_{4}, \mathrm{CO}_{2} / \mathrm{H}_{2}$ and $\mathrm{CO}_{2} / \mathrm{CH}_{4}+\mathrm{C}_{2} \mathrm{H}_{6}+\mathrm{C}_{3} \mathrm{H}_{8}$ breakthrough separations ............................36

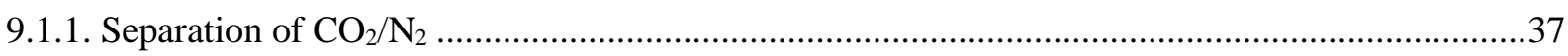

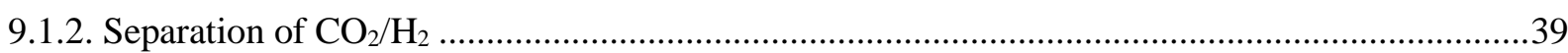

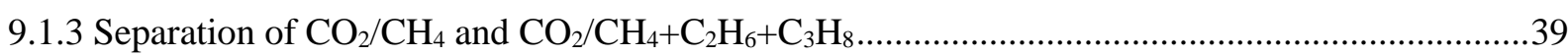

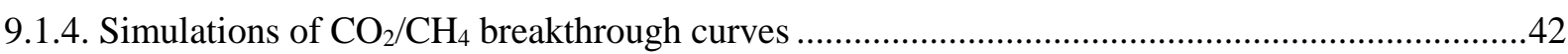

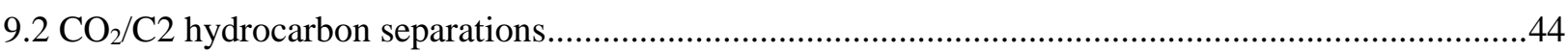

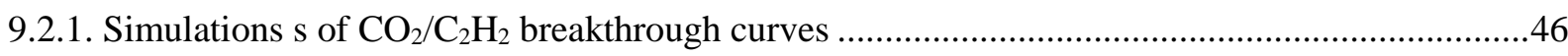

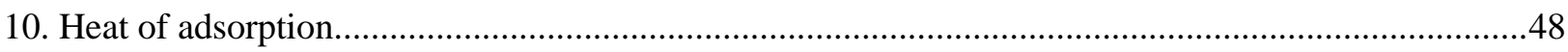

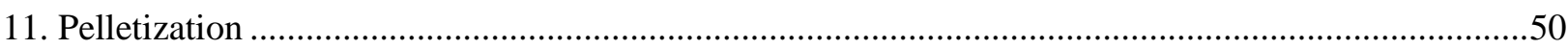

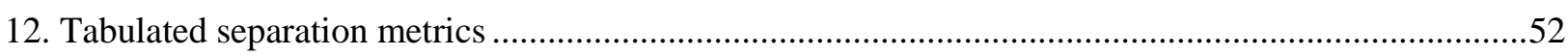




\section{General procedures and information}

All starting compounds and solvents were used as received from commercial sources without further purification unless otherwise noted. Elemental analyses were performed by the Campbell Microanalytical Laboratory at the University of Otago, New Zealand.

Single crystal structures of MUF-16, MUF-16(Mn) and MUF-16(Ni) were used directly for all the calculations and simulations without modification. The Zeo $++{ }^{1}$ code and RASPA2 $2^{2}$ were used to calculate their pore volumes and surface areas with the use of $\mathrm{H}_{2}$ and $\mathrm{He}$ probes, respectively, pore limiting diameter (i.e., the diameter of smallest opening along the pore) and largest cavity diameter (i.e., the diameter of the largest sphere that can fit within the pores).

Table S1. Some calculated and experimentally determined properties of the MUF-16 family.

\begin{tabular}{lccc}
\hline & MUF-16 & MUF-16(Mn) & MUF-16(Ni) \\
\hline Geometric surface area $\left(\mathrm{m}^{2} / \mathrm{g}\right.$, Zeo++) & 313 & 315 & 313 \\
BET surface area $\left(\mathrm{m}^{2} / \mathrm{g}\right.$, from experimental $\mathrm{N}_{2}$ isotherm/77 K) & 215 & 209 & 238 \\
Calculated void fraction $(\%$, RASPA2) & 17.3 & 17.0 & 16.7 \\
Calculated pore volume $\left(\mathrm{cm}^{3} / \mathrm{g}\right.$, RASPA2) & 0.10 & 0.11 & 0.11 \\
Pore volume $\left(\mathrm{cm}^{3} / \mathrm{g}\right.$, from experimental $\mathrm{N}_{2}$ isotherm $\left./ 77 \mathrm{~K}\right)$ & 0.11 & 0.12 & 0.11 \\
Largest cavity diameter $(\AA)$ & 3.63 & 3.58 & 3.61 \\
Pore limiting diameter $(\AA)$ & 2.95 & 2.95 & 2.96 \\
\hline
\end{tabular}

(a)

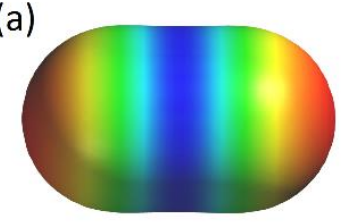

(b)

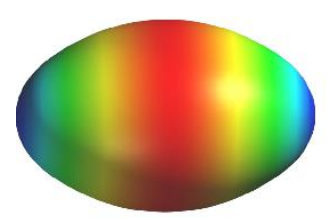

(c)

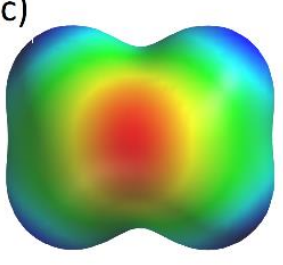

(d)

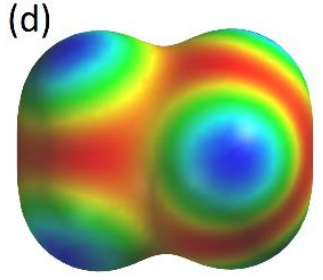

(e)

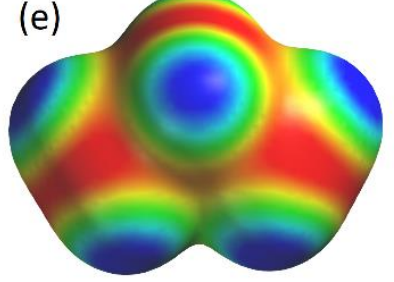

Figure S1. Electrostatic potential maps of (a) $\mathrm{CO}_{2}$, (b) $\mathrm{C}_{2} \mathrm{H}_{2}$, (c) $\mathrm{C}_{2} \mathrm{H}_{4}$, (d) $\mathrm{C}_{2} \mathrm{H}_{6}$ and (e) $\mathrm{C}_{3} \mathrm{H}_{8}$

Blue/green $=$ positive red/orange $=$ negative . 


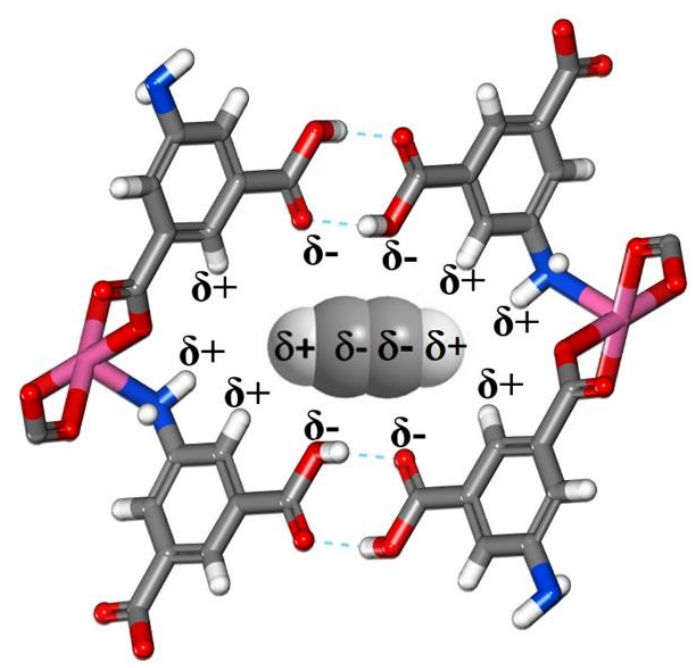

Figure S2. Schematic of electrostatic potential distribution on the pore surface of MUF-16 leads to repulsive interactions with guest $\mathrm{C}_{2} \mathrm{H}_{2}$ molecules if they occupy the sites crystallographically observed for the binding of $\mathrm{CO}_{2}$.

Table S2. Physicochemical characteristics of different gasses relevant to their separation. ${ }^{3-6}$

\begin{tabular}{|c|c|c|c|c|c|}
\hline & $\begin{array}{l}\text { Boiling point } \\
\text { (K) }\end{array}$ & $\begin{array}{c}\text { Molecular } \\
\text { dimensions ( }\end{array}$ & $\begin{array}{c}\text { Polarizability } \\
\left(\AA^{3}\right)\end{array}$ & $\begin{array}{c}\text { Dipole } \\
\text { moment } \\
\times 10^{18} / \mathrm{esu} \mathrm{cm}^{2} \\
\end{array}$ & $\begin{array}{c}\text { Quadrupole } \\
\text { moment } \\
\times 10^{26} / \mathrm{esu} \mathrm{cm}^{2} \\
\end{array}$ \\
\hline $\mathrm{CO}_{2}$ & 216.5 & $3.18 \times 3.33 \times 5.36$ & 2.91 & 0 & -4.3 \\
\hline $\mathrm{N}_{2}$ & 77.35 & $2.99 \times 3.05 \times 4.04$ & 0.80 & 0 & 1.52 \\
\hline $\mathrm{CH}_{4}$ & 111.66 & $3.82 \times 3.94 \times 4.10$ & 2.59 & 0 & 0 \\
\hline $\mathrm{H}_{2}$ & 20.27 & - & 1.74 & 0 & 0.66 \\
\hline $\mathrm{C}_{2} \mathrm{H}_{2}$ & 188.4 & $3.32 \times 3.34 \times 5.7$ & $3.33-3.93$ & 0 & +7.5 \\
\hline $\mathrm{C}_{2} \mathrm{H}_{4}$ & 169.4 & $3.28 \times 4.18 \times 4.84$ & 4.25 & 0 & +1.5 \\
\hline $\mathrm{C}_{2} \mathrm{H}_{6}$ & 184.5 & $3.81 \times 4.82 \times 4.08$ & $4.43-4.47$ & 0 & +0.65 \\
\hline $\mathrm{C}_{3} \mathrm{H}_{8}$ & 231.0 & $6.80 \times 4.20 \times 3.80$ & $6.29-6.37$ & 0.084 & - \\
\hline
\end{tabular}

\section{Synthesis}

\subsection{MUF-16 ([Co(Haip)2])}

\section{Small-scale synthesis:}

A mixture of $\mathrm{Co}(\mathrm{OAc})_{2} \cdot 4 \mathrm{H}_{2} \mathrm{O}(0.625 \mathrm{~g}, 2.5 \mathrm{mmol})$, 5-aminoisophthalic acid (1.8 g, $\left.10 \mathrm{mmol}\right)$, methanol $(80 \mathrm{~mL})$ and water $(5 \mathrm{ml})$ were sonicated for $20 \mathrm{~min}$ in a sealed $1000 \mathrm{~mL}$ Schott bottle, which was then heated in a pre-heated oven at $70{ }^{\circ} \mathrm{C}$ for 2 hours under autogenous pressure. After cooling the oven to room temperature, the resulting pink crystals were isolated by decanting off the mother liquor, washed with methanol several times and dried under vacuum at $130{ }^{\circ} \mathrm{C}$ for $20 \mathrm{~h}$. Yield: $0.98 \mathrm{~g}$ ( $94 \%$ based on cobalt) of guest-free MUF-16. 


\section{Large-scale synthesis:}

A mixture of $\mathrm{Co}(\mathrm{OAc})_{2} \cdot 4 \mathrm{H}_{2} \mathrm{O}(5.0 \mathrm{~g}, 20 \mathrm{mmol}), 5$-aminoisophthalic acid (12 g, $\left.68 \mathrm{mmol}\right)$, methanol $(490 \mathrm{~mL})$ and water $(40 \mathrm{ml})$ were sonicated for $20 \mathrm{~min}$ in a sealed $2000 \mathrm{~mL}$ Schott bottle, which was partly ( 20\%) prefilled with glass beads. The bottle was then heated in a pre-heated oven at $70{ }^{\circ} \mathrm{C}$ for 5 hours under autogenous pressure. After cooling the oven to room temperature, the resulting pink crystals were isolated by decanting off the mother liquor, washed with methanol several times and dried under vacuum at $130{ }^{\circ} \mathrm{C}$ for $20 \mathrm{~h}$. Yield: $7.8 \mathrm{~g}$ (92\% based on cobalt) of guest-free MUF-16.

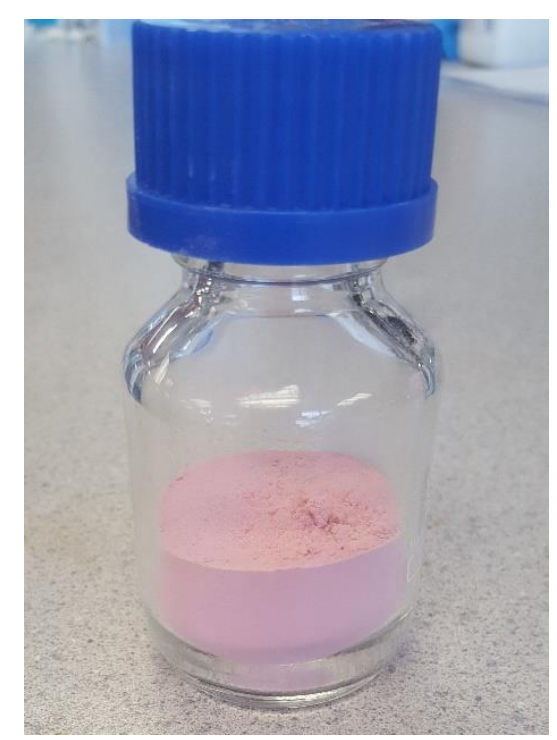

Figure S3. Photograph of MUF-16 produced on a large-scale after drying.

Cost estimate: Commercial prices are approximately $\mathrm{H}_{2}$ aip $=15 \mathrm{USD} / \mathrm{kg}$ and $\mathrm{Co}(\mathrm{OAc})_{2} .4 \mathrm{H}_{2} \mathrm{O}=10$ $\mathrm{USD} / \mathrm{kg}$. Therefore, $1 \mathrm{~kg}$ of $\mathrm{Co}(\mathrm{OAc})_{2} .4 \mathrm{H}_{2} \mathrm{O}$ (10 USD) requires $2.4 \mathrm{~kg}$ of $\mathrm{H}_{2}$ aip (36 USD) and produces $1.56 \mathrm{~kg}$ of MUF-16 for approx. 46 USD. The raw materials cost of MUF-16 is $\leq 29 \mathrm{USD} / \mathrm{kg}$.

\subsection{MUF-16(Mn) and MUF-16(Ni) ([Mn(Haip) 2$]$ and [Ni(Haip) 2$])$}

A mixture of $\mathrm{M}\left(\mathrm{ClO}_{4}\right)_{2} \cdot 6 \mathrm{H}_{2} \mathrm{O}$ (where $\mathrm{M}=\mathrm{Mn}$ or $\mathrm{Ni}$ ) (1.25 mmol), 5-aminoisophthalic acid (2.50 mmol, $0.45 \mathrm{~g})$, and $\mathrm{NH}_{4} \mathrm{NO}_{3}(2.50 \mathrm{mmol}, 0.20 \mathrm{~g})$ with a mixed-solvent of $\mathrm{CH}_{3} \mathrm{CN}(20 \mathrm{~mL})$ and $\mathrm{CH}_{3} \mathrm{OH}(15$ $\mathrm{mL}$ ) were sonicated for $20 \mathrm{~min}$ and sealed in a $100 \mathrm{~mL}$ Teflon-lined stainless-steel reaction vessel and heated at $160{ }^{\circ} \mathrm{C}$ for two days under autogenous pressure. After cooling the oven to room temperature, the resulting brownish crystals were isolated by decanting off the mother liquor, washed with methanol several times and dried under vacuum at $130{ }^{\circ} \mathrm{C}$ for $20 \mathrm{~h}$. Yields: $0.21 \mathrm{~g}$ (40\% based on $\mathrm{Mn}$ ) of guest free MUF-16(Mn), and $0.28 \mathrm{~g}(53 \%$ based on Ni) of guest-free MUF-16(Ni). 
Table S3. Elemental analysis of the MUF-16 frameworks.

\begin{tabular}{lccc}
\hline & C: calcd./found & H: calcd./found & N: calcd./found \\
\hline MUF-16 $\cdot \mathrm{H}_{2} \mathrm{O}$ & $43.95 / 43.49$ & $3.23 / 3.23$ & $6.41 / 6.40$ \\
MUF-16(Mn) $\cdot \mathrm{H}_{2} \mathrm{O}$ & $44.36 / 44.05$ & $3.26 / 3.42$ & $6.47 / 6.64$ \\
MUF-16(Ni) $\mathrm{H}_{2} \mathrm{O}$ & $43.98 / 44.18$ & $3.23 / 3.57$ & $6.41 / 6.90$ \\
\hline
\end{tabular}

\section{Thermogravimetric Analysis (TGA)}

Freshly prepared MOF samples were washed with $\mathrm{MeOH}$, and then activated at $130{ }^{\circ} \mathrm{C}$ under vacuum for 10 hours. Samples were exposed to air for 1 hour and then transferred to an aluminium sample pan, and then measurements were commenced under an $\mathrm{N}_{2}$ flow with a heating rate of $5{ }^{\circ} \mathrm{C} / \mathrm{min}$.

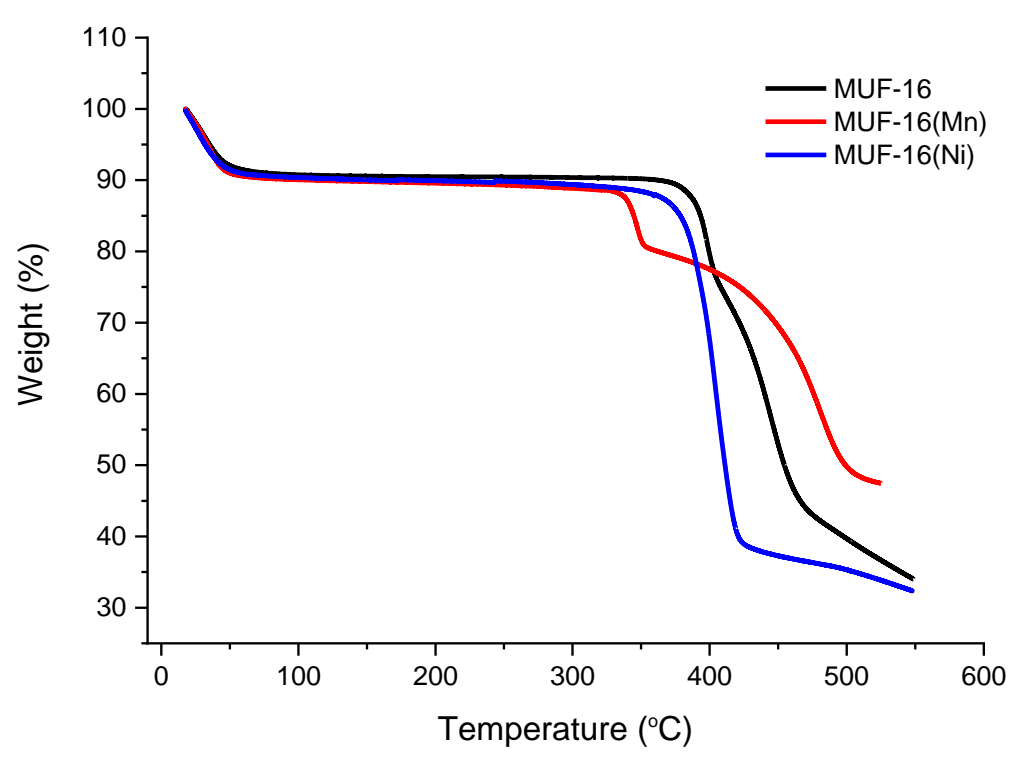

Figure S4. TGA curves of MUF-16, MUF-16(Mn), and MUF-16(Ni).

\section{Single crystal X-ray diffraction}

A Rigaku Spider diffractometer equipped with a MicroMax MM007 rotating anode generator $\left(\mathrm{Cu}_{\alpha}\right.$ radiation, $1.54180 \AA$ ), high-flux Osmic multilayer mirror optics, and a curved image plate detector was used to collect SCXRD data.

\subsection{As-synthesized MUF-16, MUF-16(Ni) and MUF-16(Mn)}

MOF crystals were analysed after removing them from methanol. Room temperature data collections produced better refinement statistics than low temperature data collections. All atoms were found in the electron density difference map. All atoms were refined anisotropically, except hydrogen atoms and certain of the water molecules in the pores. A solvent mask was calculated for MUF-16(Ni) and 124 electrons were found in a volume of $308 \AA^{3}$ in 1 void per unit cell. This is consistent with the presence of three disordered water molecules per asymmetric unit, which account for 120 electrons per unit cell. 
Table S4. Crystal data and structure refinement details for MUF-16, MUF-16(Mn) and MUF-16(Ni).

\begin{tabular}{|c|c|c|c|}
\hline & MUF-16 & MUF-16(Mn) & MUF-16(Ni) \\
\hline Formula & $\mathrm{Co}(\text { Haip })_{2} \cdot 2 \mathrm{H}_{2} \mathrm{O}$ & $\mathrm{Mn}(\text { Haip })_{2} \cdot 3 \mathrm{H}_{2} \mathrm{O}$ & $\mathrm{Ni}(\text { Haip })_{2} \cdot 3 \mathrm{H}_{2} \mathrm{O}$ \\
\hline CCDC deposition no. & 1948901 & 1948902 & 1948903 \\
\hline Empirical formula & $\mathrm{C}_{16} \mathrm{H}_{16} \mathrm{CoN}_{2} \mathrm{O}_{10}$ & $\mathrm{C}_{16} \mathrm{H}_{18} \mathrm{MnN}_{2} \mathrm{O}_{11}$ & $\mathrm{C}_{16} \mathrm{H}_{18} \mathrm{~N}_{2} \mathrm{NiO}_{11}$ \\
\hline Formula weight & 455.24 & 471.28 & 473.3 \\
\hline Temperature / K & 292 & 292 & 293.0 \\
\hline Crystal system & monoclinic & monoclinic & monoclinic \\
\hline Space group & $\mathrm{I} 2 / \mathrm{a}$ & $I 2 / a$ & $\mathrm{I} 2 / \mathrm{a}$ \\
\hline a / $\AA$ & $15.3514(15)$ & $25.2367(14)$ & $15.4963(11)$ \\
\hline $\mathrm{b} / \AA$ & $4.4232(4)$ & $4.57990(10)$ & $4.5780(2)$ \\
\hline c / $\AA$ & $25.614(4)$ & $15.4895(11)$ & $25.230(2)$ \\
\hline$\alpha /{ }^{\circ}$ & 90 & 90 & 90 \\
\hline$\beta / \circ$ & $94.294(10)$ & $96.046(8)$ & $96.177(8)$ \\
\hline$\gamma / \circ$ & 90 & 90 & 90 \\
\hline Volume / $\AA^{3}$ & $1734.4(4)$ & $1780.34(17)$ & $1779.5(2)$ \\
\hline $\mathrm{Z}$ & 4 & 4 & 4 \\
\hline$\rho_{\text {calc }} / \mathrm{g} \mathrm{cm}^{-3}$ & 1.743 & 1.758 & 1.564 \\
\hline$\mu / \mathrm{mm}^{-1}$ & 8.357 & 6.682 & 2.020 \\
\hline $\mathrm{F}(000)$ & 932.0 & 972.0 & 856.0 \\
\hline Resolution range for data/ $\AA$ & 0.81 & 0.81 & 1.0 \\
\hline Reflections collected & 7472 & 14132 & 6610 \\
\hline Independent reflections & $1594\left[\mathrm{R}_{\text {int }}=0.0918, \mathrm{R}_{\text {sigma }}=0.0917\right]$ & $1668\left[\mathrm{R}_{\text {int }}=0.1054, \mathrm{R}_{\text {sigma }}=0.1158\right]$ & $925\left[\mathrm{R}_{\mathrm{int}}=0.0917, \mathrm{R}_{\mathrm{sigma}}=0.0852\right]$ \\
\hline Data/restraints/parameters & $1594 / 2 / 136$ & $1668 / 1 / 149$ & $925 / 0 / 126$ \\
\hline Goodness-of-fit on F2 & 1.301 & 1.152 & 1.649 \\
\hline Final $R$ indices $[I>2 \sigma(I)]$ & $\mathrm{R}_{1}=0.1185, \mathrm{wR}_{2}=0.3035$ & $\mathrm{R}_{1}=0.0740, \mathrm{wR}_{2}=0.1821$ & $\mathrm{R}_{1}=0.1517, \mathrm{wR}_{2}=0.3672$ \\
\hline Final $\mathrm{R}$ indices [all data] & $\mathrm{R}_{1}=0.1576, \mathrm{wR}_{2}=0.3785$ & $\mathrm{R}_{1}=0.1350, \mathrm{wR}_{2}=0.2421$ & $\mathrm{R}_{1}=0.2061, \mathrm{wR}_{2}=0.4467$ \\
\hline Largest diff. peak/hole / e $\AA^{-3}$ & $0.93 /-1.26$ & $0.57 /-0.51$ & $0.77 /-0.83$ \\
\hline
\end{tabular}




\subsection{Single crystal $\mathrm{X}$-ray crystallography under vacuum and loaded with $\mathrm{CO}_{2}$}

Capillary SCXRD was performed for a single crystal of MUF-16(Mn) both under vacuum and loaded with $\mathrm{CO}_{2}$ at around 1.1 bar and $20^{\circ} \mathrm{C}$ based on the following steps:

First a single crystal was chosen with an appropriate size $(\sim 0.1 \times 0.1 \times 0.1 \mathrm{~mm})$ and soaked in ethanol. A small capillary tube with around $0.2 \mathrm{~mm}$ in diameter and $50 \mathrm{~mm}$ in length (which is open at both ends) was made by burning and shaping the neck of a glass pipette (referred to as the 'home-made capillary'). The home-made capillary was then used to trap the crystal inside it. Normally, the crystal flowed through the capillary carried by the ethanol stream.

The home-made capillary was then transferred into a standard $0.3 \mathrm{~mm}$ capillary. A long capillary $(0.2$ $\mathrm{mm}$ in diameter) was used to push the home-made capillary to the very bottom of the $0.3 \mathrm{~mm}$ capillary. Around 6 or 7 crystals of cobalt chloride hydrate were then transferred to the $0.3 \mathrm{~mm}$ capillary and placed on the top of the home-made capillary. The cobalt chloride was used a visual indicator of the level of water vapour in the capillary based on its pink $\rightarrow$ blue colour change upon dehydration.

The top of the $0.3 \mathrm{~mm}$ capillary was then covered by glass wool to avoid the elutriation of cobalt chloride crystals during activation.

The capillary assembly was then connected to an adsorption apparatus (Quantachrome-Autosorb-iQ2) using appropriate Swagelok fittings (Figure S4) and was kept under vacuum and a temperature of $140{ }^{\circ} \mathrm{C}$ for around 5 hours so that the vacuum level reached 0.0008 torr. At this point the cobalt chloride crystals were blue in colour (anhydrous).

The capillary was flame sealed to trap the crystal under vacuum. Alternatively, the capillary was filled with $\mathrm{CO}_{2}$ to a pressure of 1.2 bar and then flame sealed.

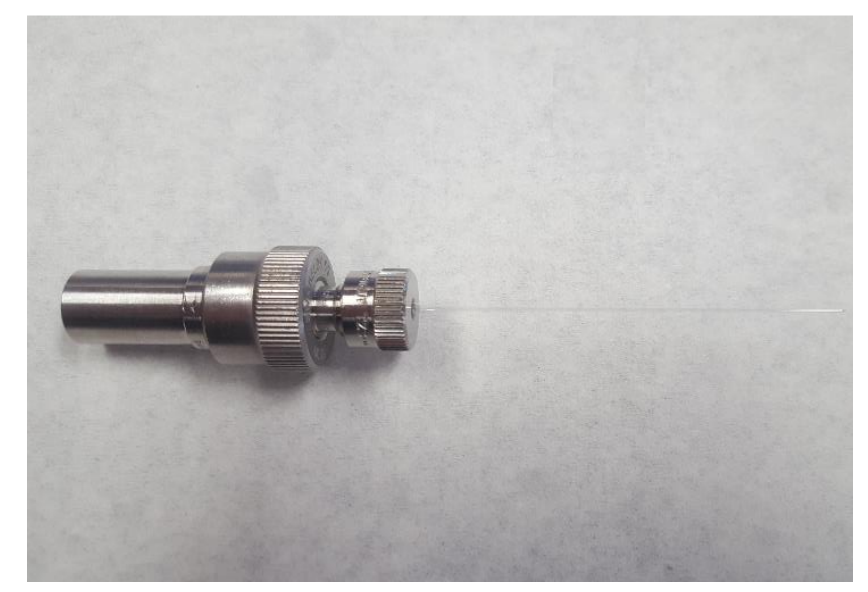

Figure S5. Swagelok fittings for connecting capillary to Quantachrome-Autosorb-iQ2. 


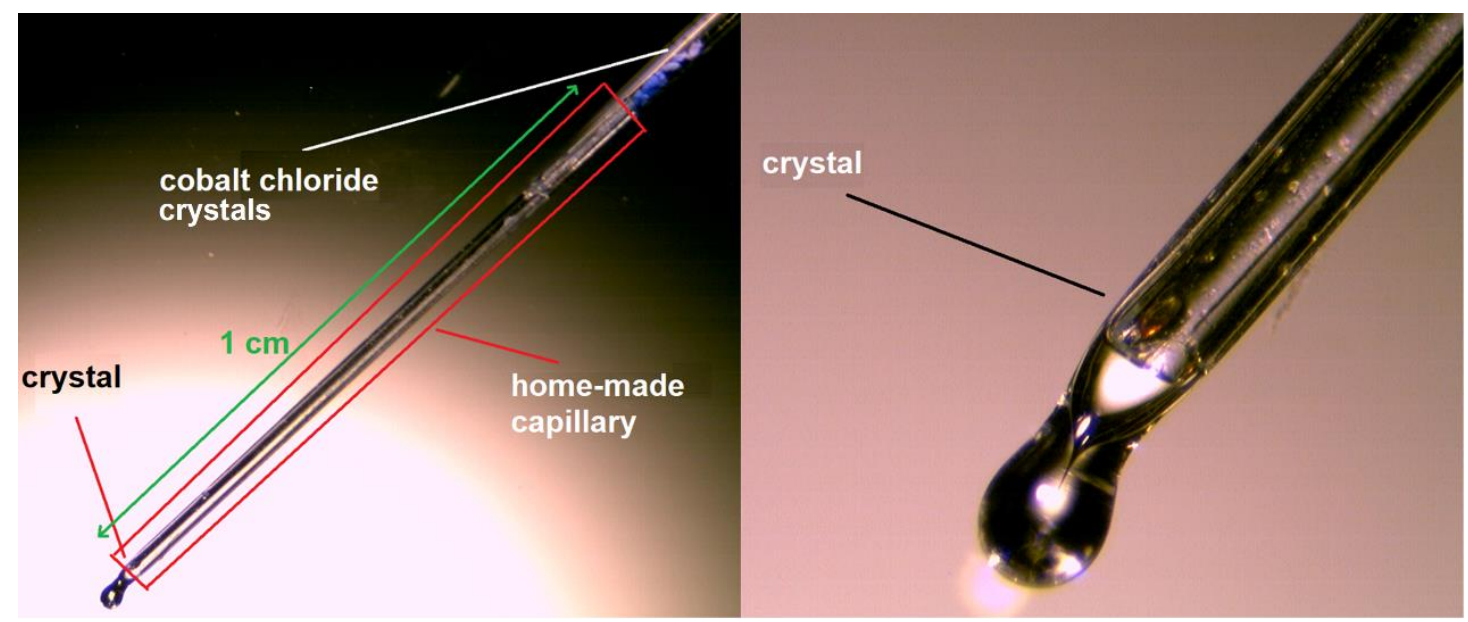

Figure S6. Schematic and dimensions of capillaries used for SCXRD.

\subsection{Refinement details for guest-free and $\mathrm{CO}_{2}$-loaded MUF-16(Mn)}

Certain reflections were omitted from the refinement process since they were mismeasured due to the presence of the glass capillary. All non-hydrogen atoms were found in the Fourier difference map. For the $\mathrm{CO}_{2}$-loaed structure, a strong electron density peak was observed in the middle of the pore and two weaker areas of electron density towards the pore surface. The central dense area was assigned to be an oxygen (O15) with a fixed occupancy of 1 (lowing for its location on a special position), while the other two areas were ascribed to oxygen $(\mathrm{O} 16)$ and carbon $(\mathrm{C} 17)$ atoms with fixed occupancies of 0.5. This describes two disordered $\mathrm{CO}_{2}$ molecules that occupy one of two sites. The two molecules share an $\mathrm{O}$ atom. Overall, this equates to one $\mathrm{CO}_{2}$ molecule per $\mathrm{Mn}$ centre which is in agreement with the adsorption isotherm. The $\mathrm{C}=\mathrm{O}$ bond lengths were restrained to $1.16 \AA$ and the $\mathrm{O}=\mathrm{C}=\mathrm{O}$ angle to $180^{\circ}$ and $\mathrm{C}$ and $\mathrm{O}$ atoms refined isotropically. 
Table S5. SCXRD data and refinement details of guest-free and $\mathrm{CO}_{2}$-loaded MUF-16(Mn).

\begin{tabular}{|c|c|c|}
\hline & MUF-16(Mn) in vacuo & MUF-16(Mn) under $\mathrm{CO}_{2}(1.1$ bar $)$ \\
\hline Formula & Mn(Haip) $)_{2}$ & $\mathrm{Mn}$ (Haip) $)_{2} \cdot \mathrm{CO}_{2}$ \\
\hline CCDC deposition no. & 1948905 & 1948904 \\
\hline Empirical formula & $\mathrm{C}_{16} \mathrm{H}_{12} \mathrm{MnN}_{2} \mathrm{O}_{8}$ & $\mathrm{C}_{17} \mathrm{H}_{12} \mathrm{MnN}_{2} \mathrm{O}_{10}$ \\
\hline Formula weight & 415.22 & 459.23 \\
\hline Temperature/K & 292 & 292 \\
\hline Crystal system & monoclinic & monoclinic \\
\hline Space group & $I 2 / \mathrm{a}$ & $I 2 / \mathrm{a}$ \\
\hline $\mathrm{a} / \AA ̊$ & $15.4872(11)$ & $15.5719(10)$ \\
\hline $\mathrm{b} / \AA ̊$ & $4.51930(10)$ & $4.52010(10)$ \\
\hline$c / \AA$ & 25.4913(13) & $25.438(2)$ \\
\hline$\alpha /{ }^{\circ}$ & 90 & 90 \\
\hline$\beta /{ }^{\circ}$ & $97.080(16)$ & $97.108(8)$ \\
\hline$\gamma /{ }^{\circ}$ & 90 & 90 \\
\hline Volume $/ \AA^{3}$ & $1770.56(17)$ & $1776.7(2)$ \\
\hline $\mathrm{Z}$ & 4 & 4 \\
\hline$\rho_{\text {calc }} / \mathrm{g} \mathrm{cm}^{-3}$ & 1.558 & 1.717 \\
\hline$\mu / \mathrm{mm}^{-1}$ & 6.512 & 6.646 \\
\hline $\mathrm{F}(000)$ & 844.0 & 932.0 \\
\hline Data range for refinement/ $\AA$ & 0.90 & 1.08 \\
\hline Reflections collected/ind. & $7515 / 1214\left[R_{\text {int }}=0.1632, R_{\sigma}=0.1964\right]$ & $8177 / 713\left[\mathrm{R}_{\mathrm{int}}=0.1104, \mathrm{R}_{\sigma}=0.0804\right]$ \\
\hline Data/restraints/parameters & $1214 / 0 / 129$ & $713 / 90 / 136$ \\
\hline Goodness-of-fit on $\mathrm{F}^{2}$ & 0.862 & 1.216 \\
\hline Final $R$ indexes $[I>=2 \sigma(I)]$ & $\mathrm{R}_{1}=0.0510, \mathrm{wR}_{2}=0.0954$ & $\mathrm{R}_{1}=0.0868, \mathrm{wR}_{2}=0.2280$ \\
\hline Final $\mathrm{R}$ indexes [all data] & $\mathrm{R}_{1}=0.1341, \mathrm{wR}_{2}=0.1112$ & $\mathrm{R}_{1}=0.1278, \mathrm{wR}_{2}=0.2915$ \\
\hline Largest diff. peak/hole / e $\AA^{-3}$ & $0.35 /-0.48$ & $0.56 /-0.58$ \\
\hline
\end{tabular}




\section{Powder X-ray diffraction patterns}

The data were obtained from freshly prepared MOF samples that had been washed several times with $\mathrm{MeOH}$. $\mathrm{MOF}$ crystals were analysed right after removing them from $\mathrm{MeOH}$. The two-dimensional images of the Debye rings were integrated with 2DP to give $2 \theta$ vs I diffractograms. Predicted powder patterns were generated from single crystal structures using Mercury.

For aging experiments on the frameworks, after washing as-synthesized samples several times with $\mathrm{MeOH}$, they were activated and were aged in air at $70-85 \%$ relative humidity or water at $20{ }^{\circ} \mathrm{C}$.

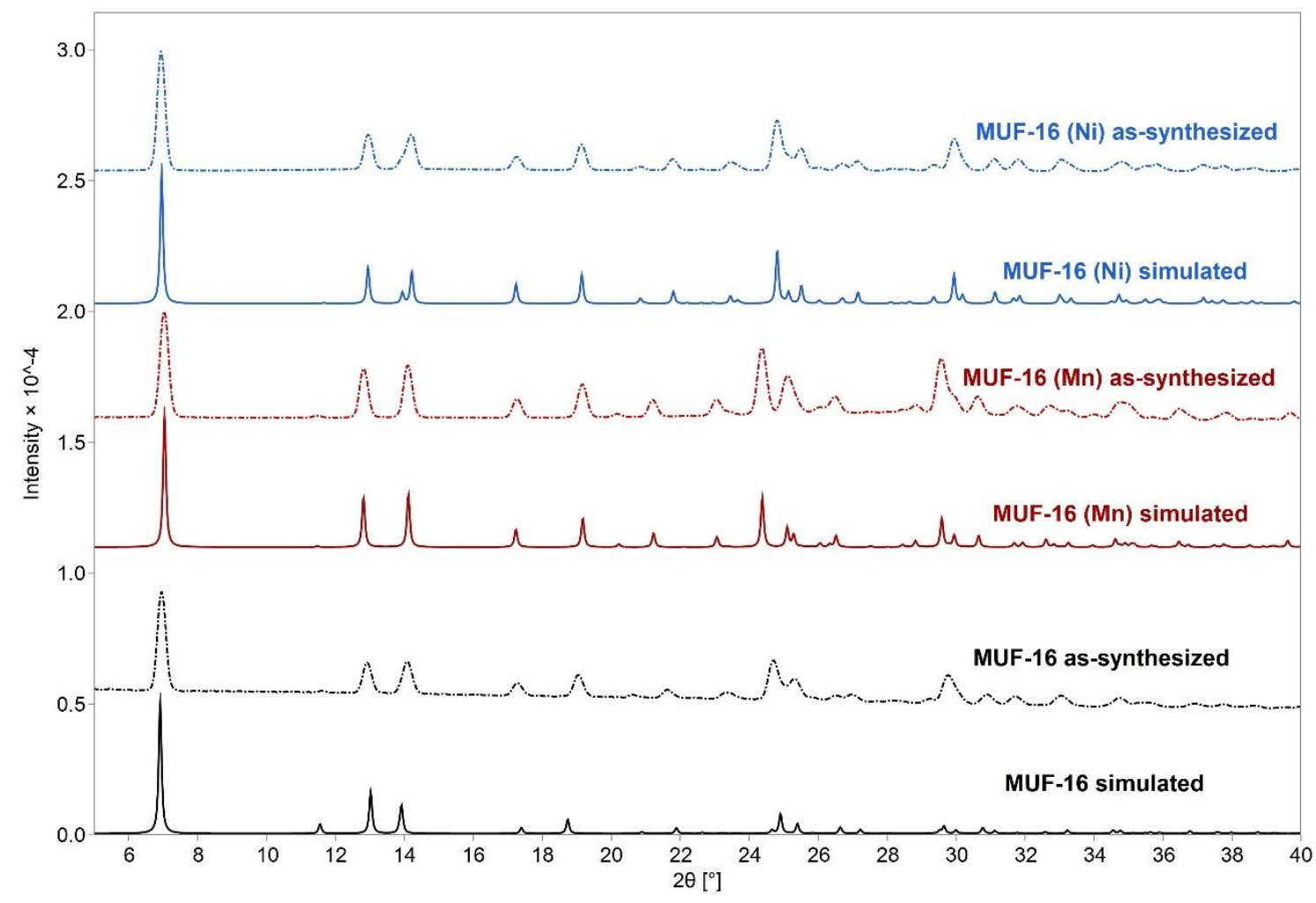

Figure S7. PXRD patterns of MUF-16, MUF-16(Mn) and MUF-(Ni) with comparisons between measurements on as-synthesized bulk samples and diffractograms predicted from SCXRD structures. 


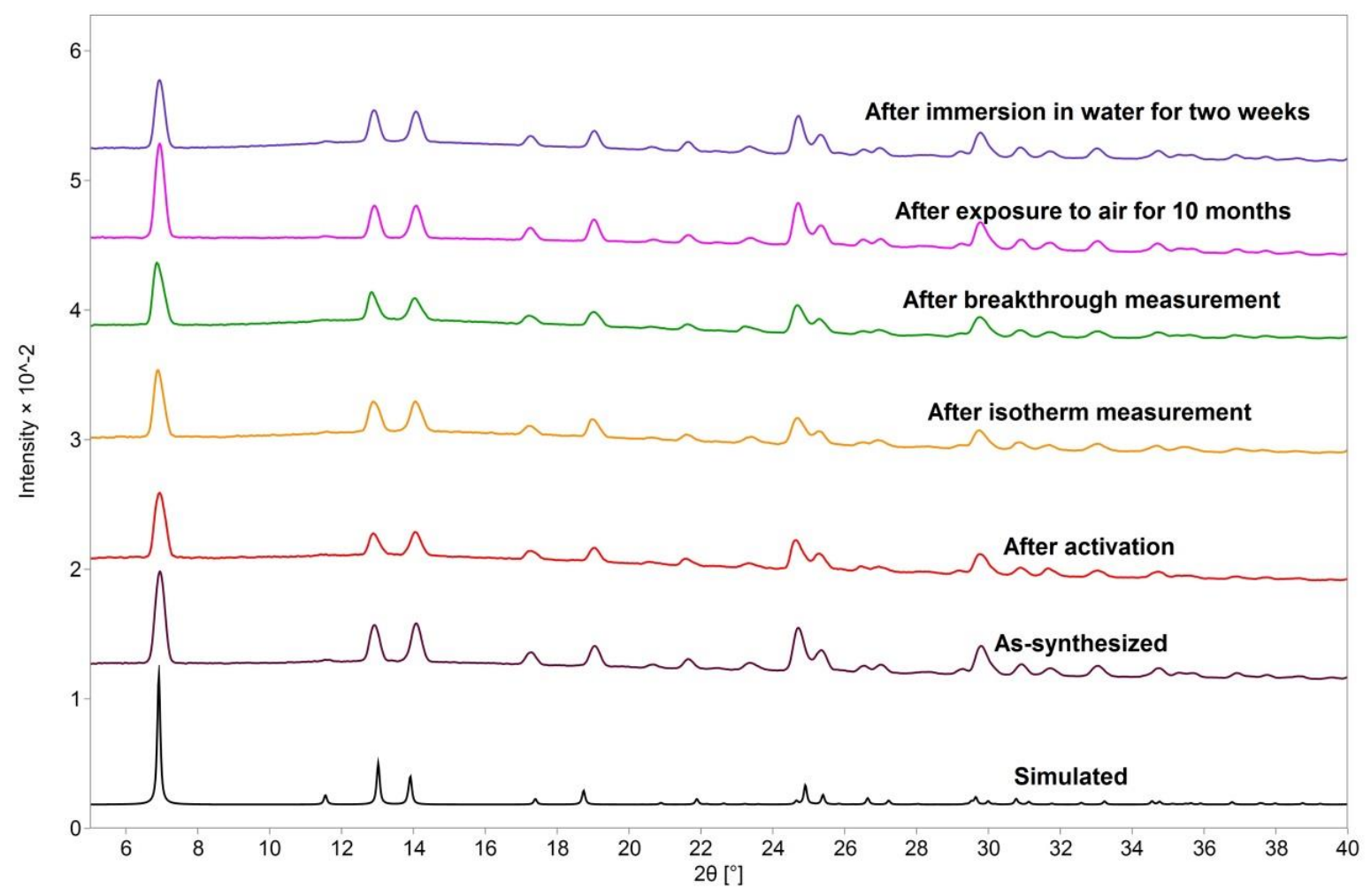

FigureS8. PXRD patterns of MUF-16 showing that its structure remains unchanged after activation at $130{ }^{\circ} \mathrm{C}$ under vacuum, after isotherm measurements, after breakthrough experiments, after exposure to an air with relative humidity of $>80 \%$ for at least 12 months and after immersion in water for two weeks.

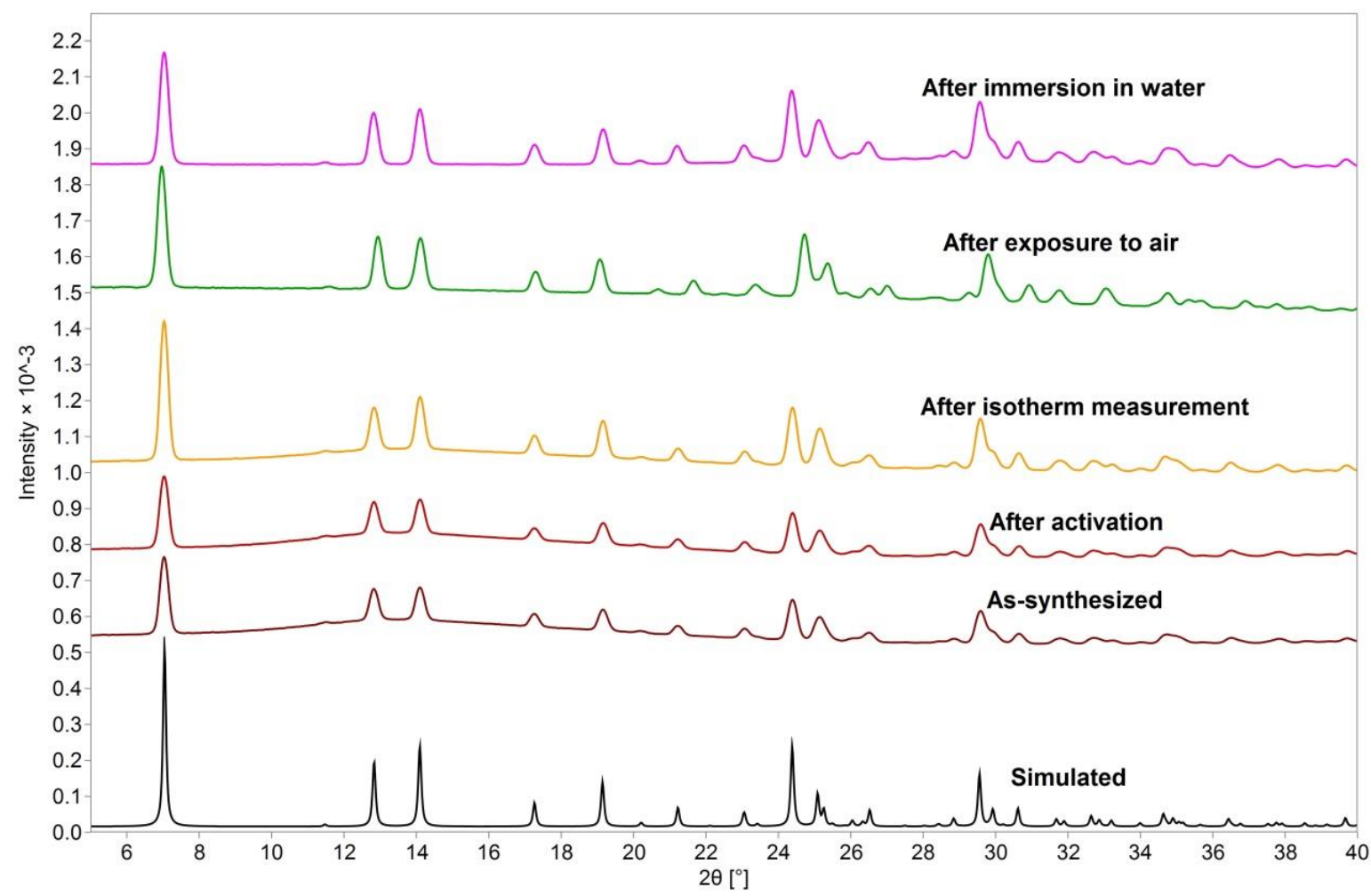

Figure S9. PXRD patterns of MUF-16(Mn) showing that its structure remains unchanged after activation at $130{ }^{\circ} \mathrm{C}$ under vacuum, after isotherm measurements, after exposure to an air with relative humidity of $>80 \%$ for at least 12 months and after immersion in water for 2 weeks. 


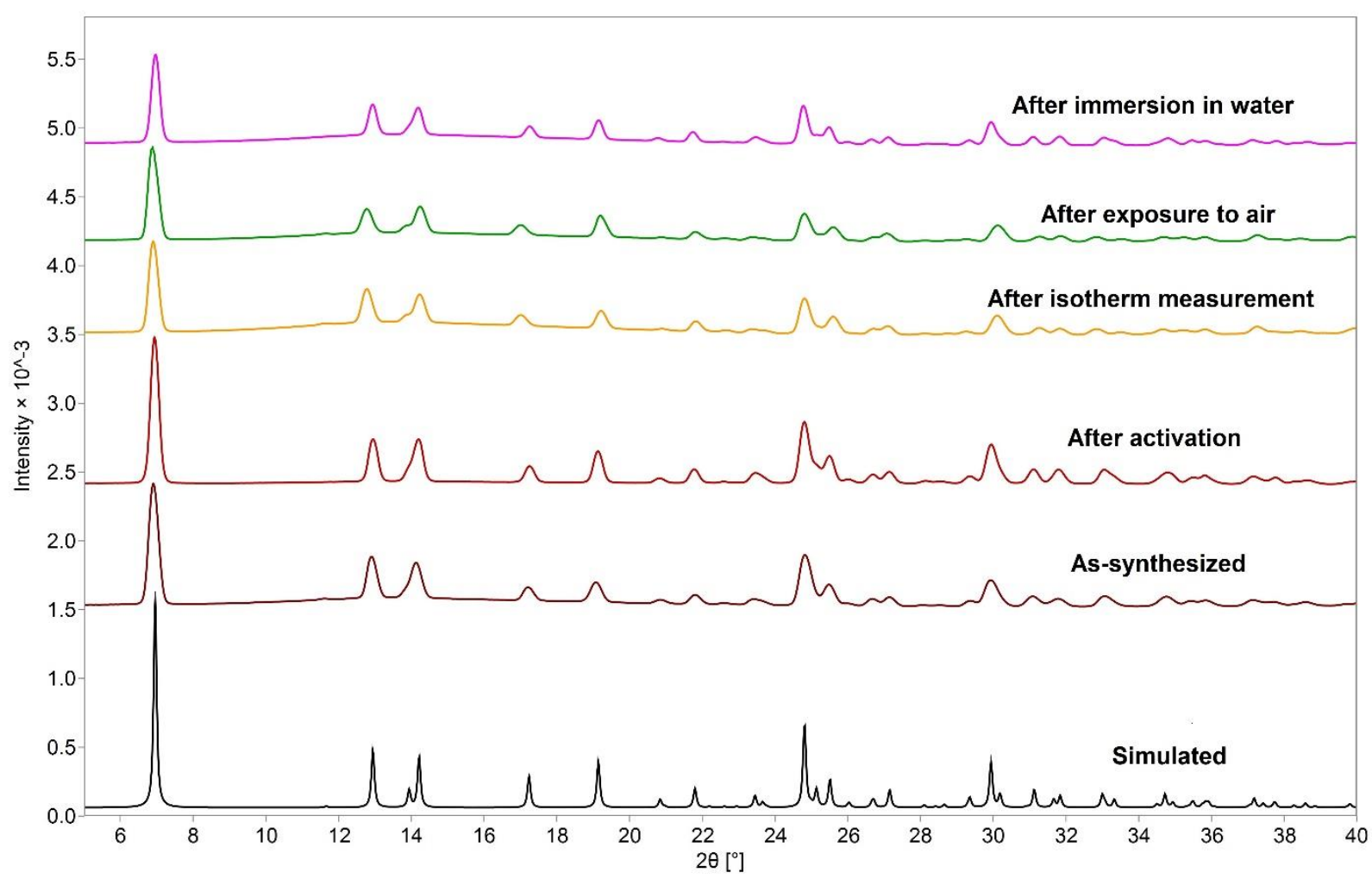

Figure S10. PXRD patterns of MUF-16(Ni) showing that its structure remains unchanged after activation at $130{ }^{\circ} \mathrm{C}$ under vacuum, after isotherm measurements, after exposure to an air with relative humidity of $>80 \%$ for at least 12 months and after immersion in water for 2 weeks.

\section{Low-pressure gas adsorption measurements}

The as-synthesized samples were washed with anhydrous methanol several times and 50-1000 mg was transferred into a pre-dried and weighed sample tube. Large sample quantities were used to measure isotherms of the weakly-adsorbing gases to ensure reliable results. To activate the sample, it was heated at rate of $10^{\circ} \mathrm{C} / \mathrm{min}$ to a temperature of $130{ }^{\circ} \mathrm{C}$ under a dynamic vacuum with a turbomolecular pump for 20 hours.

Table S6. Uptake capacity of $\mathrm{CO}_{2}$ at $293 \mathrm{~K}$ and 1 bar of MUF-16.

\begin{tabular}{lcccc}
\hline & $\begin{array}{c}\text { Uptake } \\
(\mathbf{w t} \%)\end{array}$ & $\begin{array}{c}\text { Molecules of } \mathbf{C O}_{2} \text { per unit } \\
\text { cell }\end{array}$ & $\begin{array}{c}\text { Molecules of } \mathrm{CO}_{2} \text { per } \\
\text { metal }\end{array}$ & $\begin{array}{c}\text { Fraction of void volume } \\
\text { occupied by } \mathbf{C O}_{2} *\end{array}$ \\
\hline MUF-16 & 9.38 & 3.57 & 0.89 & 0.67 \\
MUF-16(Ni) & 9.41 & 3.58 & 0.89 & 0.68 \\
MUF-16(Mn) & 9.90 & 3.74 & 0.93 & 0.70 \\
\hline
\end{tabular}

*The fraction of the total free volume of MUF-16 that is occupied by adsorbate molecules. This was calculated from the accessible void fraction given by RASPA2 software (Table S1), the molecular volume of the $\mathrm{CO}_{2}$ adsorbates $(56.75$ $\AA^{3} /$ molecule) and the total number of adsorbate molecules. 


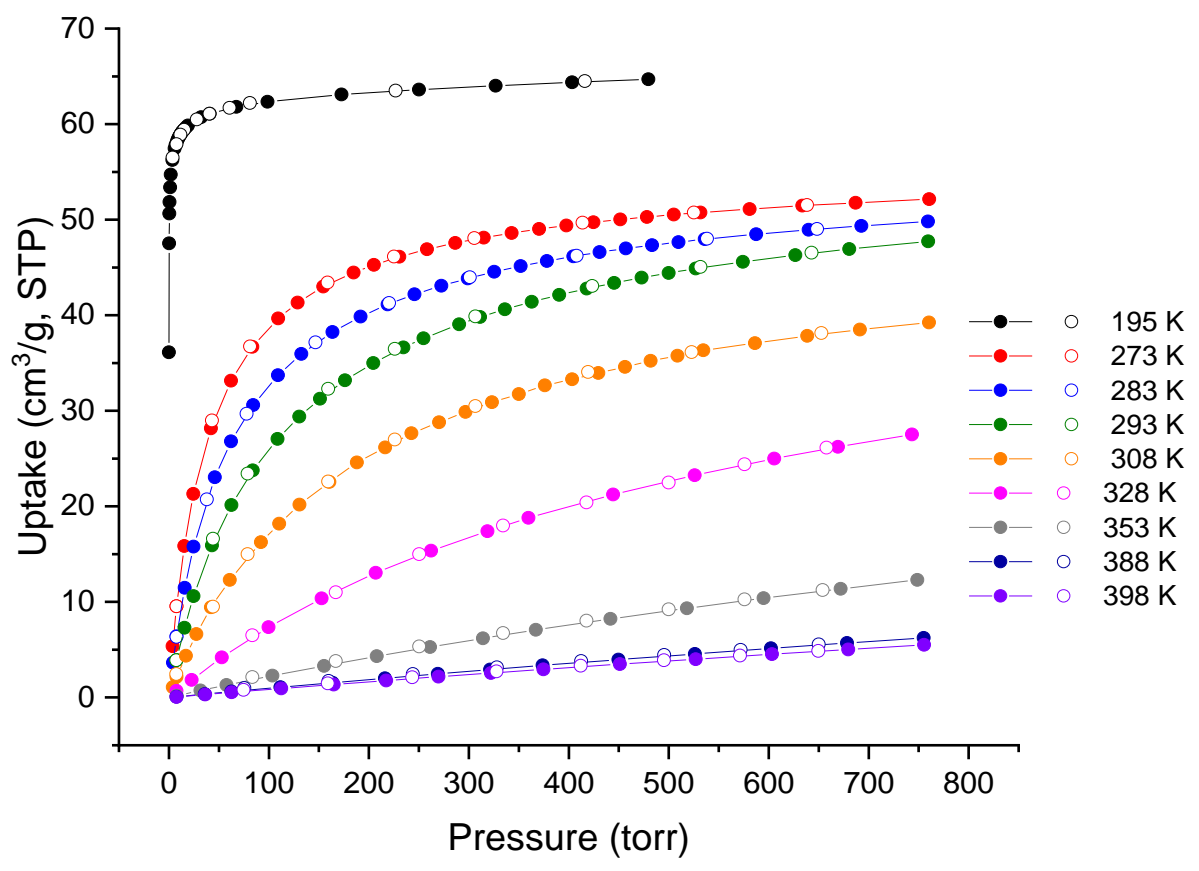

Figure S11. Volumetric adsorption (filled circles) and desorption (open circles) isotherms of $\mathrm{CO}_{2}$ at different temperatures for MUF-16.

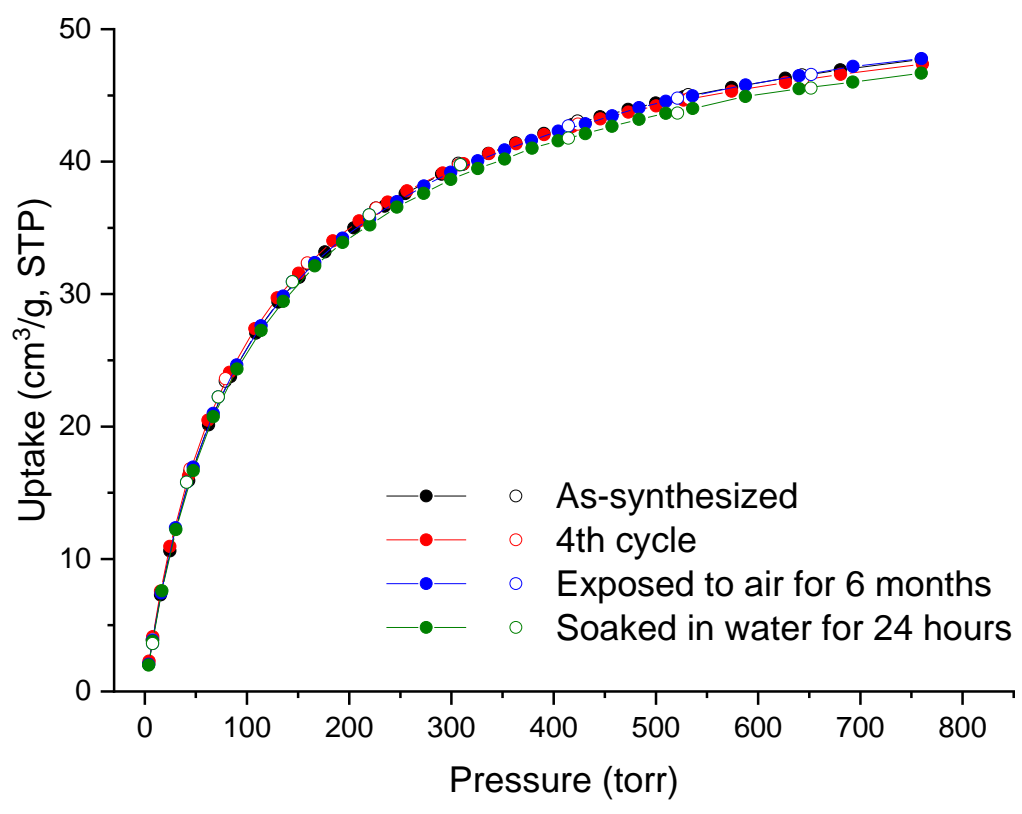

Figure S12. $\mathrm{CO}_{2}$ adsorption isotherms $(293 \mathrm{~K}$ ) of as-synthesized MUF-16 after four consecutive adsorption-desorption cycles, after exposing it to air with $\sim 80 \%$ humidity for 6 months, and after immersion in water for 48 hours. 


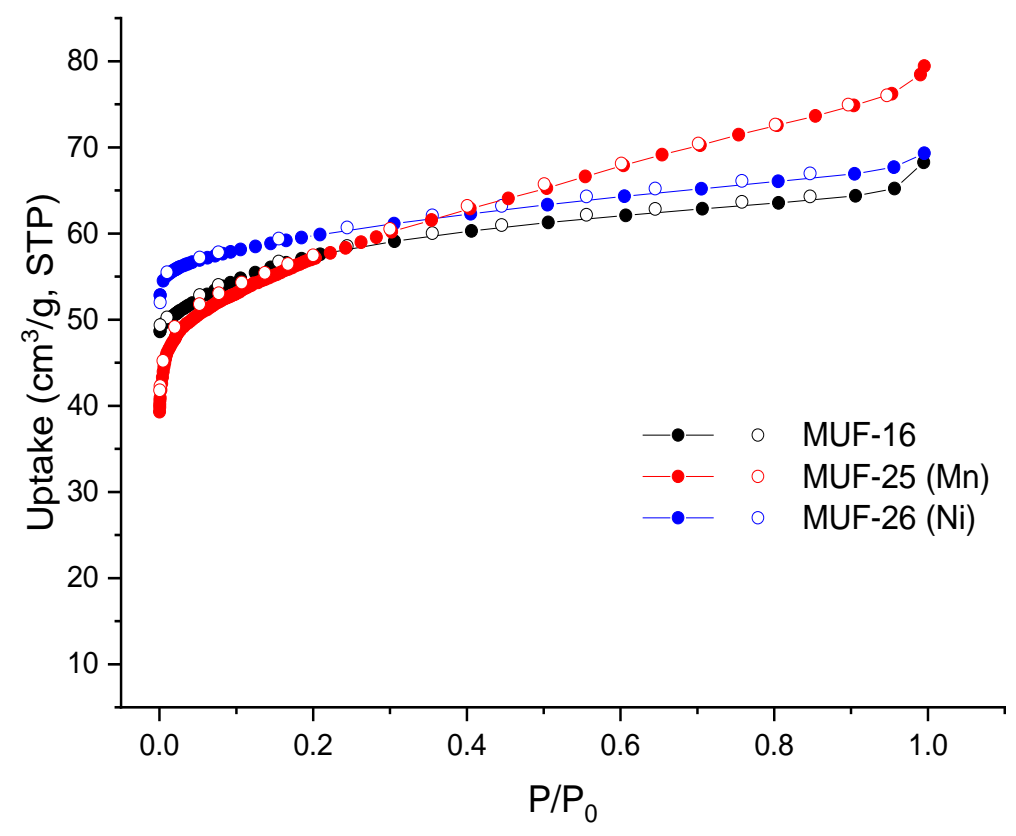

Figure S13. Volumetric adsorption (filled circles) and desorption (open circles) isotherms of $\mathrm{N}_{2}$ for MUF-16 (black), MUF-16(Mn) (red) and MUF-16(Ni) (blue) measured at $77 \mathrm{~K}$.

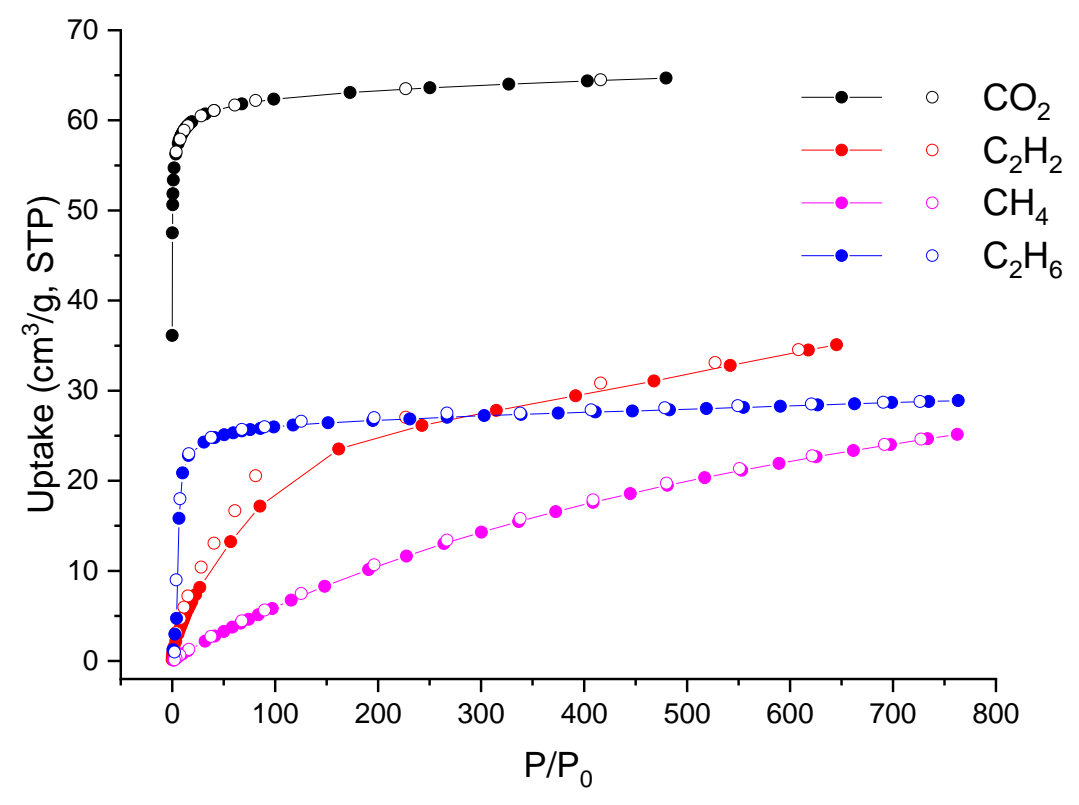

Figure S14. Volumetric adsorption (filled circles) and desorption (open circles) isotherms of $\mathrm{CO}_{2}$ (black), $\mathrm{C}_{2} \mathrm{H}_{2}$ (red), $\mathrm{C}_{2} \mathrm{H}_{6}$ (blue) and $\mathrm{CH}_{4}$ (purple) measured at $195 \mathrm{~K}$ for MUF-16. 


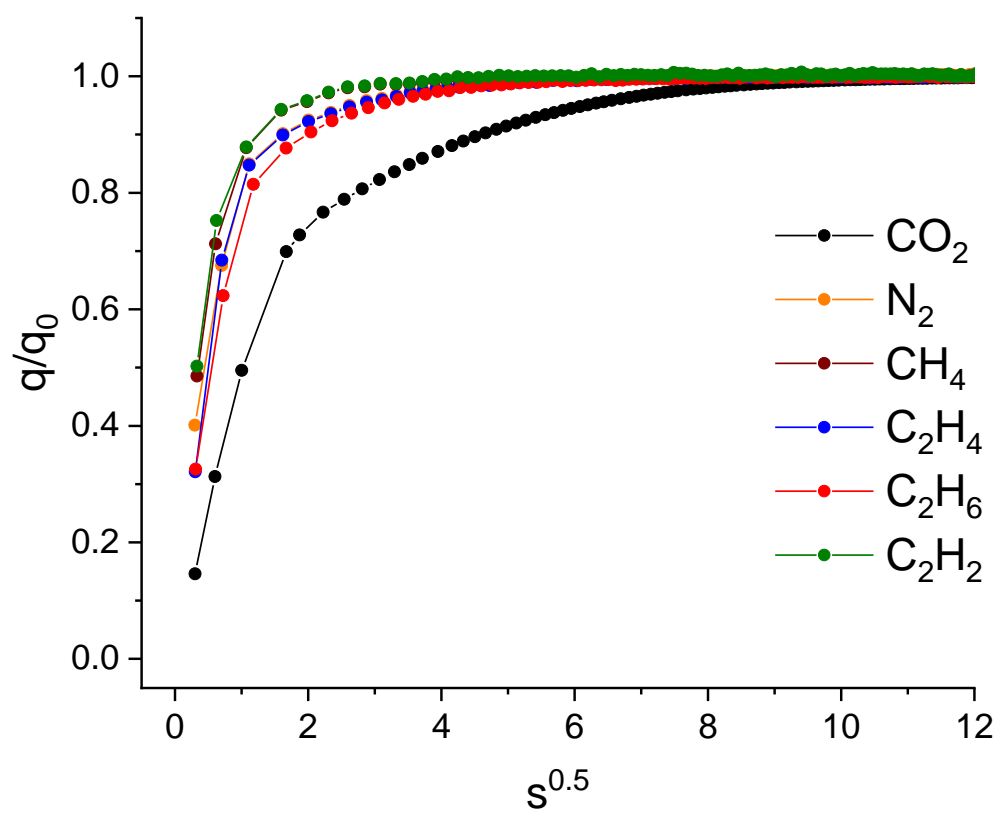

Figure S15. Kinetic profiles of different gas uptake by MUF-16 at $293 \mathrm{~K}$ upon exposing an evacuated sample to a dose of gas equal to its measured total adsorption of that gas at 1 bar. $\mathrm{q}$ is the amount of uptake at time $t$ and $\mathrm{q}_{0}$ is the final uptake amount.

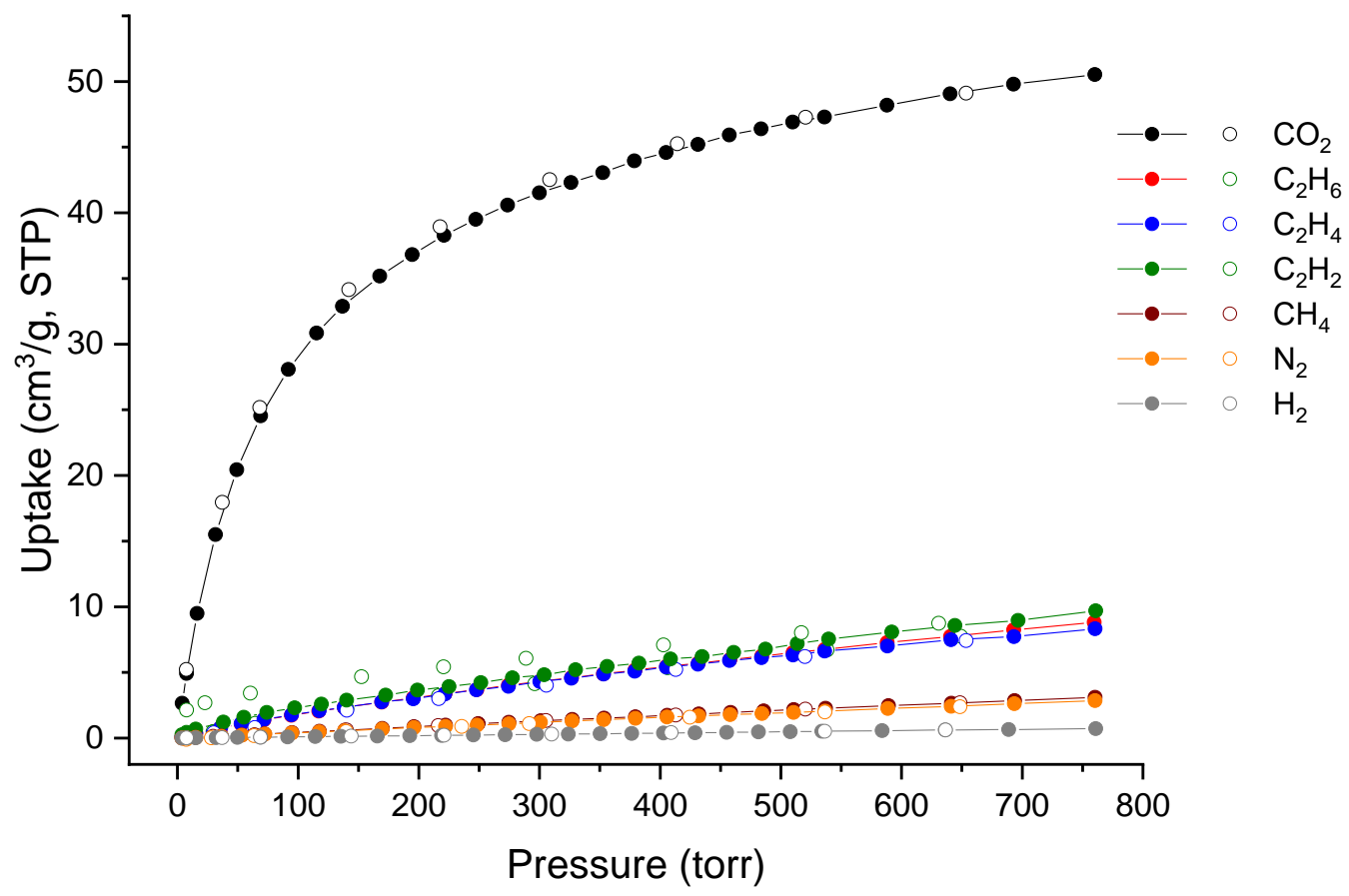

Figure S16. Volumetric adsorption (filled circles) and desorption (open circles) isotherms of different gases by MUF-16(Mn) at $293 \mathrm{~K}$. 


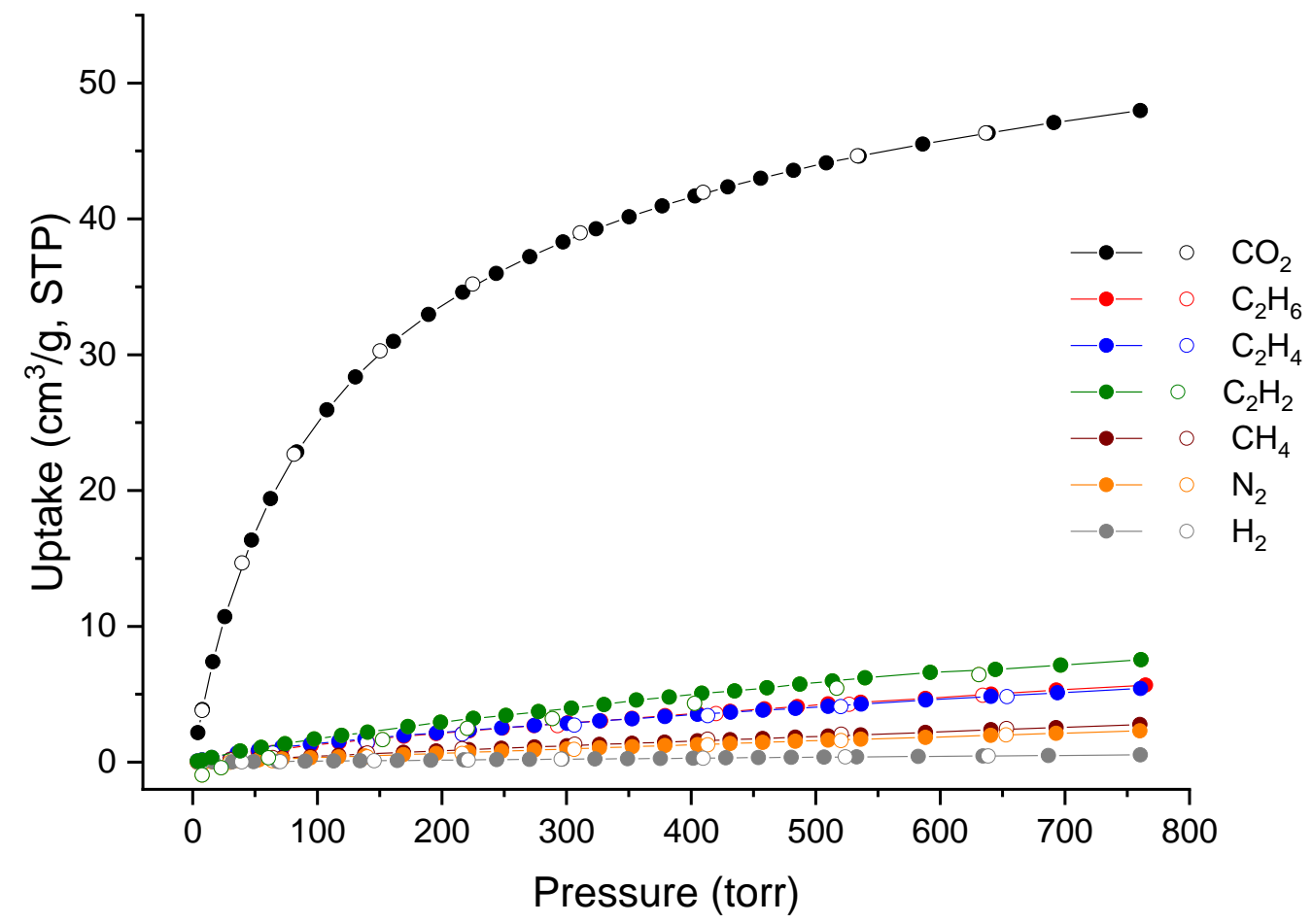

Figure S17. Volumetric adsorption (filled circles) and desorption (open circles) isotherms of different gases by MUF-16(Ni) at $293 \mathrm{~K}$.

\section{Calculation of BET surface areas}

BET surface areas were calculated from $\mathrm{N}_{2}$ adsorption isotherms at $77 \mathrm{~K}$ according to the following procedures $^{7}$ :

1) The isotherm region where $v\left(1-P / P_{0}\right)$ increases versus $P / P_{0}$, where $v$ is the amount of $\mathrm{N}_{2}$ adsorbed, was identified.

2) Within this isotherm region, sequential data points that led to a positive intercept in the plot of $\frac{P / P_{0}}{v\left(1-P / P_{0}\right)}$ against $P / P_{0}$, were found. This plot yields a slope $a$, and a positive intercept $b$. The amount of gas molecules adsorbed in the initial monolayer is $v_{m}=\frac{1}{a+b}$.

3) The BET surface area was calculated according to the following equation:

$A_{B E T}=v_{m}\left(\mathrm{~cm}^{3} \mathrm{~g}^{-1}\right) * \frac{1(\mathrm{~mol})}{22400\left(\mathrm{~cm}^{3}\right)} * \sigma_{0}\left(\AA^{2}\right) * N_{A}\left(\mathrm{~mol}^{-1}\right) * 10^{-20}\left(\frac{\mathrm{m}^{2}}{\AA^{2}}\right)$

Where $\mathrm{N}_{\mathrm{A}}$ is Avogadro's constant, and $\sigma_{0}$ is the cross-sectional area of a $\mathrm{N}_{2}$ molecule, which is $16.2 \AA^{2}$. 

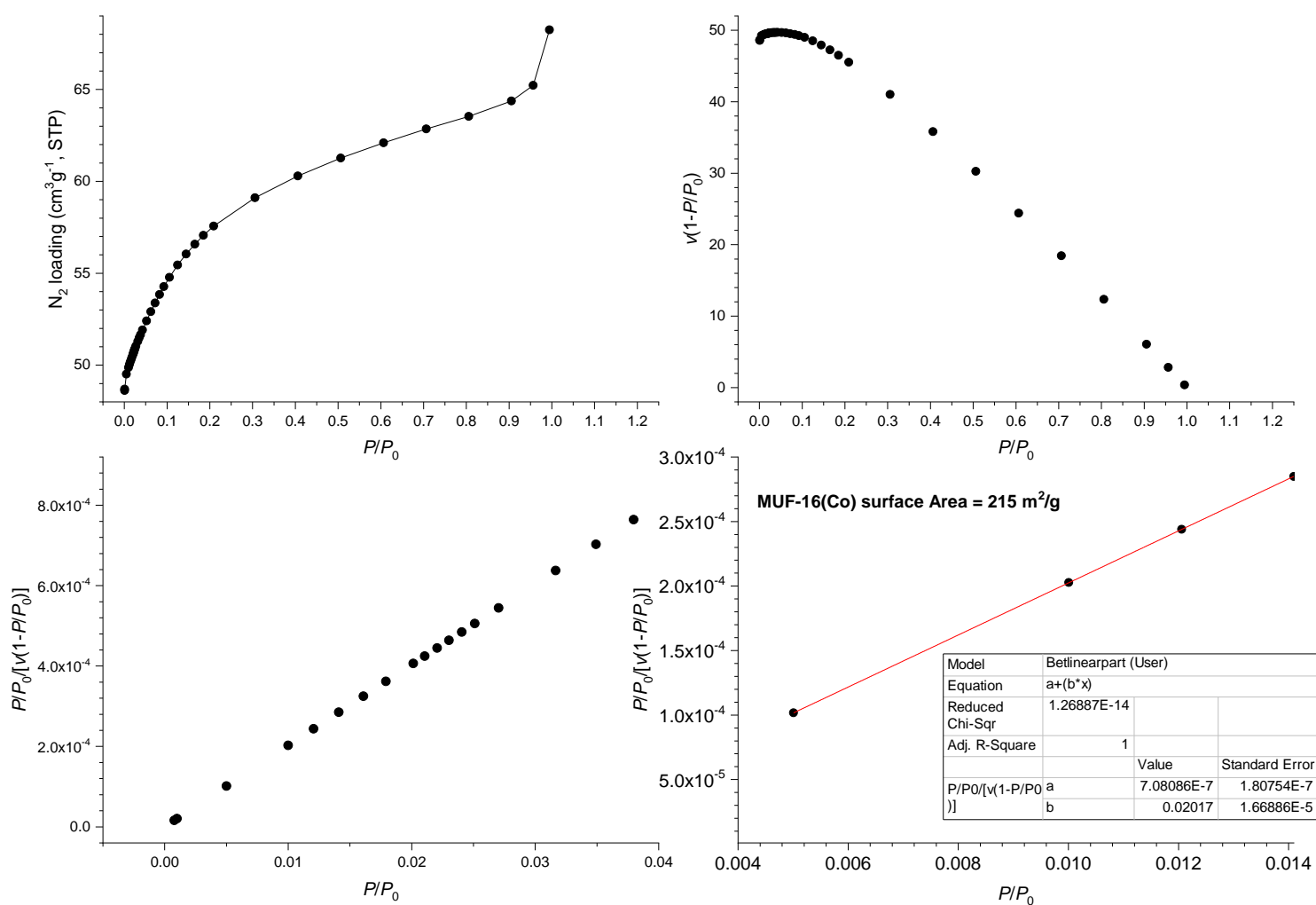

Figure S18. $\mathrm{N}_{2}$ adsorption isotherm at $77 \mathrm{~K}$ and BET surface area plots for MUF-16.
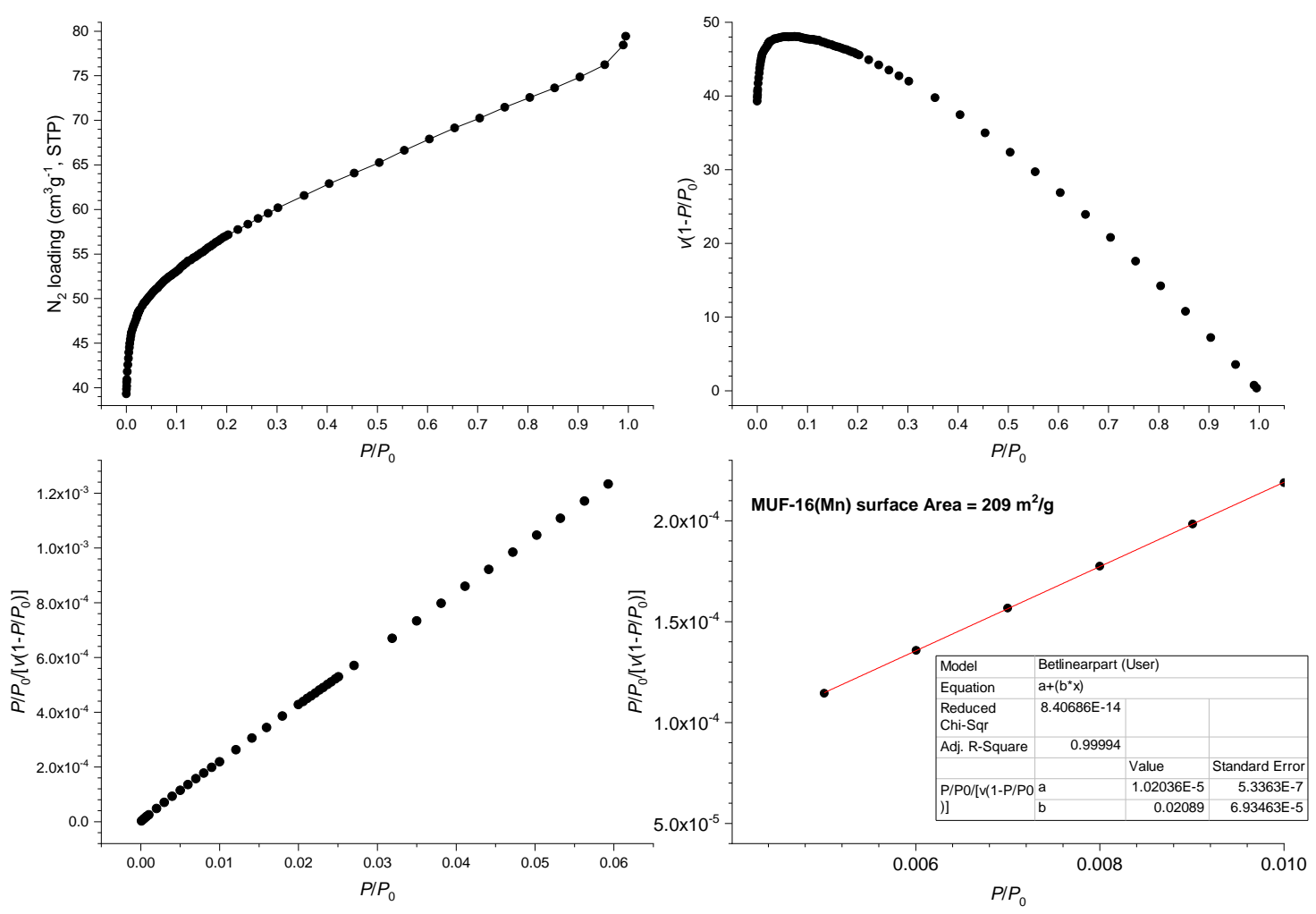

Figure S19. $\mathrm{N}_{2}$ adsorption isotherm at $77 \mathrm{~K}$ and BET surface area plots for MUF-16(Mn). 

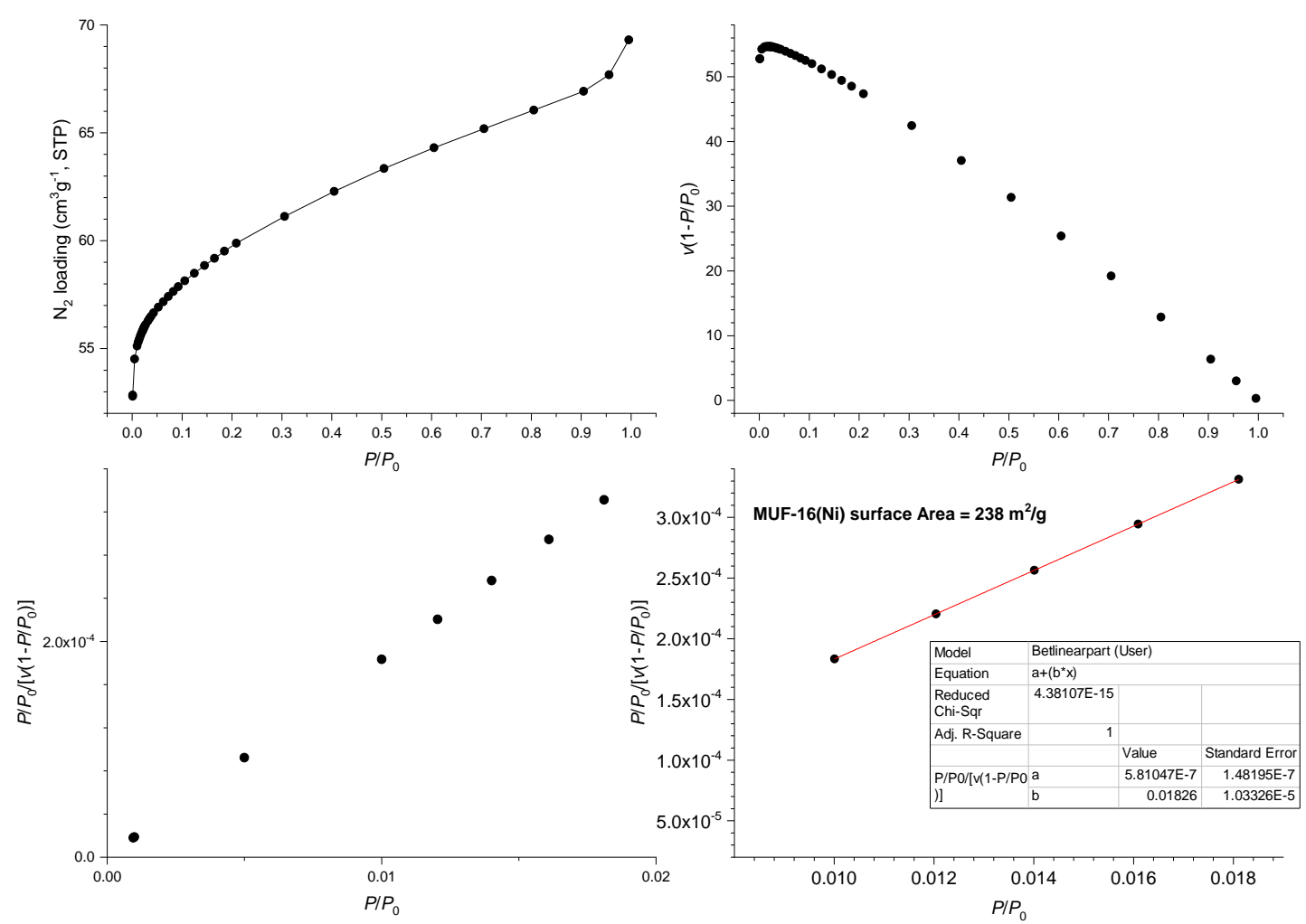

Figure S20. $\mathrm{N}_{2}$ adsorption isotherm at $77 \mathrm{~K}$ and BET surface area plots for MUF-16(Ni).

\section{IAST calculations}

Mixed gas adsorption isotherms and gas selectivities for different mixtures of $\mathrm{CO}_{2} / \mathrm{C}_{2} \mathrm{H}_{2}, \mathrm{CO}_{2} / \mathrm{C}_{2} \mathrm{H}_{4}$, $\mathrm{CO}_{2} / \mathrm{C}_{2} \mathrm{H}_{6}, \mathrm{CO}_{2} / \mathrm{N}_{2}, \mathrm{CO}_{2} / \mathrm{CH}_{4}$ and $\mathrm{CO}_{2} / \mathrm{H}_{2}$ at $293 \mathrm{~K}$ were calculated based on the ideal adsorbed solution theory (IAST) proposed by Myers and Prausnitz ${ }^{8}$. The pyIAST package ${ }^{9}$ was used to perform the IAST calculations. In order to predict the sorption performance of MUF-16 toward the separation of binary mixed gases, the single-component adsorption isotherms were first fit to a Dual Site Langmuir or Dual Site Langmuir Freundlich model as below:

$q=\frac{q_{1} b_{1} P}{1+b_{1} P}+\frac{q_{2} b_{2} P}{1+b_{2} P}$

$q=\frac{q_{1} b_{1} P^{1 / t_{1}}}{1+b_{1} P^{1 / t_{1}}}+\frac{q_{2} b_{2} P^{1 / t_{2}}}{1+b_{2} P^{1 / t_{2}}}$

Where $\mathrm{q}$ is the uptake of a gas; $\mathrm{P}$ is the equilibrium pressure and $\mathrm{q}_{1}, \mathrm{~b}_{1}, \mathrm{t}_{1}, \mathrm{q}_{2}, \mathrm{~b}_{2}$ and $\mathrm{t}_{2}$ are constants. These parameters were used subsequently to carry out the IAST calculations. 


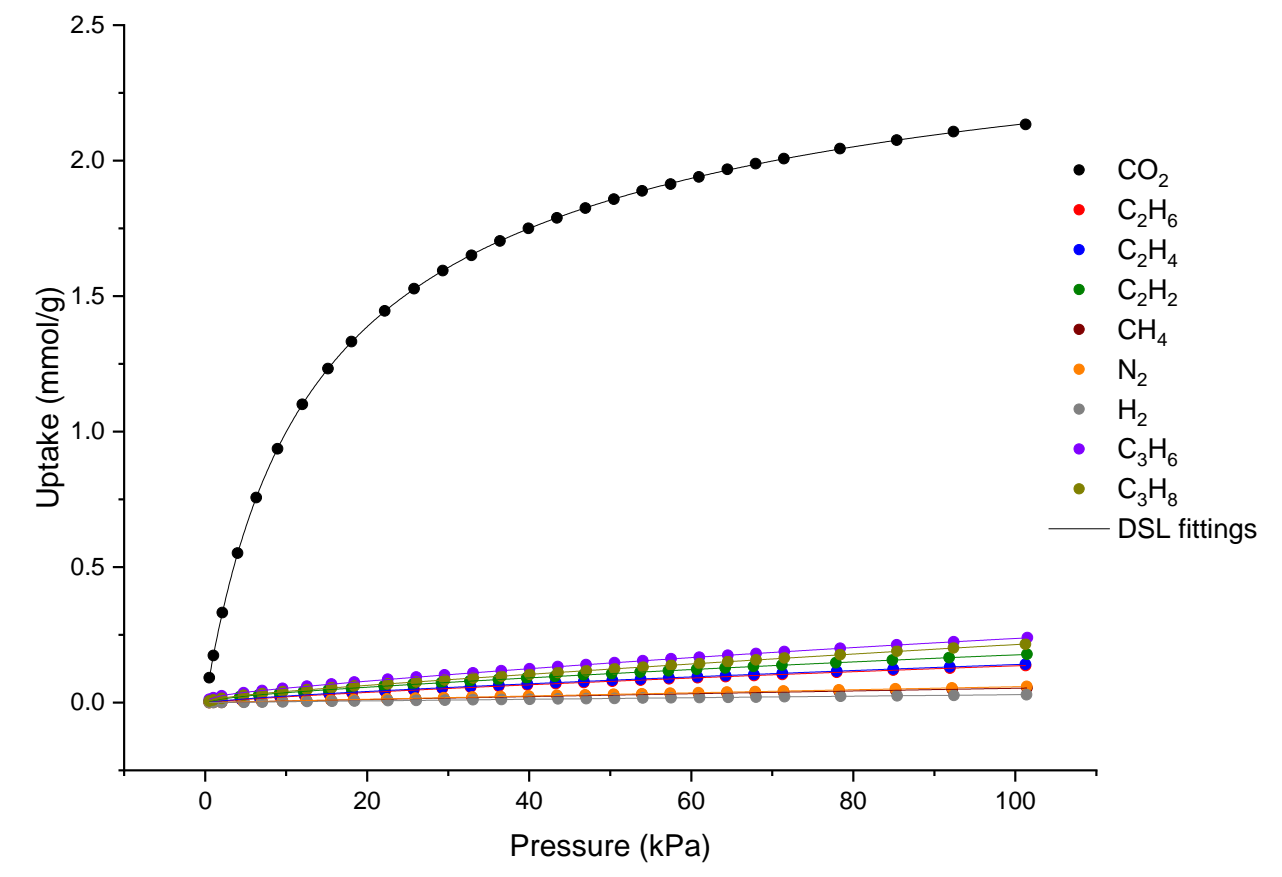

\begin{tabular}{|c|c|c|c|c|c|c|c|c|c|}
\hline Model & & & & & DSL (User) & & & & \\
\hline Equation & & & & & 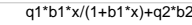 & ${ }^{2} x /\left(1+b 2^{*} x\right)$ & & & \\
\hline Plot & $\mathrm{CO} 2$ & $\mathrm{C} 2 \mathrm{H} 6$ & $\mathrm{C} 2 \mathrm{H} 4$ & $\mathrm{C} 2 \mathrm{H} 2$ & $\mathrm{CH} 4$ & N2 & $\mathrm{H} 2$ & $\mathrm{C} 3 \mathrm{H} 6$ & $\mathrm{C} 3 \mathrm{H} 8$ \\
\hline q1 & $1.92197 \pm 0.03622$ & $0.01903 \pm 7.58427 \mathrm{E}-4$ & $0.90455 \pm 0.02194$ & $0.84858 \pm 0.02172$ & $-1.37048 \mathrm{E}-4 \pm 2.62012 \mathrm{E}-5$ & $-1.30883 \mathrm{E}-4 \pm 1.93944 \mathrm{E}-5$ & $1.46115 \mathrm{E}-4 \pm 1.23483 \mathrm{E}-4$ & $0.92327 \pm 0.02031$ & $0.02582 \pm 8.46918 \mathrm{E}-4$ \\
\hline b1 & $0.09147 \pm 0.00142$ & $0.06919 \pm 0.00295$ & $0.00155 \pm 4.83418 \mathrm{E}-5$ & $0.00219 \pm 7.32671 \mathrm{E}-5$ & $\quad 2.40335 \pm 2.41269$ & $1.42902 \pm 0.89123$ & $1.47 \pm 0$ & $0.00289 \pm 8.52827 \mathrm{E}-5$ & $0.38985 \pm 0.03262$ \\
\hline q2 & $0.71591 \pm 0.02029$ & $0.91643 \pm 0.02976$ & $0.02077 \pm 4.66874 \mathrm{E}-4$ & $0.02486 \pm 4.712 \mathrm{E}-4$ & $0.63958 \pm 0.01292$ & $0.86986 \pm 0.01365$ & $0.4377 \pm 0.00344$ & $0.03023 \pm 4.69954 E-4$ & $2.11273 \pm 0.21651$ \\
\hline b2 & $0.01264 \pm 0.0014$ & $0.00149 \pm 6.32966 \mathrm{E}-5$ & $0.09736 \pm 0.00278$ & $0.29065 \pm 0.01171$ & $9.04454 \mathrm{E}-4 \pm 2.00076 \mathrm{E}-5$ & $7.2231 \mathrm{E}-4 \pm 1.22207 \mathrm{E}-5$ & $7.1 \mathrm{E}-4 \pm 0$ & $0.92871 \pm 0.04824$ & $9.83565 \mathrm{E}-4 \pm 1.13365 \mathrm{E}-4$ \\
\hline Reduced Chi-Sqr & $2.547 \mathrm{E}-6$ & $4.27057 \mathrm{E}-9$ & 4.09689E-9 & $3.87189 \mathrm{E}-8$ & $1.11837 \mathrm{E}-9$ & 4.7599E-10 & $1.0175 \mathrm{E}-7$ & $1.63183 \mathrm{E}-7$ & $2.34956 \mathrm{E}-7$ \\
\hline R-Square (COD) & 0.99999 & 1 & 1 & 0.99999 & 1 & 1 & 0.99871 & 0.99997 & 0.99994 \\
\hline Adj. R-Square & 0.99999 & 1 & 1 & 0.99998 & 1 & 1 & 0.99866 & 0.99996 & 0.99994 \\
\hline
\end{tabular}

Figure S21 Dual-site Langmuir fits of various adsorption isotherms for MUF-16 at 293 K. 


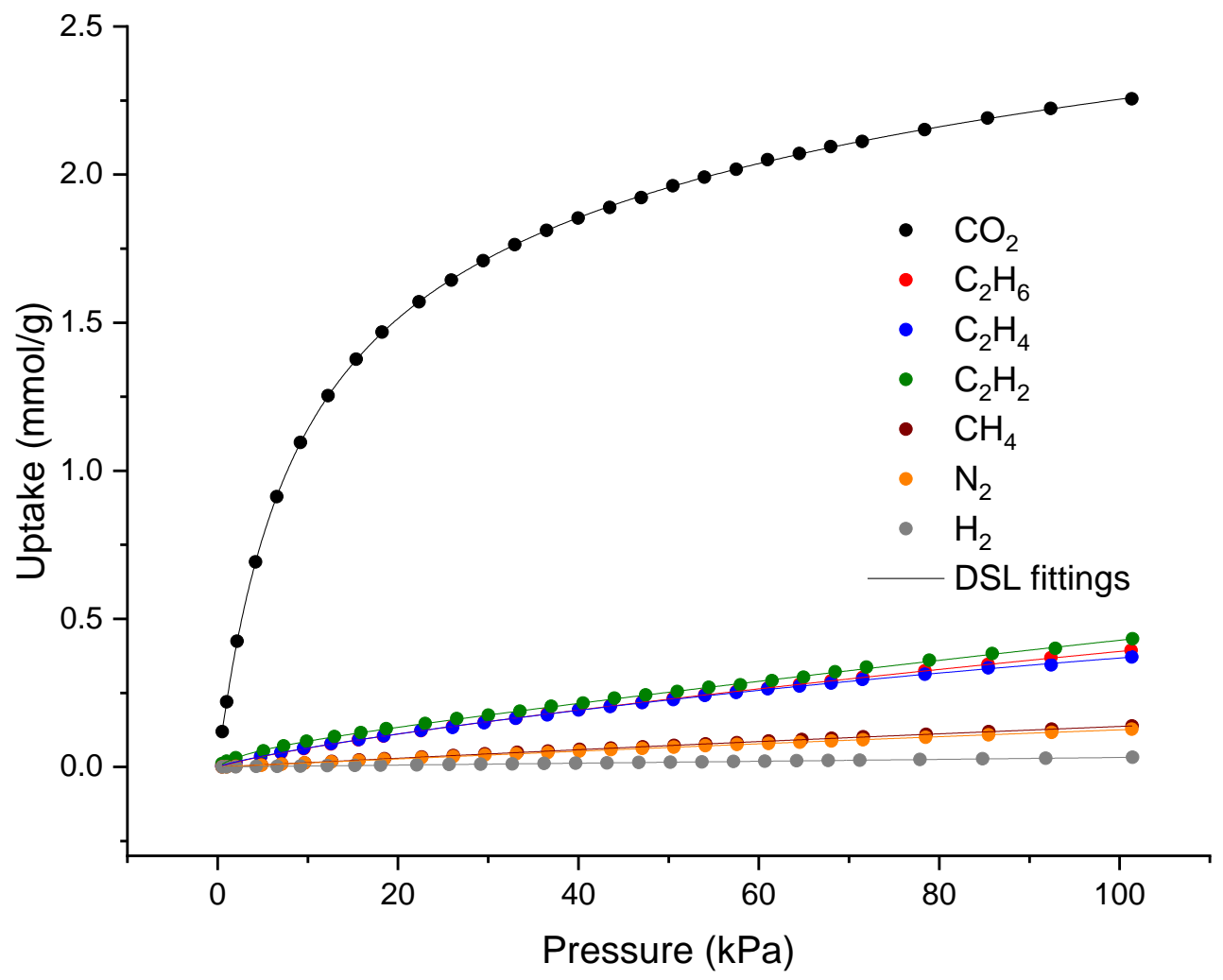

\begin{tabular}{|c|c|c|c|c|c|c|c|}
\hline \multirow{3}{*}{\begin{tabular}{|l|} 
Model \\
Equation \\
Plot
\end{tabular}} & \multicolumn{7}{|c|}{ DSL (User) } \\
\hline & \multicolumn{7}{|c|}{$\mathrm{q} 1^{*} \mathrm{~b} 1^{*} \mathrm{x} /\left(1+\mathrm{b} 1^{*} \mathrm{x}\right)+\mathrm{q} 2^{*} \mathrm{~b} 2^{*} \mathrm{x} /\left(1+\mathrm{b} 2^{*} \mathrm{x}\right)$} \\
\hline & $\mathrm{CO} 2$ & $\mathrm{C} 2 \mathrm{H} 6$ & $\mathrm{C} 2 \mathrm{H} 4$ & $\mathrm{C} 2 \mathrm{H} 2$ & $\mathrm{CH} 4$ & N2 & $\mathrm{H} 2$ \\
\hline$q 1$ & $1.94289 \pm 0.0227$ & $0.04806 \pm 0.00391$ & $1.11314 \pm 0.0652$ & $3.94913 \pm 1.20449$ & $1.20612 \pm 0.06748$ & $1.33778 \pm 0.08483$ & $13.5332 \pm--$ \\
\hline b1 & $0.12229 \pm 0.00169$ & $0.09141 \pm 0.009$ & $0.00448 \pm 4.81593 \mathrm{E}-$ & $0.00102 \pm 3.53725 \mathrm{E}$ & $0.00129 \pm 8.15601 \mathrm{E}-5$ & $0.00103 \pm 7.0371 \mathrm{E}-$ & $-2.3718 \mathrm{E}-5 \pm$ \\
\hline q2 & $1.14216 \pm 0.04571$ & $2.04938 \pm 0.09902$ & $0.02464 \pm 0.00777$ & $0.06637 \pm 0.00631$ & $-8.32165 \mathrm{E}-4 \pm 2.43966 \mathrm{E}$ & $0 \pm 0$ & $0 \pm 0$ \\
\hline b2 & $0.0067 \pm 8.46612 \mathrm{E}-$ & $0.00204 \pm 1.38007 \mathrm{E}-$ & $0.20141 \pm 0.10616$ & $0.24669 \pm 0.04921$ & $10.03567 \pm 38.12063$ & $0 \pm 0$ & $0 \pm 0$ \\
\hline Reduced Chi-Sq & $6.81414 \mathrm{E}-6$ & $2.15657 \mathrm{E}-7$ & 3.7049E-6 & 6.09794E-6 & 1.33437E-7 & $2.12406 \mathrm{E}-7$ & $1.0589 \mathrm{E}-8$ \\
\hline R-Square (COD) & 0.99998 & 0.99999 & 0.99973 & 0.99963 & 0.99993 & 0.99987 & 0.9999 \\
\hline Adj. R-Square & 0.99998 & 0.99998 & 0.99969 & 0.99958 & 0.99992 & 0.99985 & 0.99988 \\
\hline
\end{tabular}

Figure S22. Dual-site Langmuir fits of various adsorption isotherms for MUF-16(Mn) at $293 \mathrm{~K}$. 


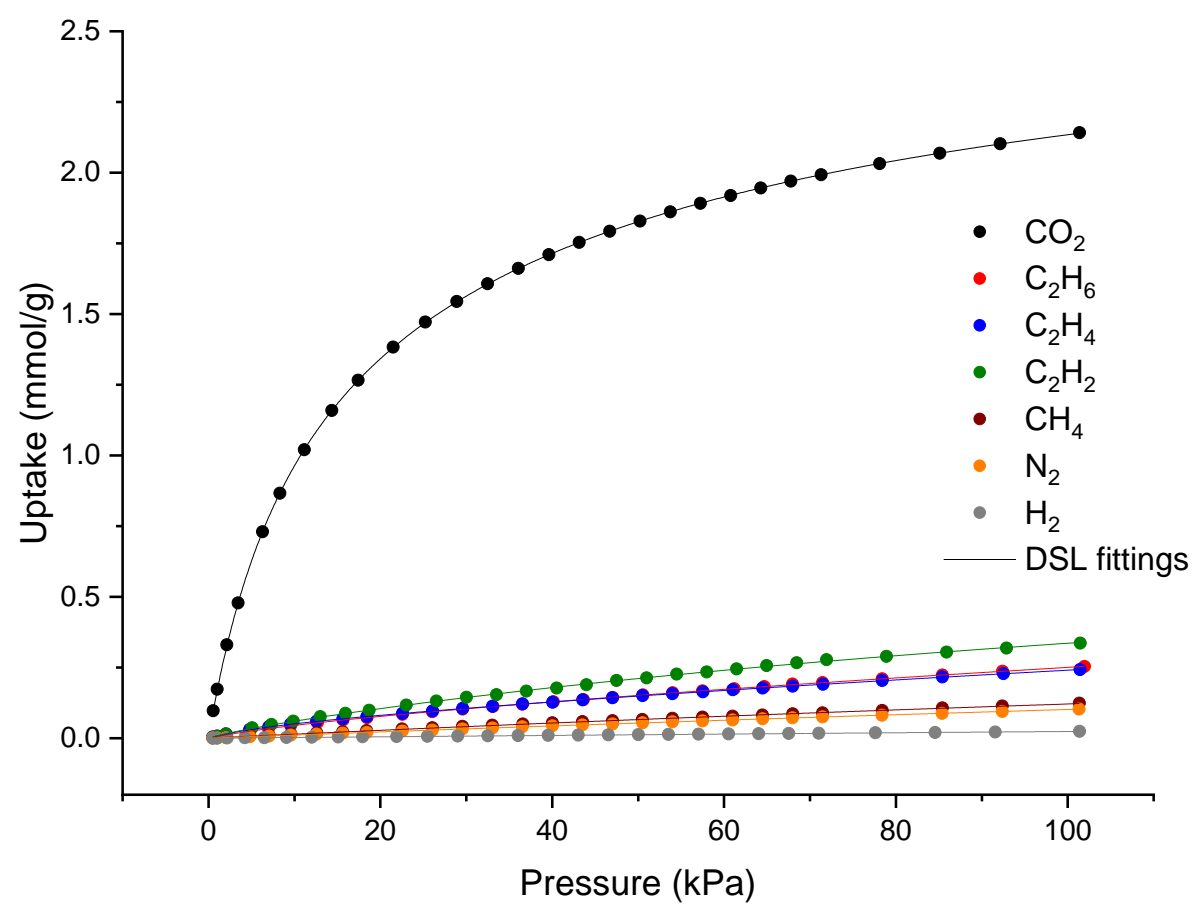

\begin{tabular}{|c|c|c|c|c|c|c|c|}
\hline Model & \multicolumn{7}{|c|}{ DSL (User) } \\
\hline Equation & \multicolumn{7}{|c|}{$\mathrm{q} 1^{*} \mathrm{~b} 1^{*} \times /\left(1+b 1^{*} x\right)+q 2^{*} b 2^{*} x /\left(1+b 2^{*} x\right)$} \\
\hline Plot & $\mathrm{CO} 2$ & $\mathrm{C} 2 \mathrm{H} 6$ & $\mathrm{C} 2 \mathrm{H} 4$ & $\mathrm{C} 2 \mathrm{H} 2$ & $\mathrm{CH} 4$ & N2 & $\mathrm{H} 2$ \\
\hline$q 1$ & $1.57274 \pm 0.02824$ & $0.05244 \pm 0.00708$ & $1.27493 \pm 0.09994$ & $0.88496 \pm 0.04798$ & $0.74301 \pm 0.05154$ & $0.98989 \pm 0.04447$ & $0.33055 \pm 0.01407$ \\
\hline b1 & $0.10503 \pm 0.00153$ & $0.07063 \pm 0.01023$ & $0.00176 \pm 1.81686 \mathrm{E}-4$ & $0.0056 \pm 6.32939 \mathrm{E}-$ & $0.00195 \pm 1.53031 \mathrm{E}-4$ & $0.00114 \pm 5.5489 \mathrm{E}-$ & $7.71273 \mathrm{E}-4 \pm 3.46228 \mathrm{E}-$ \\
\hline q2 & $1.12788 \pm 0.01983$ & $1.38112 \pm 0.20289$ & $0.05362 \pm 0.00249$ & $0.01883 \pm 0.00847$ & $0 \pm 0$ & $0 \pm 0$ & $0 \pm 0$ \\
\hline b2 & $0.01624 \pm 7.28604 \mathrm{E}-4$ & $0.00174 \pm 3.48805 E-4$ & $0.1148 \pm 0.00734$ & $0.23099 \pm 0.18081$ & $0 \pm 0$ & $0 \pm 0$ & $0 \pm 0$ \\
\hline Reduced Chi-Sqr & $1.49036 \mathrm{E}-6$ & $3.73129 \mathrm{E}-7$ & 1.65794E-7 & $5.0543 E-6$ & 7.98591E-7 & 8.47826E-8 & 1.87959E-9 \\
\hline R-Square (COD) & 1 & 0.99994 & 0.99997 & 0.99956 & 0.99946 & 0.99992 & 0.99997 \\
\hline Adj. R-Square & 1 & 0.99993 & 0.99997 & 0.99951 & 0.99939 & 0.99991 & 0.99996 \\
\hline
\end{tabular}

Figure S23. Dual-site Langmuir fits of various adsorption isotherms for MUF-16(Ni) at $293 \mathrm{~K}$.

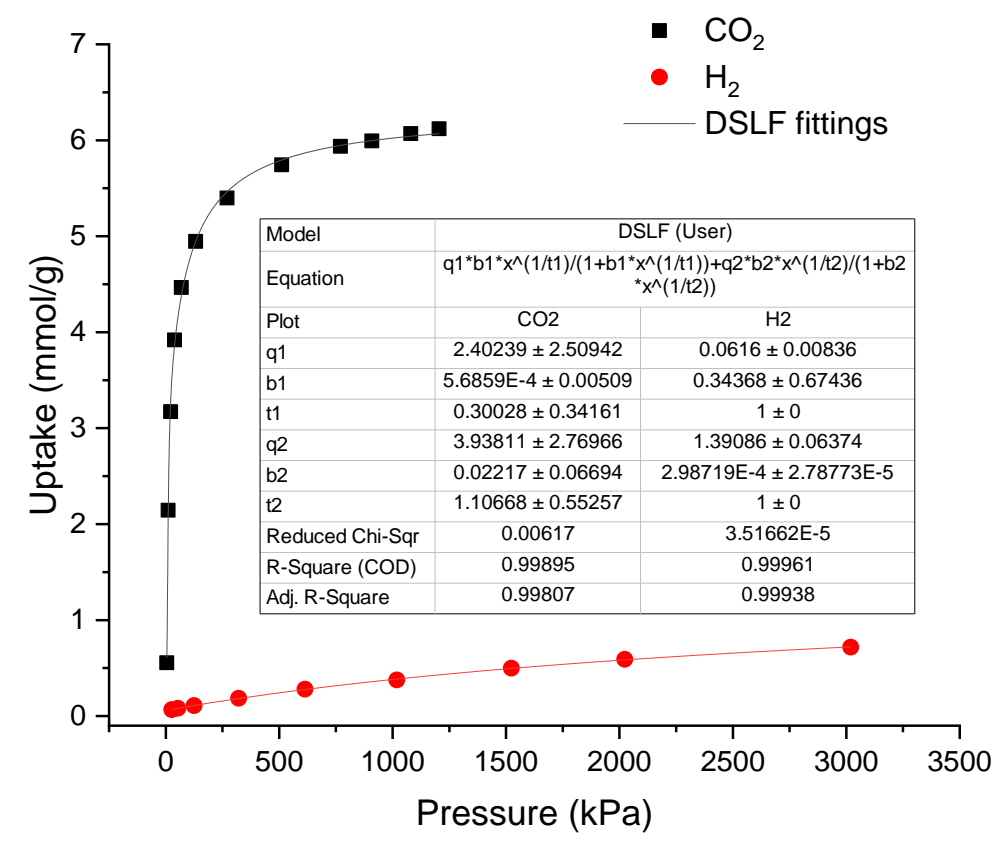

Figure S24. Dual-site Langmuir Freundlich fits for Zeolite $13 \mathrm{X}$ at $313 \mathrm{~K}$. Isotherm data were taken from ${ }^{10}$. 


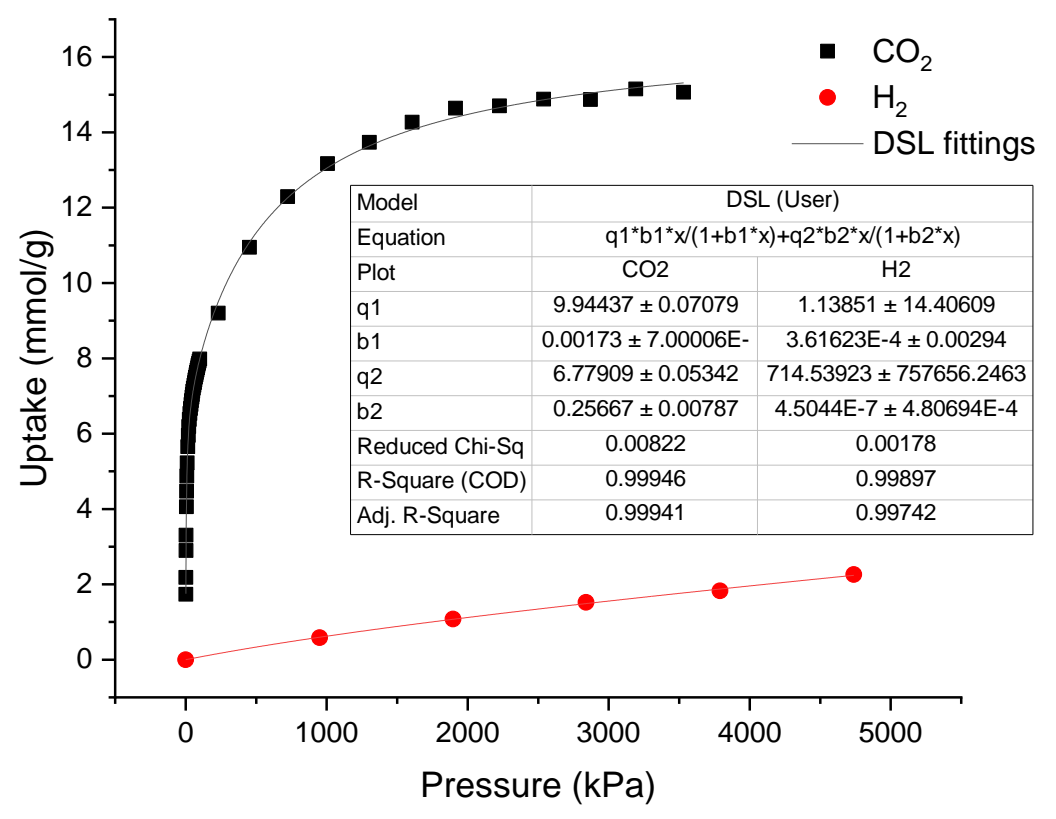

Figure S25. Dual-site Langmuir Freundlich fits for Mg-dobdc at $313 \mathrm{~K}$. Isotherm data were taken from ${ }^{11}$.

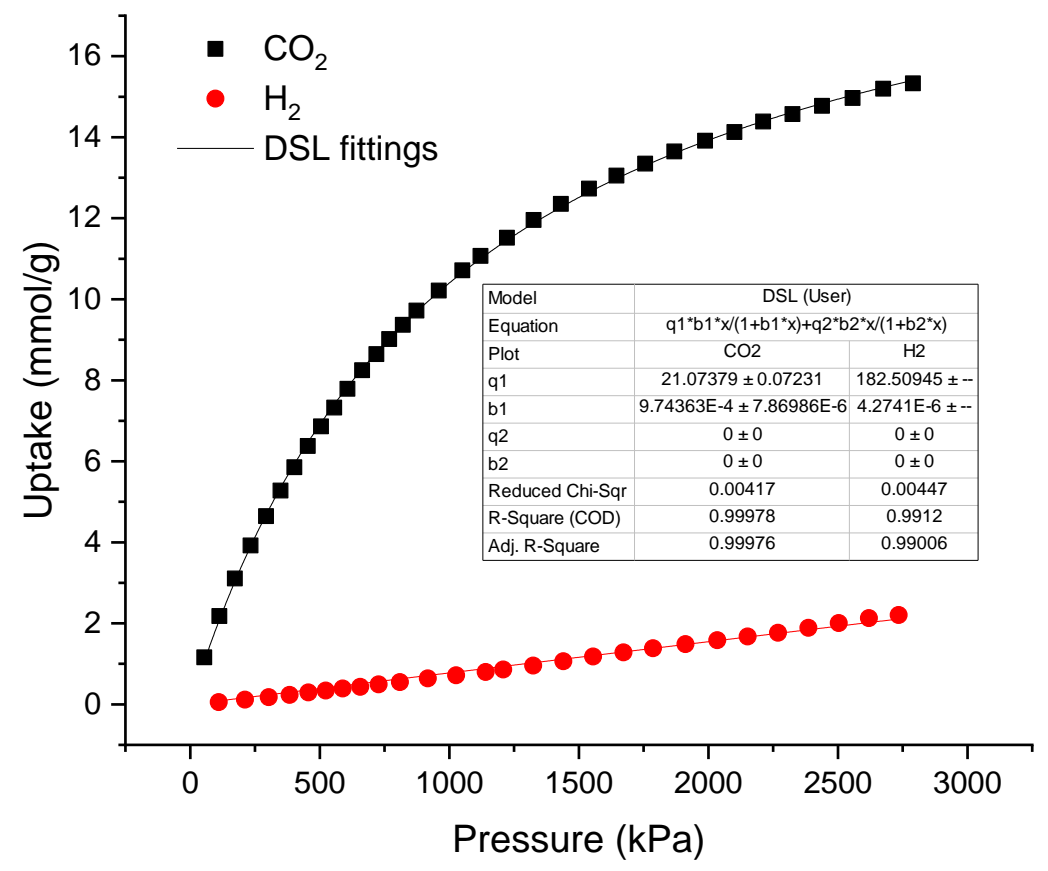

Figure S26. Dual-site Langmuir Freundlich fits for Cu-BTTri at $313 \mathrm{~K}$. Isotherm data were taken from 11 . 


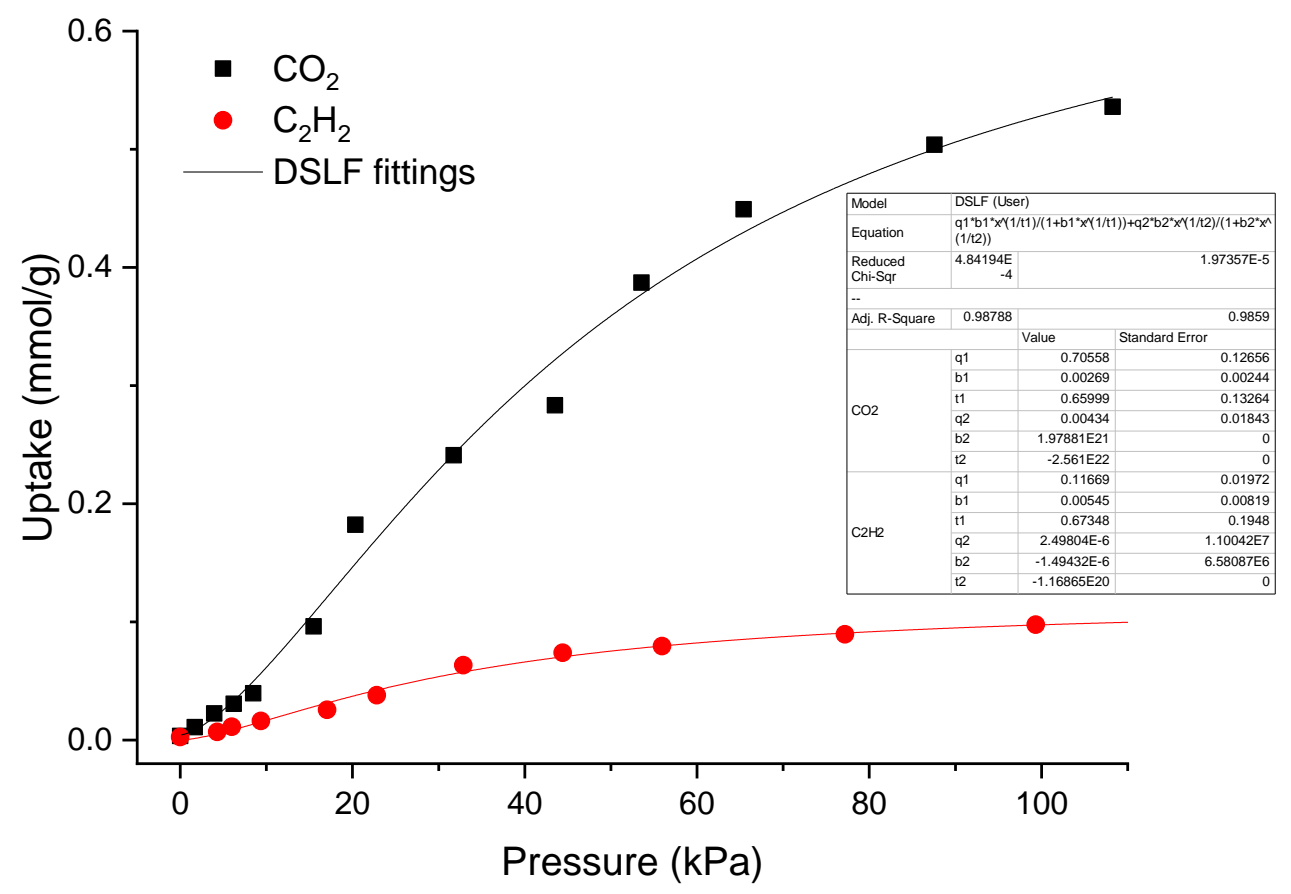

Figure S27. Dual-site Langmuir Freundlich fits for $\mathrm{K}_{2}\left[\mathrm{Cr}_{3} \mathrm{O}(\mathrm{OOCH})_{6}(4 \text {-ethylpyridine })_{3}\right]_{2}\left[\alpha-\mathrm{SiW}_{12} \mathrm{O}_{40}\right]$ at $278 \mathrm{~K}$. Isotherm data were extracted from ${ }^{4}$ using a digitizer software.

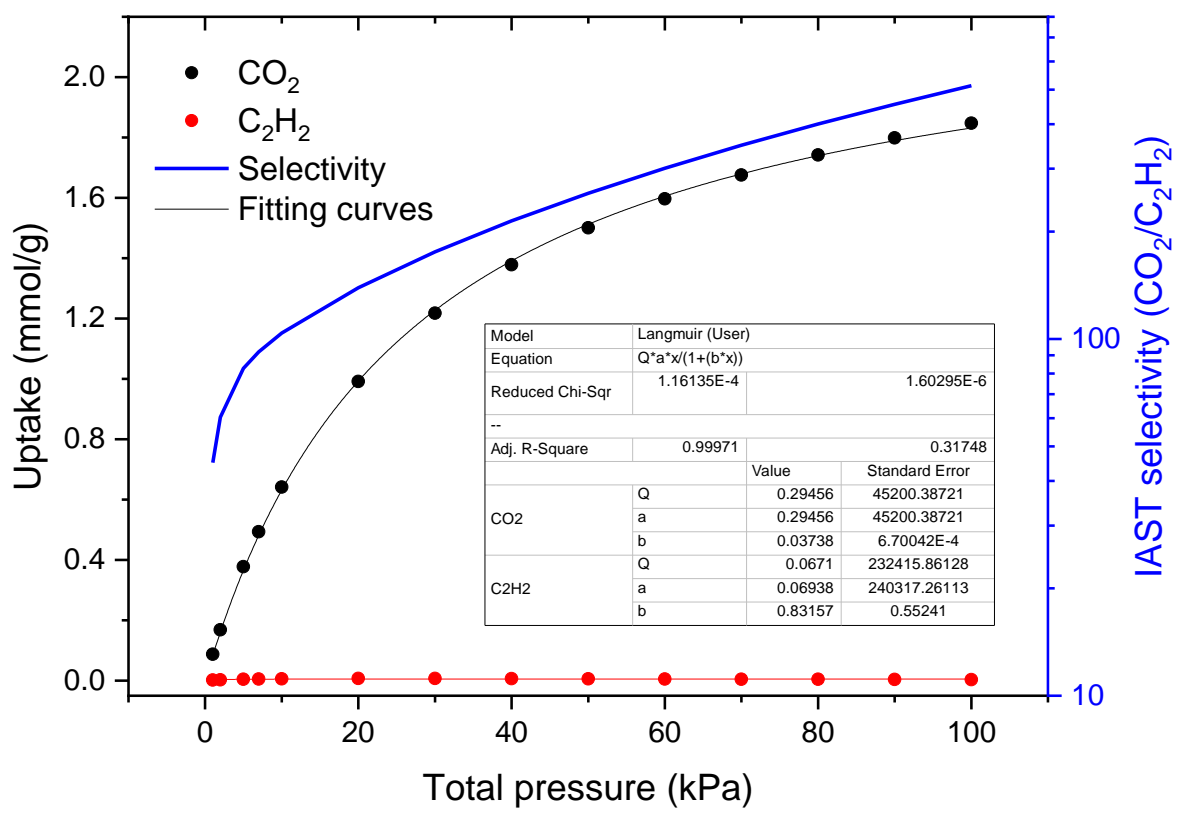

Figure S28. Mixed-gas isotherms and selectivity of MUF-16 predicted by IAST for a mixture of 50/50 $\mathrm{CO}_{2} / \mathrm{C}_{2} \mathrm{H}_{2}$ at $293 \mathrm{~K}$. 


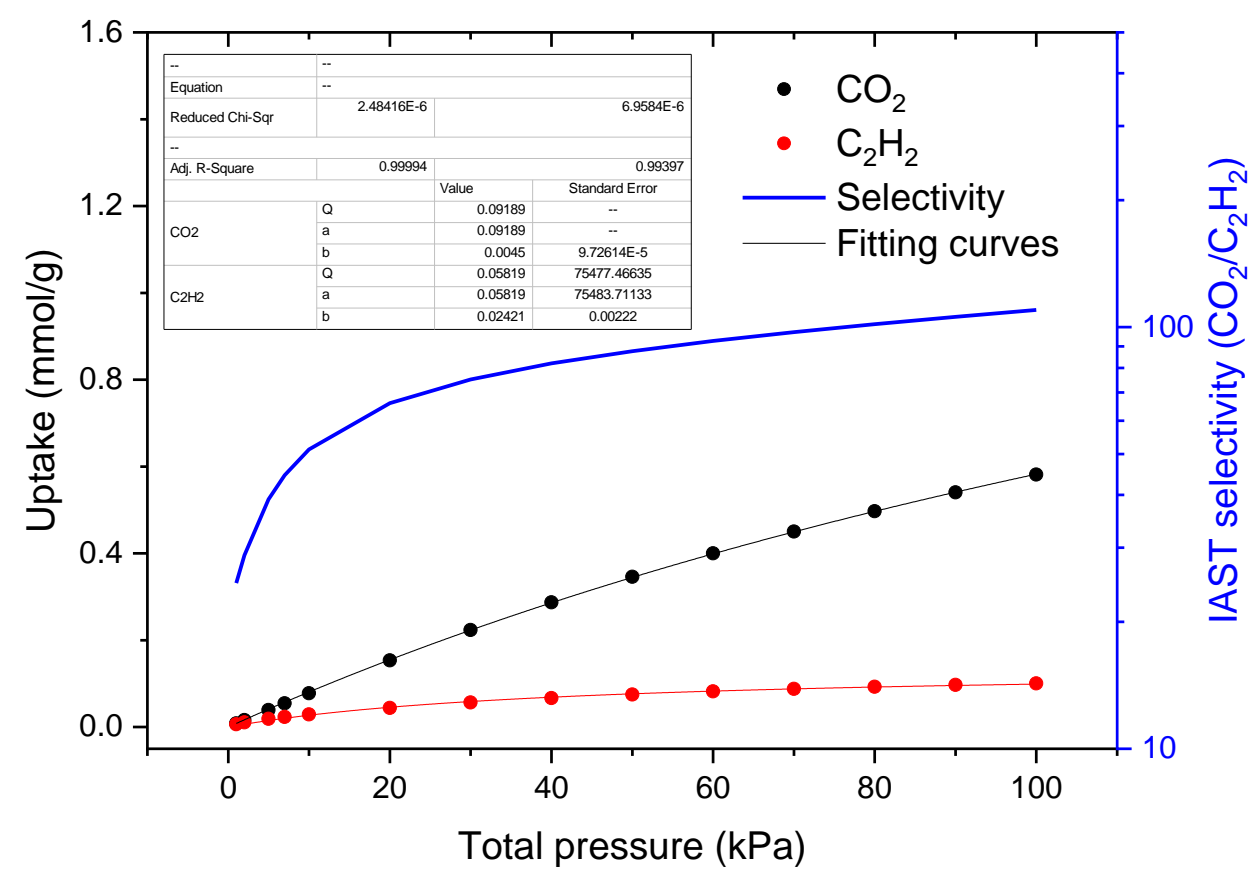

Figure S29. Mixed-gas isotherms and selectivity of MUF-16 predicted by IAST for a mixture of 5/95 $\mathrm{CO}_{2} / \mathrm{C}_{2} \mathrm{H}_{2}$ at $293 \mathrm{~K}$.

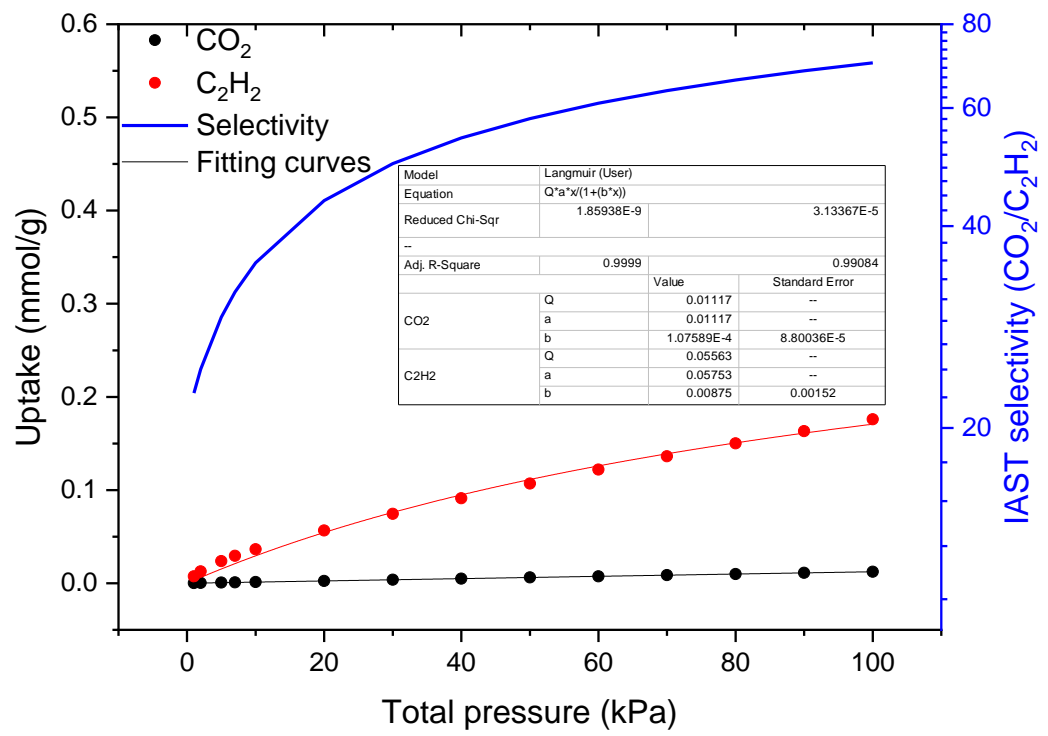

Figure S30. Mixed-gas isotherms and selectivity of MUF-16 predicted by IAST for a mixture of $0.1 / 99.9 \mathrm{CO}_{2} / \mathrm{C}_{2} \mathrm{H}_{2}$ at $293 \mathrm{~K}$. 


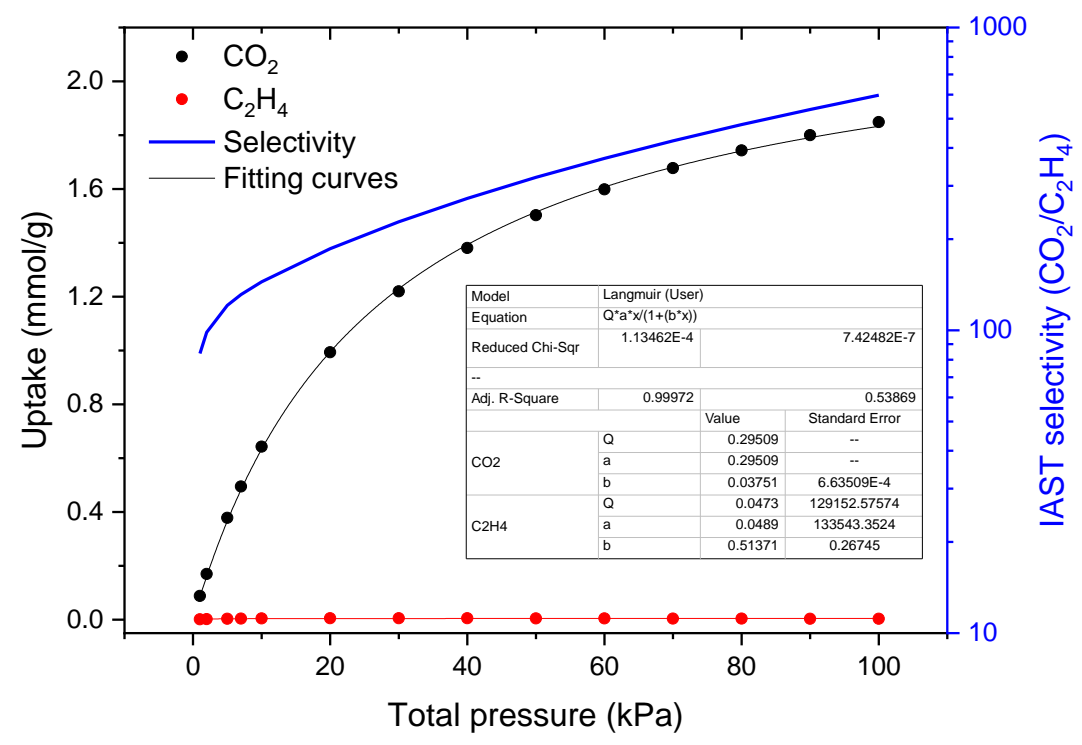

Figure S31. Mixed-gas isotherms and selectivity of MUF-16 predicted by IAST for a mixture of 50/50 $\mathrm{CO}_{2} / \mathrm{C}_{2} \mathrm{H}_{4}$ at $293 \mathrm{~K}$.

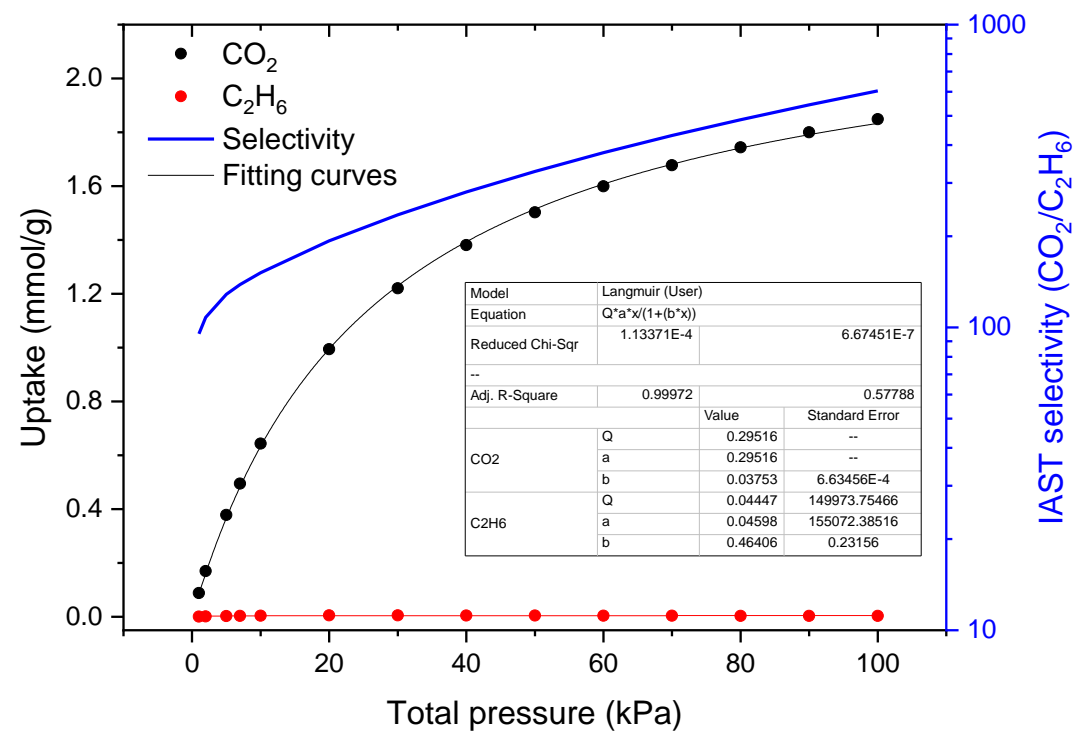

Figure S32. Mixed-gas isotherms and selectivity of MUF-16 predicted by IAST for a mixture of 50/50 $\mathrm{CO}_{2} / \mathrm{C}_{2} \mathrm{H}_{6}$ at $293 \mathrm{~K}$. 


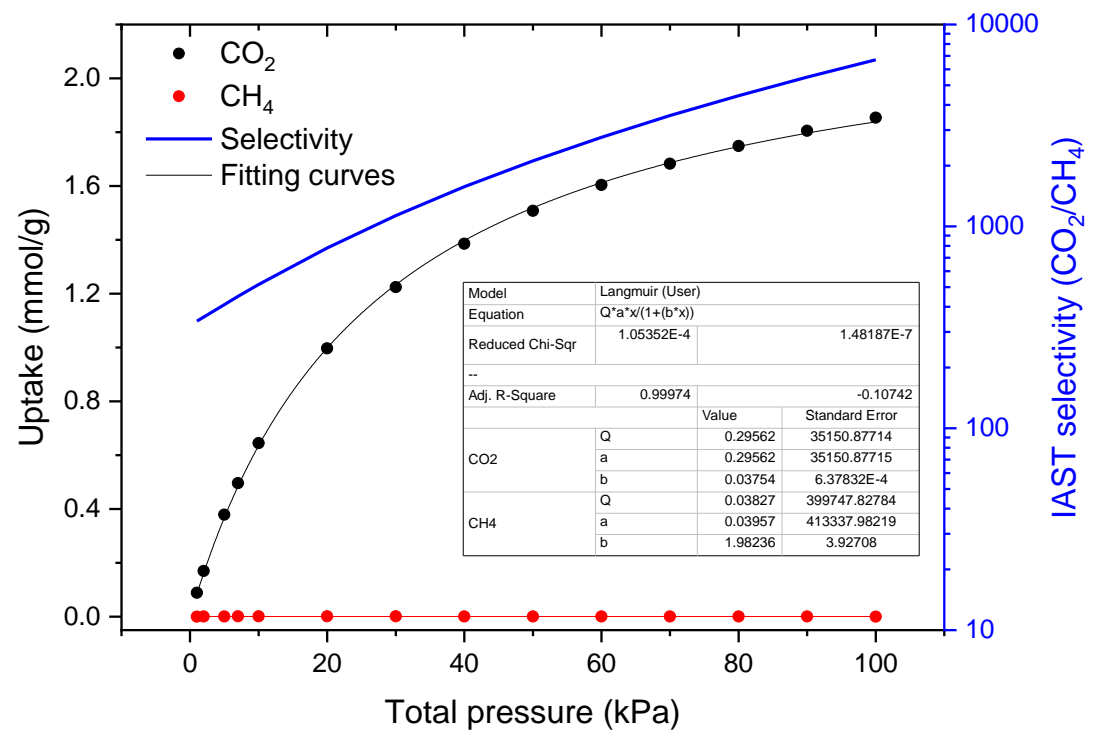

Figure S33. Mixed-gas isotherms and selectivity of MUF-16 predicted by IAST for a mixture of 50/50 $\mathrm{CO}_{2} / \mathrm{CH}_{4}$ at $293 \mathrm{~K}$.

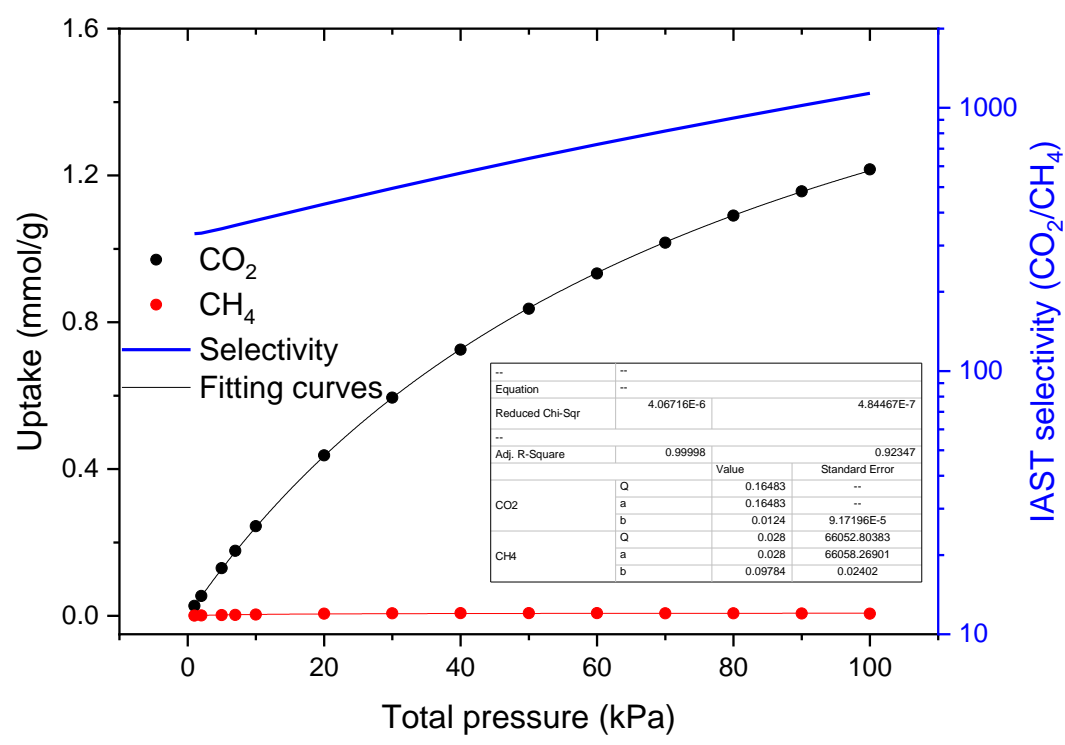

Figure S34. Mixed-gas isotherms and selectivity of MUF-16 predicted by IAST for a mixture of 15/85 $\mathrm{CO}_{2} / \mathrm{CH}_{4}$ at $293 \mathrm{~K}$. 


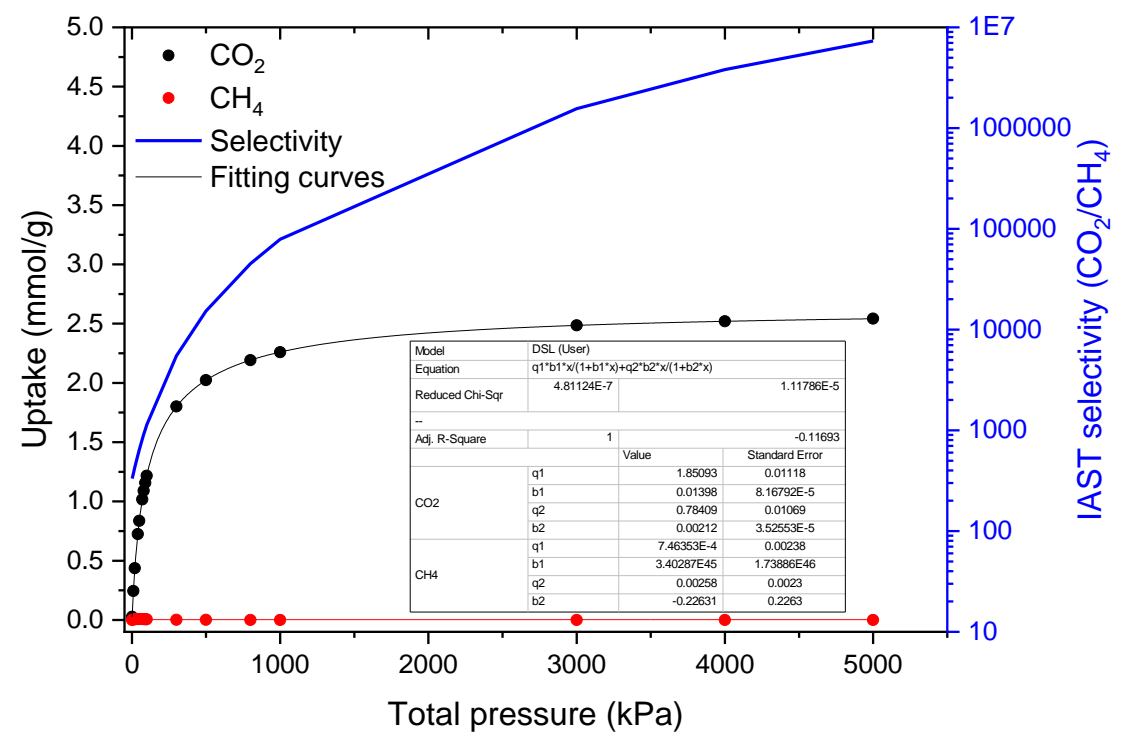

Figure S35. Mixed-gas isotherms and selectivity of MUF-16 predicted by IAST for a mixture of 15/85 $\mathrm{CO}_{2} / \mathrm{CH}_{4}$ at $293 \mathrm{~K}$ up to 50 bar.

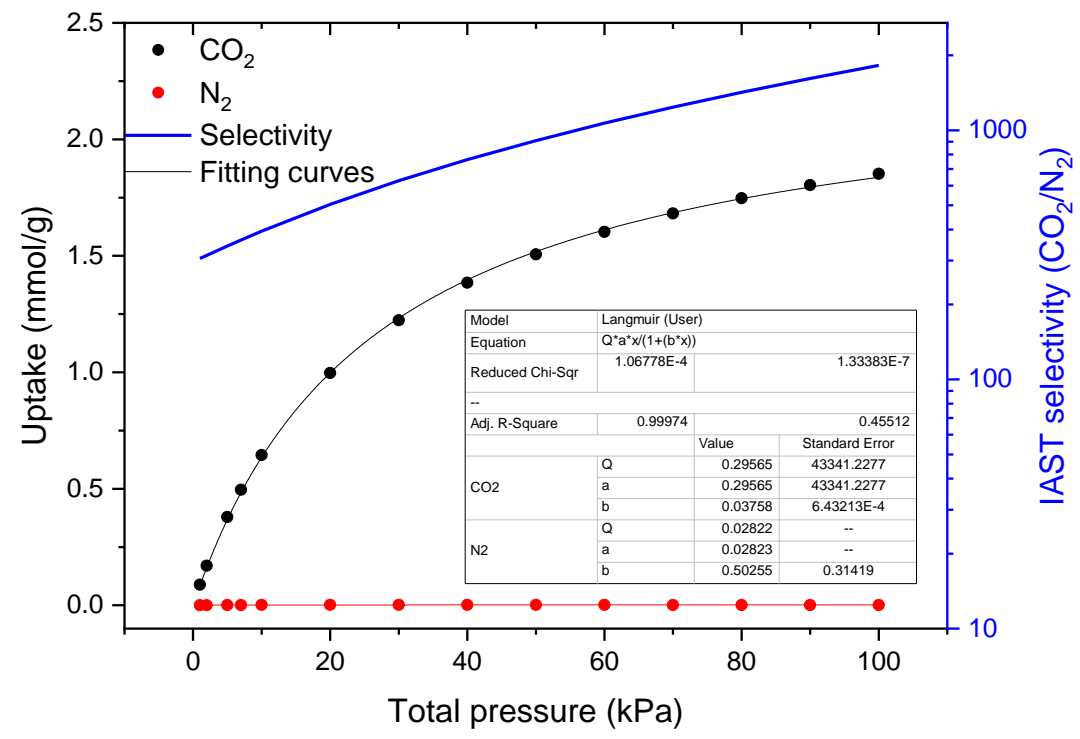

Figure S36. Mixed-gas isotherms and selectivity of MUF-16 predicted by IAST for a mixture of 50/50 $\mathrm{CO}_{2} / \mathrm{N}_{2}$ at $293 \mathrm{~K}$. 


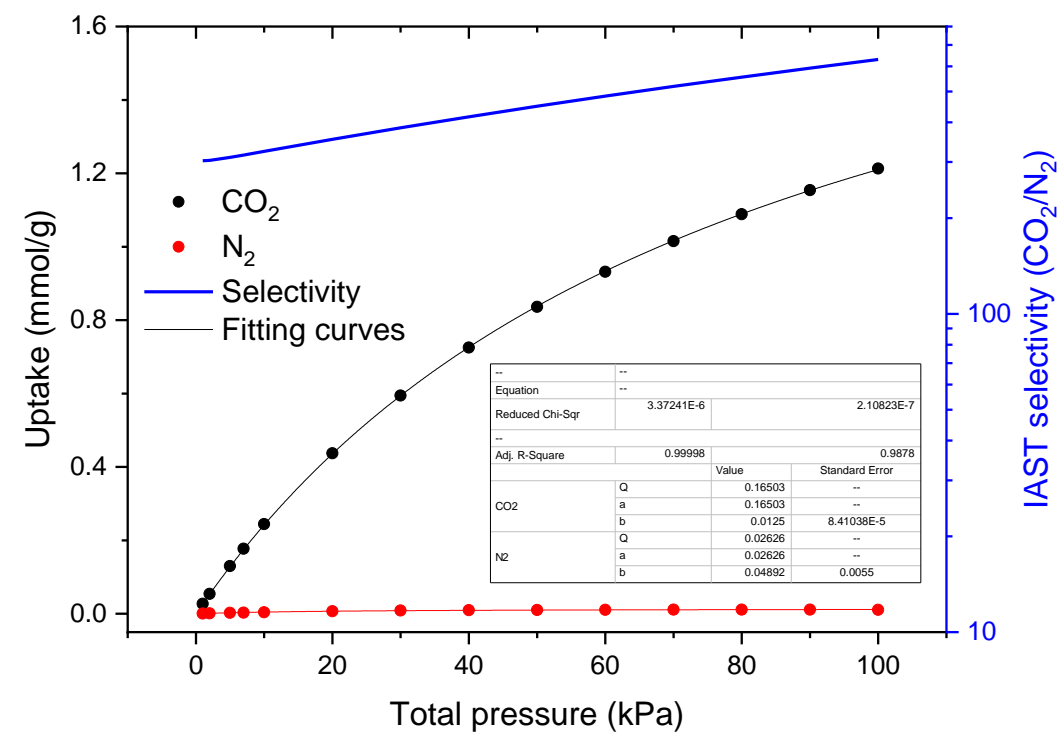

Figure S37. Mixed-gas isotherms and selectivity of MUF-16 predicted by IAST for a mixture of 15/85 $\mathrm{CO}_{2} / \mathrm{N}_{2}$ at $293 \mathrm{~K}$.

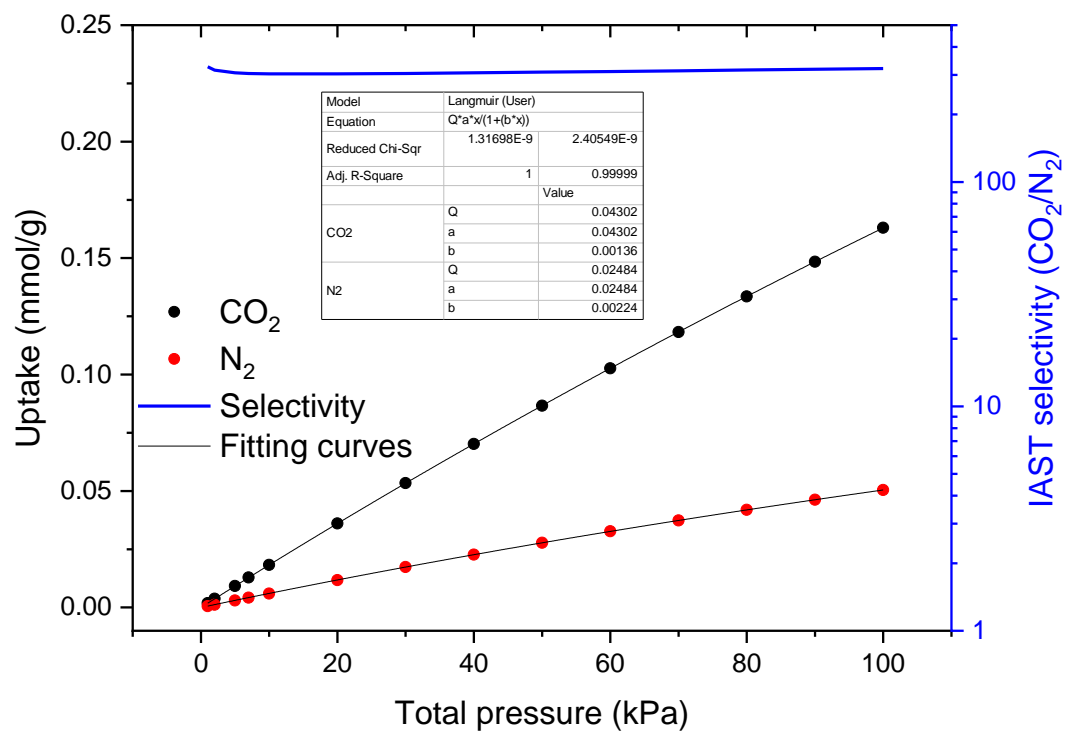

Figure S38. Mixed-gas isotherms and selectivity of MUF-16 predicted by IAST for a mixture of 1/99 $\mathrm{CO}_{2} / \mathrm{N}_{2}$ at $293 \mathrm{~K}$. 


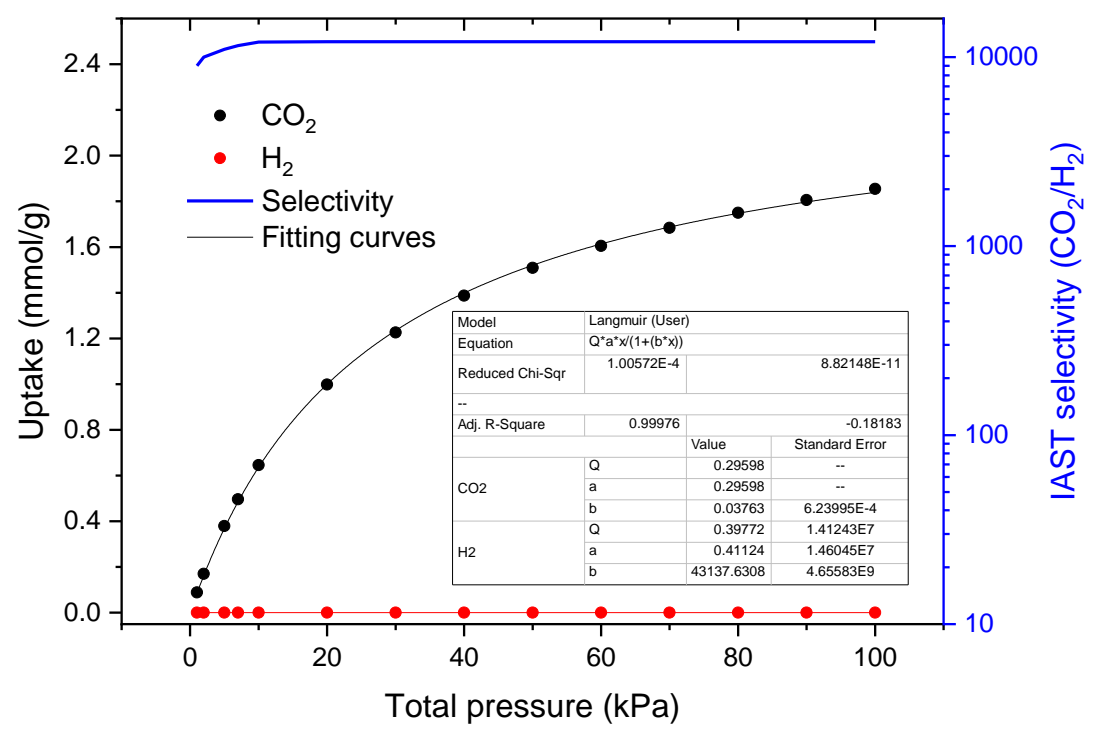

Figure S39. Mixed-gas isotherms and selectivity of MUF-16 predicted by IAST for a mixture of 50/50 $\mathrm{CO}_{2} / \mathrm{H}_{2}$ at $293 \mathrm{~K}$.

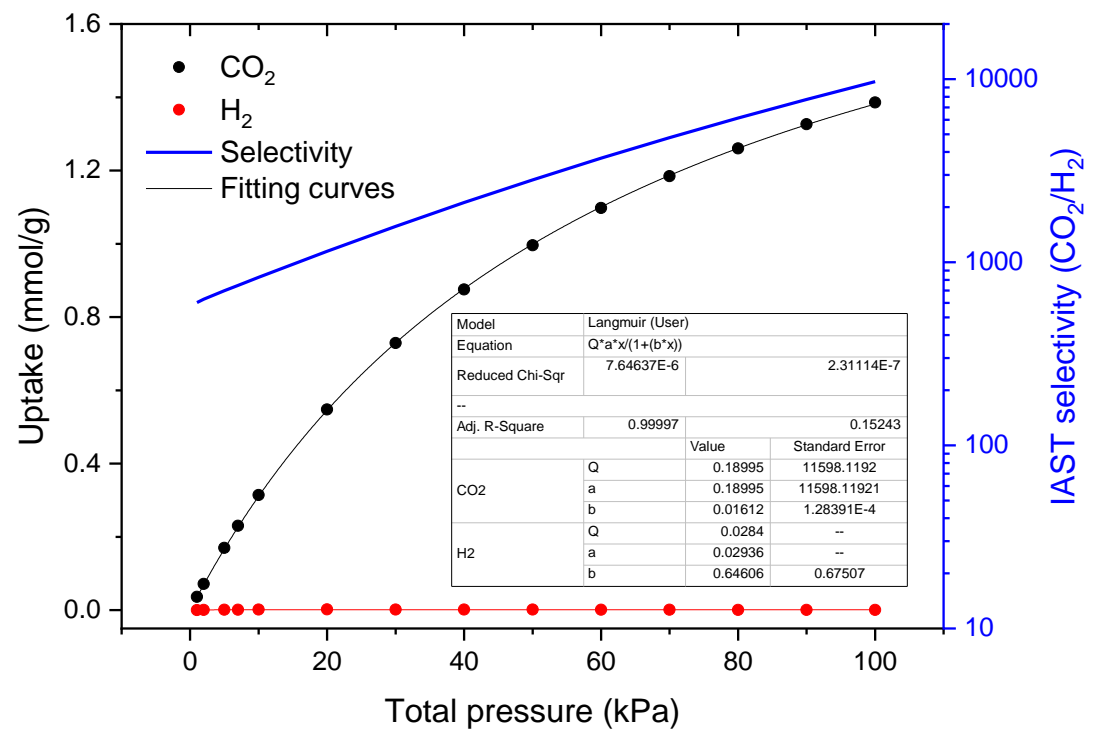

Figure S40. Mixed-gas isotherms and selectivity of MUF-16 predicted by IAST for a mixture of 20/80 $\mathrm{CO}_{2} / \mathrm{H}_{2}$ at $293 \mathrm{~K}$. 


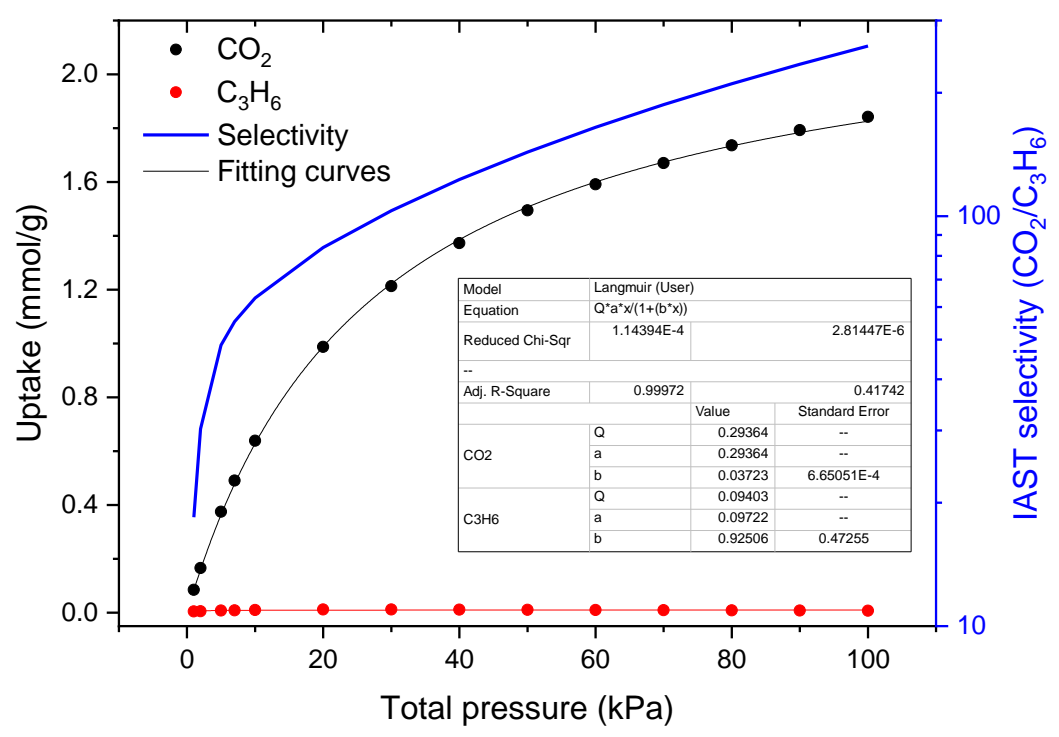

Figure S41. Mixed-gas isotherms and selectivity of MUF-16 predicted by IAST for a mixture of 50/50 $\mathrm{CO}_{2} / \mathrm{C}_{3} \mathrm{H}_{6}$ at $293 \mathrm{~K}$.

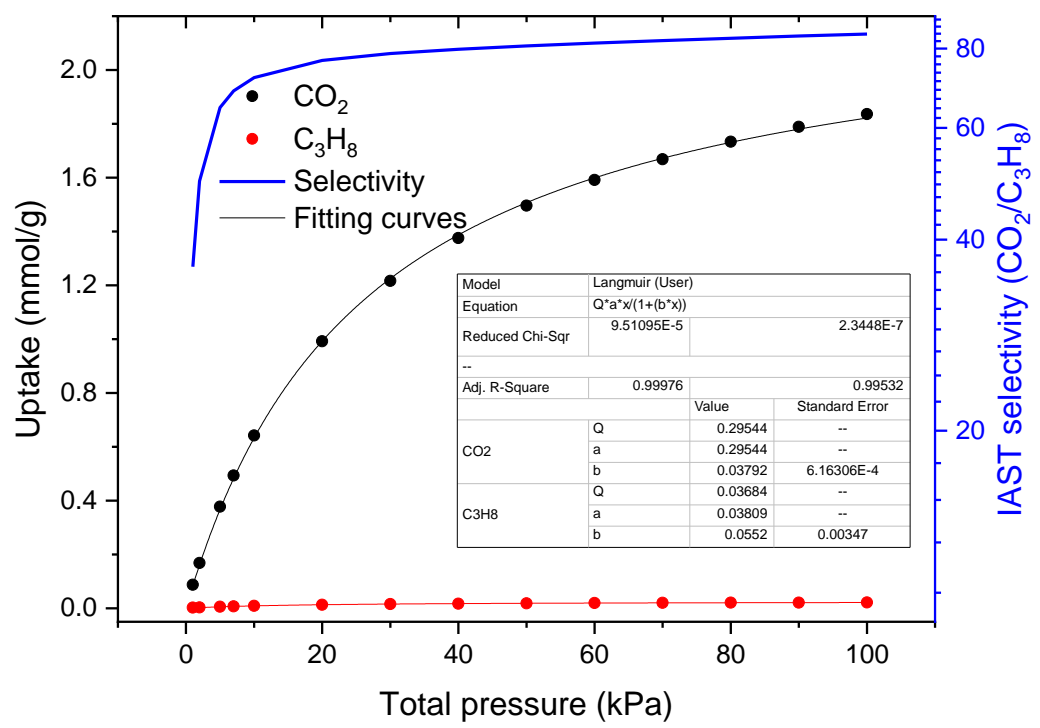

Figure S42. Mixed-gas isotherms and selectivity of MUF-16 predicted by IAST for a mixture of 50/50 $\mathrm{CO}_{2} / \mathrm{C}_{3} \mathrm{H}_{8}$ at $293 \mathrm{~K}$. 


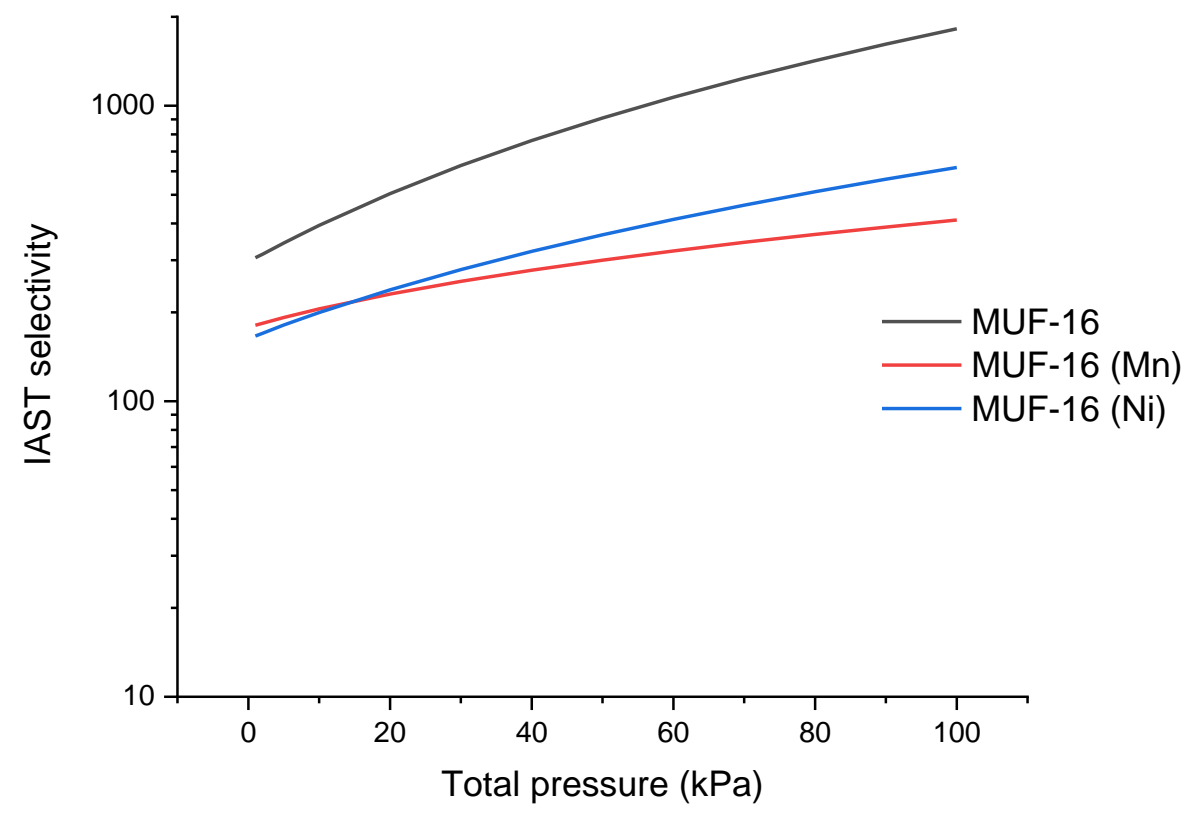

Figure S43. IAST selectivity for a 50/50 mixture of $\mathrm{CO}_{2} / \mathrm{N}_{2}$ at $293 \mathrm{~K}$ for the MUF-16 family.

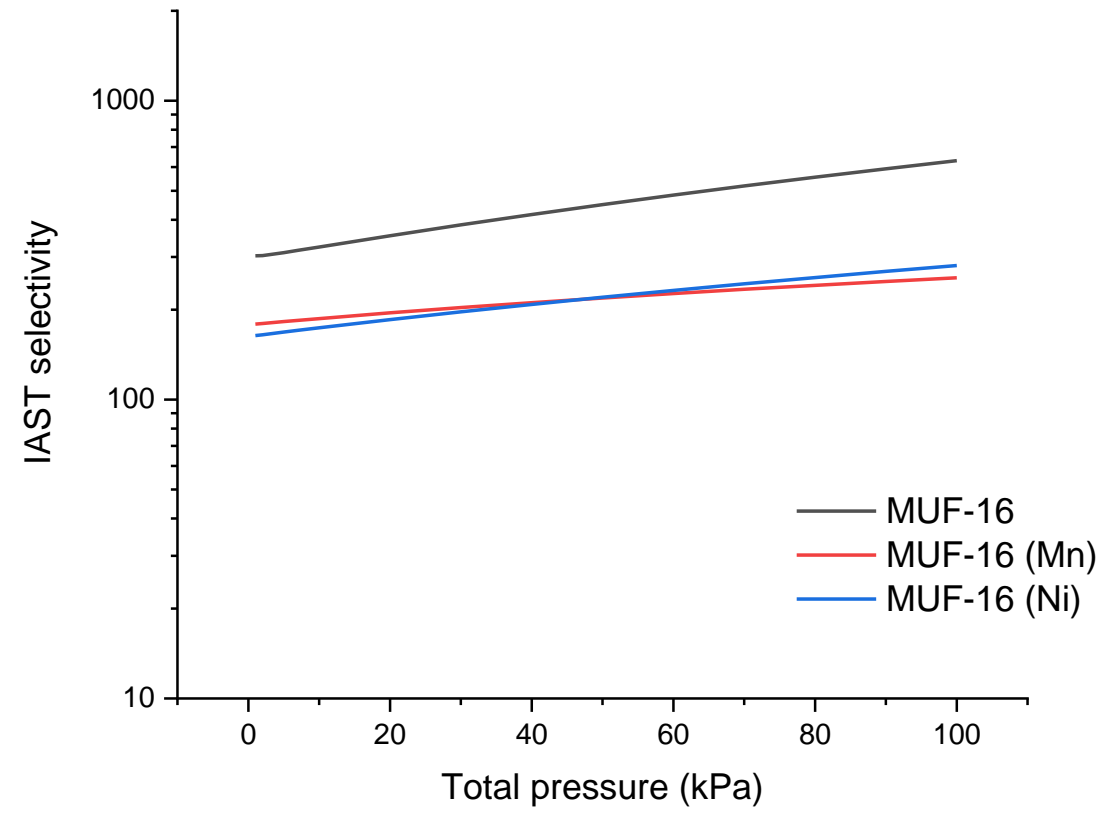

Figure S44. IAST selectivity for a $15 / 85$ mixture of $\mathrm{CO}_{2} / \mathrm{N}_{2}$ at $293 \mathrm{~K}$ for the MUF-16 family. 


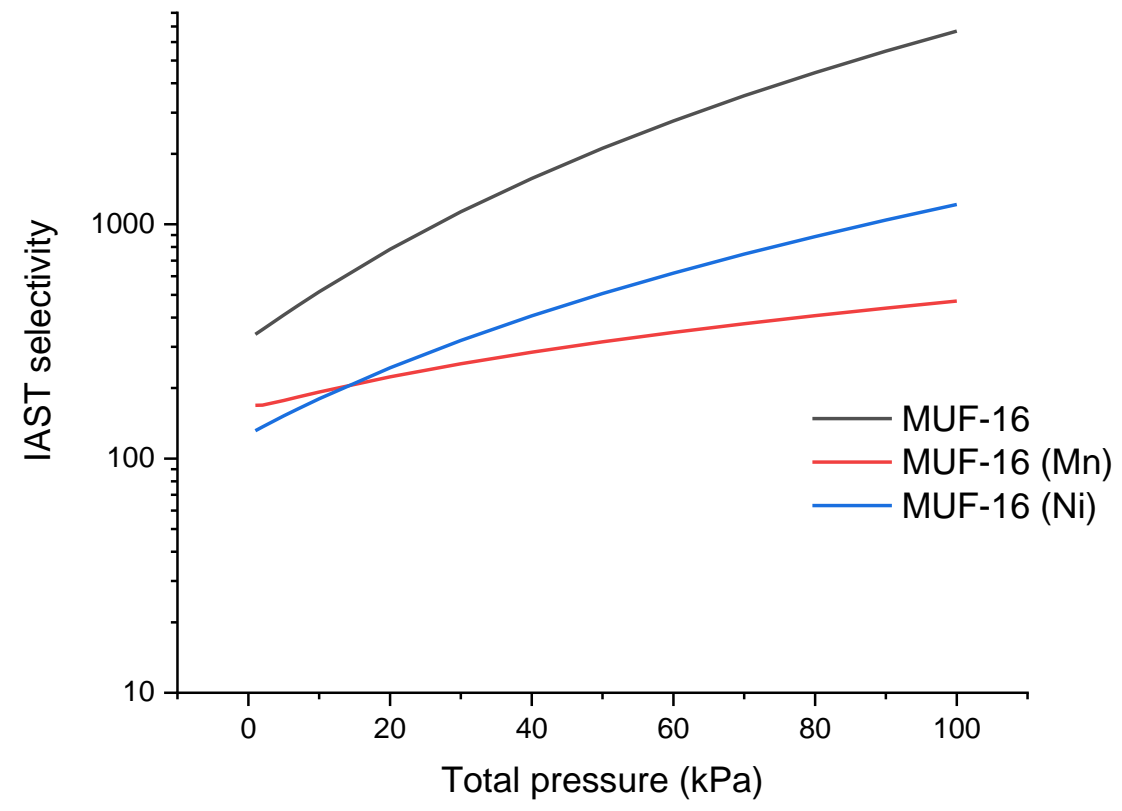

Figure S45. IAST selectivity for a 50/50 mixture of $\mathrm{CO}_{2} / \mathrm{CH}_{4}$ at $293 \mathrm{~K}$ for the MUF-16 family.

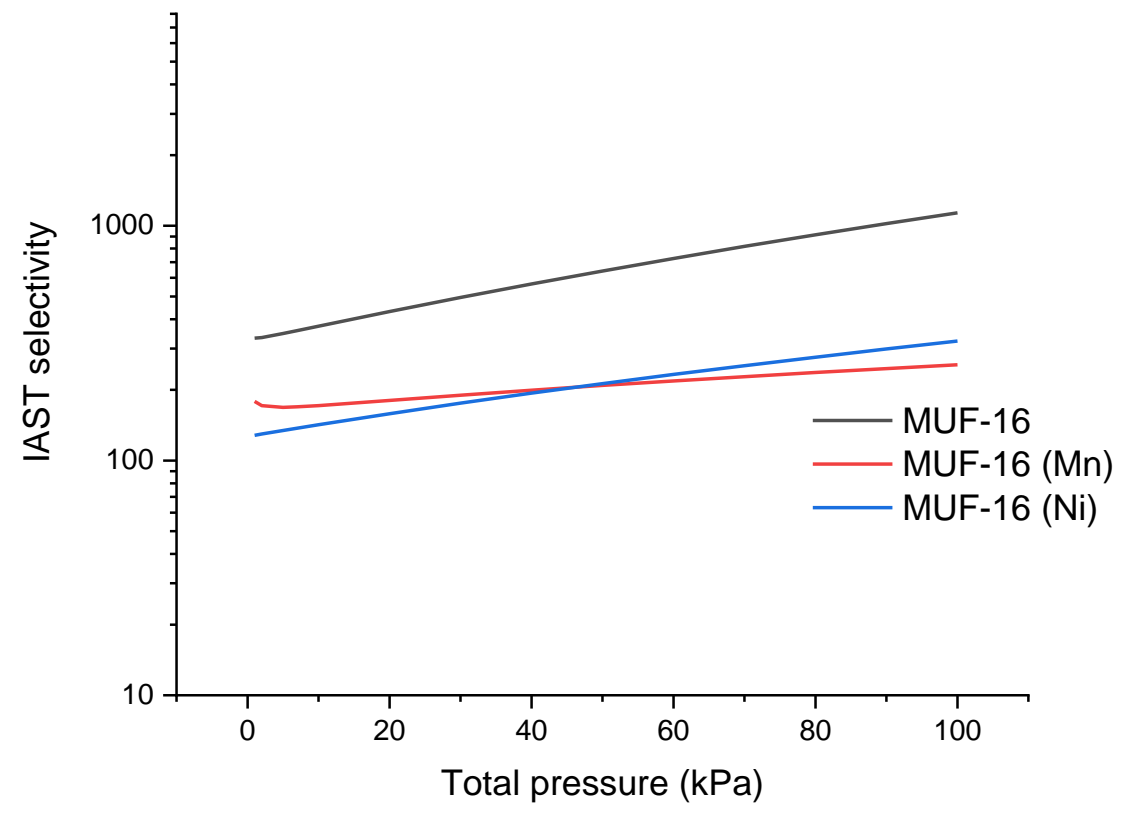

Figure S46. IAST selectivity for a $15 / 85$ mixture of $\mathrm{CO}_{2} / \mathrm{N}_{2}$ at $293 \mathrm{~K}$ for the MUF-16 family. 


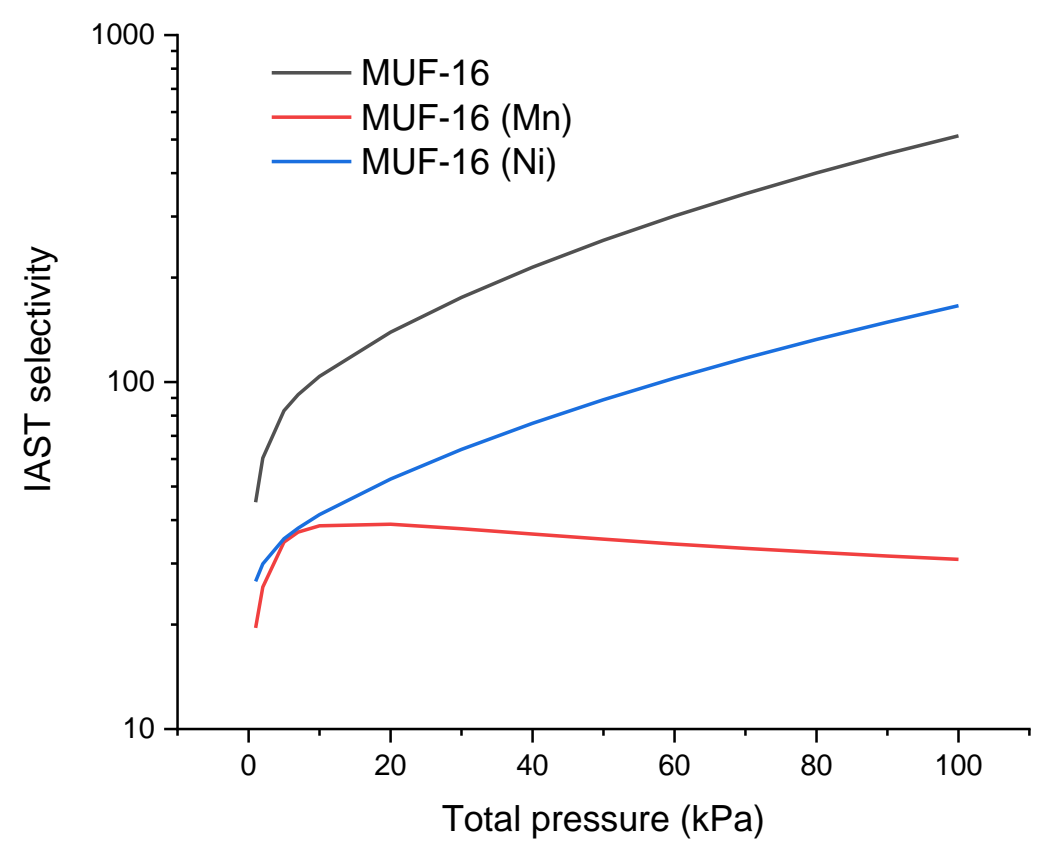

Figure S47. IAST selectivity for a 50/50 mixture of $\mathrm{CO}_{2} / \mathrm{C}_{2} \mathrm{H}_{2}$ at $293 \mathrm{~K}$ for the MUF-16 family.

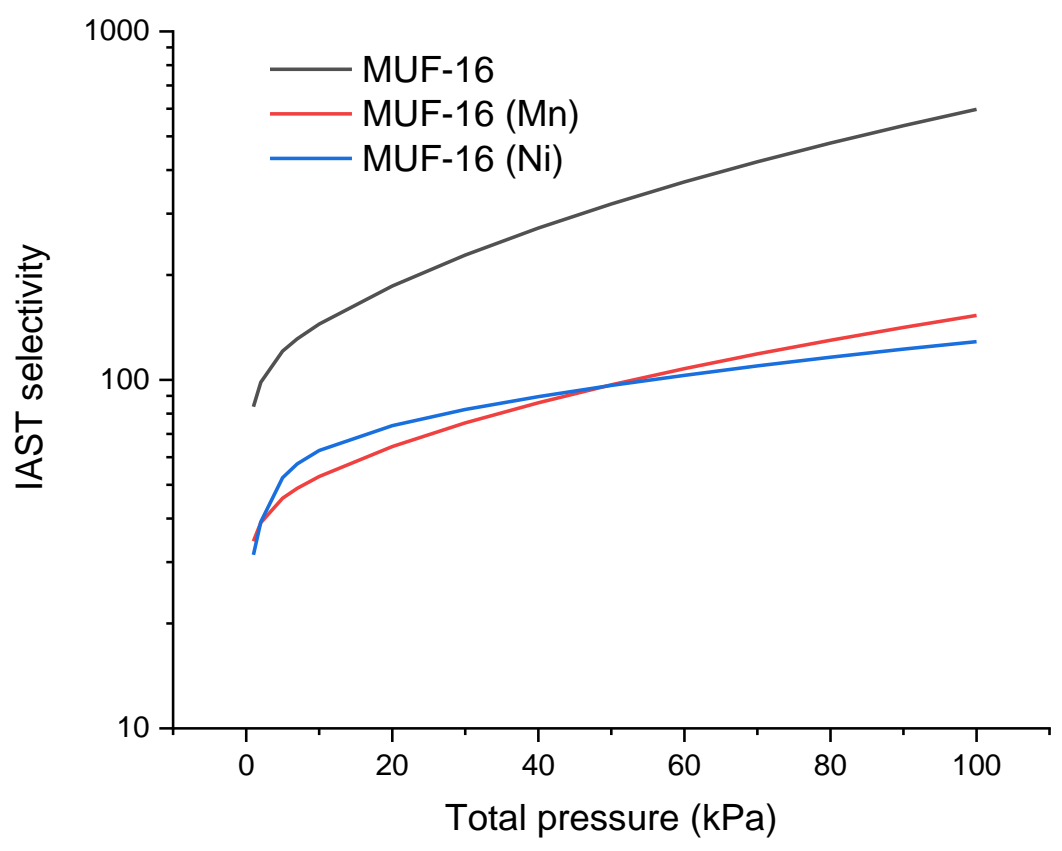

Figure S48. IAST selectivity for a 50/50 mixture of $\mathrm{CO}_{2} / \mathrm{C}_{2} \mathrm{H}_{4}$ at $293 \mathrm{~K}$ for the MUF-16 family. 


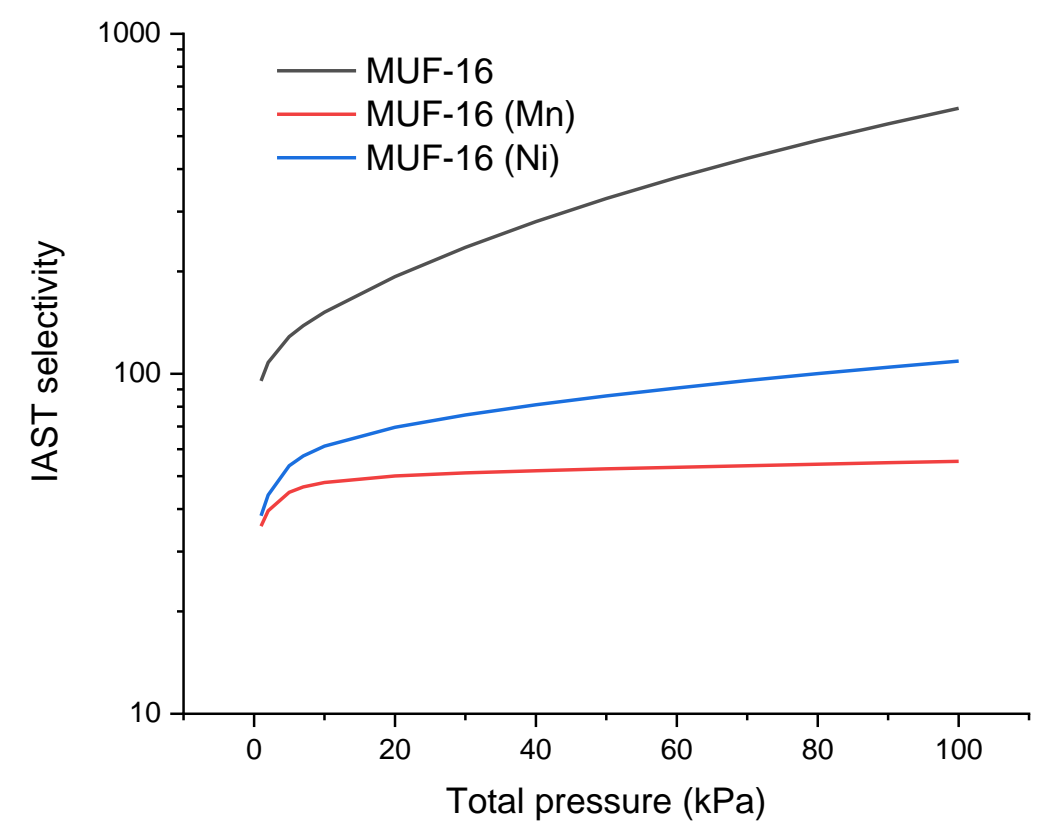

Figure S49. IAST selectivity for a 50/50 mixture of $\mathrm{CO}_{2} / \mathrm{C}_{2} \mathrm{H}_{6}$ at $293 \mathrm{~K}$ for the MUF-16 family.

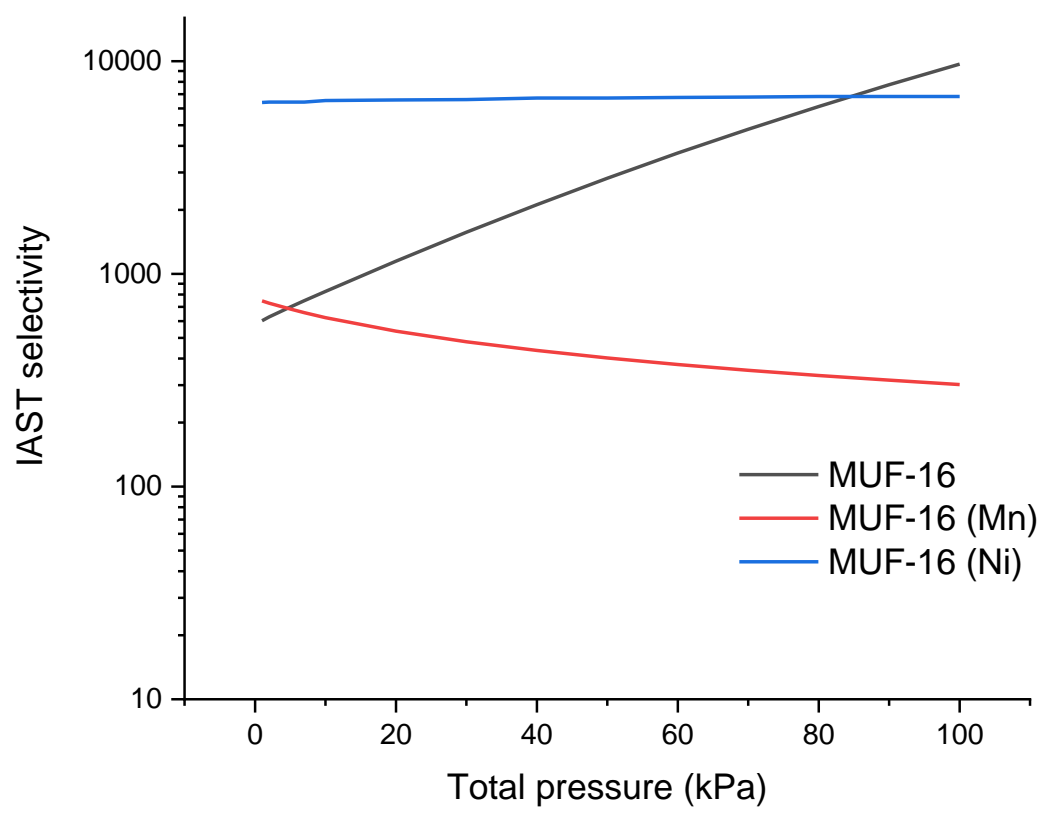

Figure S50. IAST selectivity for a 50/50 mixture of $\mathrm{CO}_{2} / \mathrm{H}_{2}$ at $293 \mathrm{~K}$ for the MUF-16 family. 


\section{Breakthrough separation experiments and simulations}

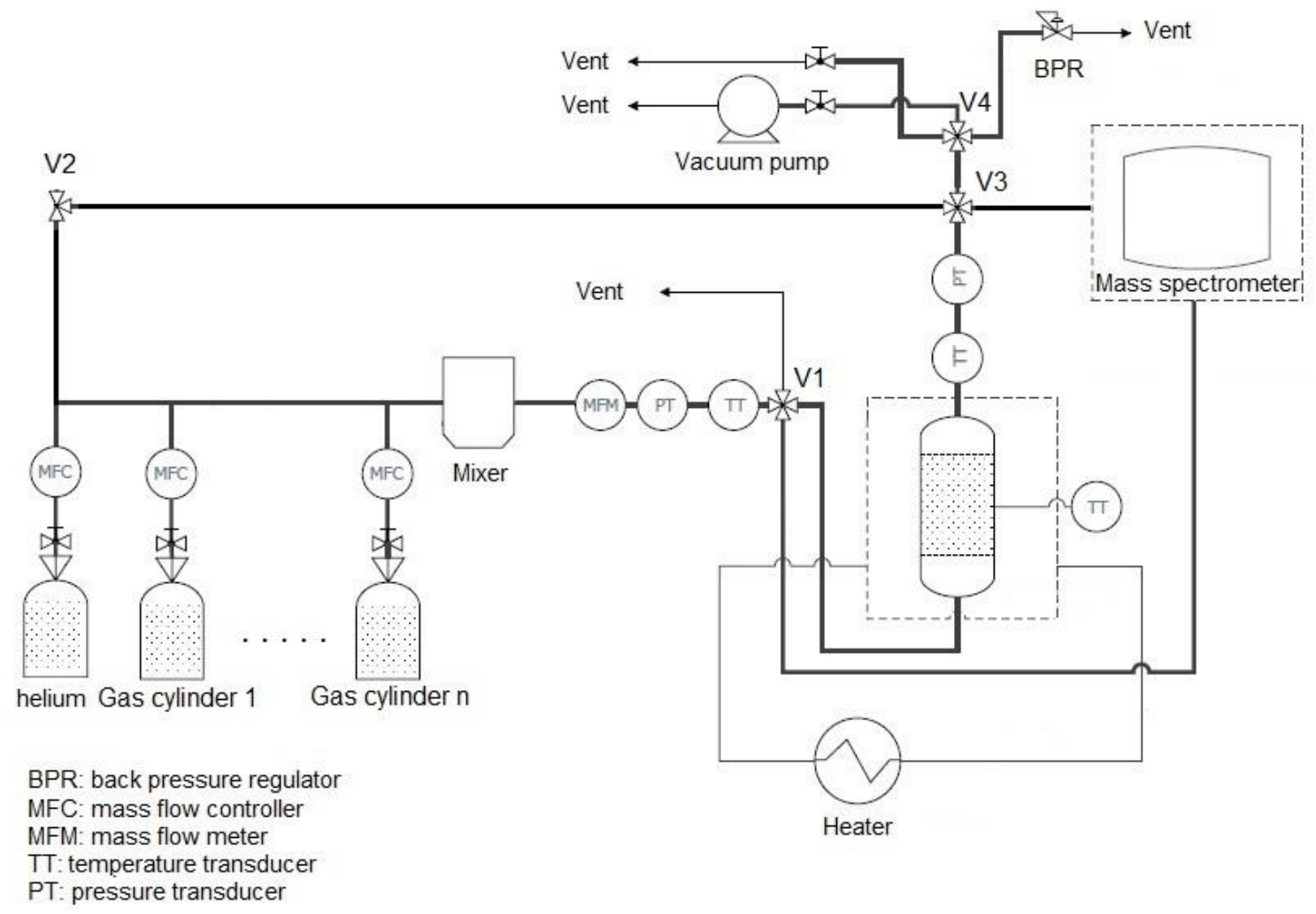

Figure S51. A schematic of the experimental column breakthrough setup. 
Table S7. Summary of inlet gas feed streams, outlet compositions and associated data for experimental breakthrough tests using a MUF-16 adsorbent bed.

\begin{tabular}{|c|c|c|c|c|c|c|c|c|}
\hline Gas mixture & $\begin{array}{l}\text { Total } \\
\text { pressure } \\
\text { (bar) }\end{array}$ & $\begin{array}{l}\text { Inlet } \mathrm{CO}_{2} \\
\text { partial } \\
\text { pressure } \\
\text { (bar) }\end{array}$ & $\begin{array}{c}\text { Flowrate } \\
\left(\mathrm{mL}_{\mathrm{N}} / \mathrm{min}\right)\end{array}$ & $\begin{array}{c}\text { Upper limit for } \mathrm{CO}_{2} \\
\text { concentration in } \\
\text { effluent }(\mathrm{ppmv})\end{array}$ & $\begin{array}{c}\text { Breakthrough } \\
\text { point of } \mathrm{CO}_{2} \\
(\mathrm{~min})\end{array}$ & $\begin{array}{l}\mathrm{CO}_{2} \text { concentration in } \\
\text { effluent at } \\
\text { breakthrough point } \\
(\mathrm{ppmv})\end{array}$ & $\begin{array}{c}\text { Dynamic } \\
\text { adsorption } \\
\text { capacity } \\
\text { (mmol/g) }\end{array}$ & $\begin{array}{c}\text { Equilibrium } \\
\text { adsorption } \\
\text { capacity } \\
\text { (mmol/g) }\end{array}$ \\
\hline $\mathrm{CO}_{2} / \mathrm{N}_{2}(50 / 50)$ & 1 & 0.5 & 6 & 500 & 10.6 & 600 & 1.57 & 1.85 \\
\hline $\mathrm{CO}_{2} / \mathrm{N}_{2}(15 / 85)$ & 1 & 0.15 & 6 & 520 & 24.1 & 600 & 1.08 & 1.23 \\
\hline $\mathrm{CO}_{2} / \mathrm{N}_{2}(1 / 99)$ & 1 & 0.01 & 6 & 530 & 40.7 & 600 & 0.12 & 0.17 \\
\hline $\mathrm{CO}_{2} / \mathrm{N}_{2}(0.4 / 99.6)$ & 1 & 0.004 & 10 & 500 & 28.5 & 600 & 0.06 & 0.09 \\
\hline $\mathrm{CO}_{2} / \mathrm{CH}_{4}(50 / 50)$ & 1 & 0.5 & 6 & 500 & 10.6 & 600 & 1.53 & 1.85 \\
\hline $\mathrm{CO}_{2} / \mathrm{CH}_{4}(15 / 85)$ & 1 & 0.15 & 6 & 520 & 25.6 & 600 & 1.13 & 1.23 \\
\hline $\mathrm{CO}_{2} / \mathrm{CH}_{4}(15 / 85)$ & 9 & 0.15 & 6 & 360 & 44.8 & 600 & 2.01 & - \\
\hline $\begin{array}{l}\mathrm{CO}_{2} / \mathrm{CH}_{4}+\mathrm{C}_{2} \mathrm{H}_{6}+\mathrm{C}_{3} \mathrm{H}_{8} \\
(15 / 80 / 4 / 1)\end{array}$ & 1 & 0.15 & 6 & 520 & 24.6 & 600 & 1.09 & 1.23 \\
\hline $\begin{array}{l}\mathrm{CO}_{2} / \mathrm{CH}_{4}+\mathrm{C}_{2} \mathrm{H}_{6}+\mathrm{C}_{3} \mathrm{H}_{8} \\
(15 / 80 / 4 / 1)\end{array}$ & 9 & 0.15 & 6 & 390 & 42.5 & 600 & 1.93 & - \\
\hline $\mathrm{CO}_{2} / \mathrm{C}_{2} \mathrm{H}_{2}(50 / 50)^{*}$ & 1 & 0.33 & 6 & 500 & 12.3 & 600 & 1.23 & 1.64 \\
\hline $\mathrm{CO}_{2} / \mathrm{C}_{2} \mathrm{H}_{2}(5 / 95)$ & 1 & 0.035 & 6.85 & 540 & 15.1 & 600 & 0.18 & 0.46 \\
\hline $\mathrm{CO}_{2} / \mathrm{C}_{2} \mathrm{H}_{4}(50 / 50)^{*}$ & 1 & 0.33 & 6 & 500 & 11.9 & 600 & 1.19 & 1.64 \\
\hline $\mathrm{CO}_{2} / \mathrm{C}_{2} \mathrm{H}_{6}(50 / 50)^{*}$ & 1 & 0.33 & 6 & 500 & 12.2 & 600 & 1.22 & 1.64 \\
\hline $\mathrm{CO}_{2} / \mathrm{H}_{2}(50 / 50)$ & 1 & 0.5 & 6 & 500 & 10.8 & 600 & 1.62 & 1.85 \\
\hline $\mathrm{CO}_{2} / \mathrm{H}_{2}(15 / 85)$ & 1 & 0.5 & 6 & 510 & 24.4 & 600 & 1.11 & 1.85 \\
\hline
\end{tabular}




\section{1 $\mathrm{CO}_{2} / \mathrm{N}_{2}, \mathrm{CO}_{2} / \mathrm{CH}_{4}, \mathrm{CO}_{2} / \mathrm{H}_{2}$ and $\mathrm{CO}_{2} / \mathrm{CH}_{4}+\mathrm{C}_{2} \mathrm{H}_{6}+\mathrm{C}_{3} \mathrm{H}_{8}$ breakthrough separations}

In a typical breakthrough experiment, activated MUF-16 (0.9 g) was placed in an adsorption column (6.4 $\mathrm{mm}$ in diameter $\times 11 \mathrm{~cm}$ in length) to form a fixed bed. The adsorbent was activated at $130{ }^{\circ} \mathrm{C}$ under high vacuum for 7 hours and then the column was left under vacuum for another 3 hours while being cooled to $20{ }^{\circ} \mathrm{C}$. The column was then purged under a $20 \mathrm{~mL} / \mathrm{min}$ flow of He gas for $1 \mathrm{hr}$ at 1.1 bar prior to the breakthrough experiment. A gas mixture containing different mixture of $\mathrm{CO}_{2} / \mathrm{N}_{2}, \mathrm{CO}_{2} / \mathrm{CH}_{4}$, $\mathrm{CO}_{2} / \mathrm{H}_{2}$ and $\mathrm{CO}_{2} / \mathrm{CH}_{4}+\mathrm{C}_{2} \mathrm{H}_{6}+\mathrm{C}_{3} \mathrm{H}_{8}$ was introduced to the column at 1.1 bar (and 9 bar for $\mathrm{CO}_{2} / \mathrm{CH}_{4}$ and $\left.\mathrm{CO}_{2} / \mathrm{CH}_{4}+\mathrm{C}_{2} \mathrm{H}_{6}+\mathrm{C}_{3} \mathrm{H}_{8}\right)$ and $20{ }^{\circ} \mathrm{C}$. A feed flowrate of $6 \mathrm{mLN} / \mathrm{min}\left(10 \mathrm{~mL} / \mathrm{min}\right.$ for $0.4 / 99.6 \mathrm{CO}_{2} / \mathrm{N}_{2}$ mixture) was set. The operating pressure was controlled at 1.1 or 9 bar with a back-pressure regulator. The outlet composition was continuously monitored by a SRS UGA200 mass spectrometer. The $\mathrm{CO}_{2}$ was deemed to have broken through from the column when its concentration reached $600 \mathrm{ppmv}$.

\section{Regeneration experiment}

The adsorbates (primarily $\mathrm{CO}_{2}$ ) were stripped from the column to regenerate the adsorbent by purging with dry air at ambient temperature $\left(20^{\circ} \mathrm{C}\right)$ and a flow rate of $20 \mathrm{mLN} / \mathrm{min}$ at 1.1 bar. The effluent from the adsorption bed was monitored by mass spectrometry to show that all of the $\mathrm{CO}_{2}$ was removed at $20{ }^{\circ} \mathrm{C}$ over a period of around 25 minutes, with no further loss of $\mathrm{CO}_{2}$ observed at $40,60,80$ or $130{ }^{\circ} \mathrm{C}$. For the recycling experiments, the adsorption bed was subsequently used to separate $\mathrm{CO}_{2} / \mathrm{N}_{2} 15 / 85$ (6 $\mathrm{mL} / \mathrm{min}$ ) before being regenerated again with a flow of air. This process was repeated 200 times.

Alternatively, the adsorption bed could be regenerated under a dynamic vacuum (turbomolecular pump) for around 15-20 mins at room temperature, but this procedure was not typically employed. 


\subsubsection{Separation of $\mathrm{CO}_{2} / \mathrm{N}_{2}$}

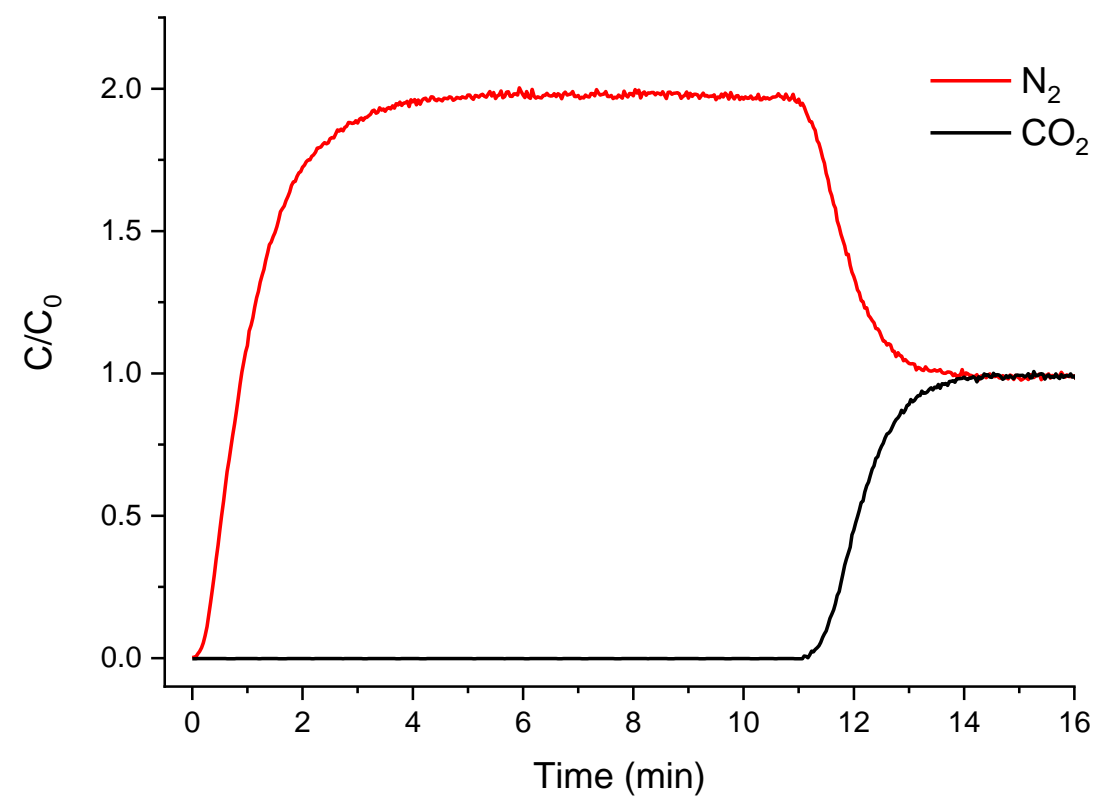

Figure S52. Experimental breakthrough curves for a mixture of $50 / 50 \mathrm{CO}_{2} / \mathrm{N}_{2}$ at 1.1 bar and $293 \mathrm{~K}$ in an adsorption column packed with MUF-16.

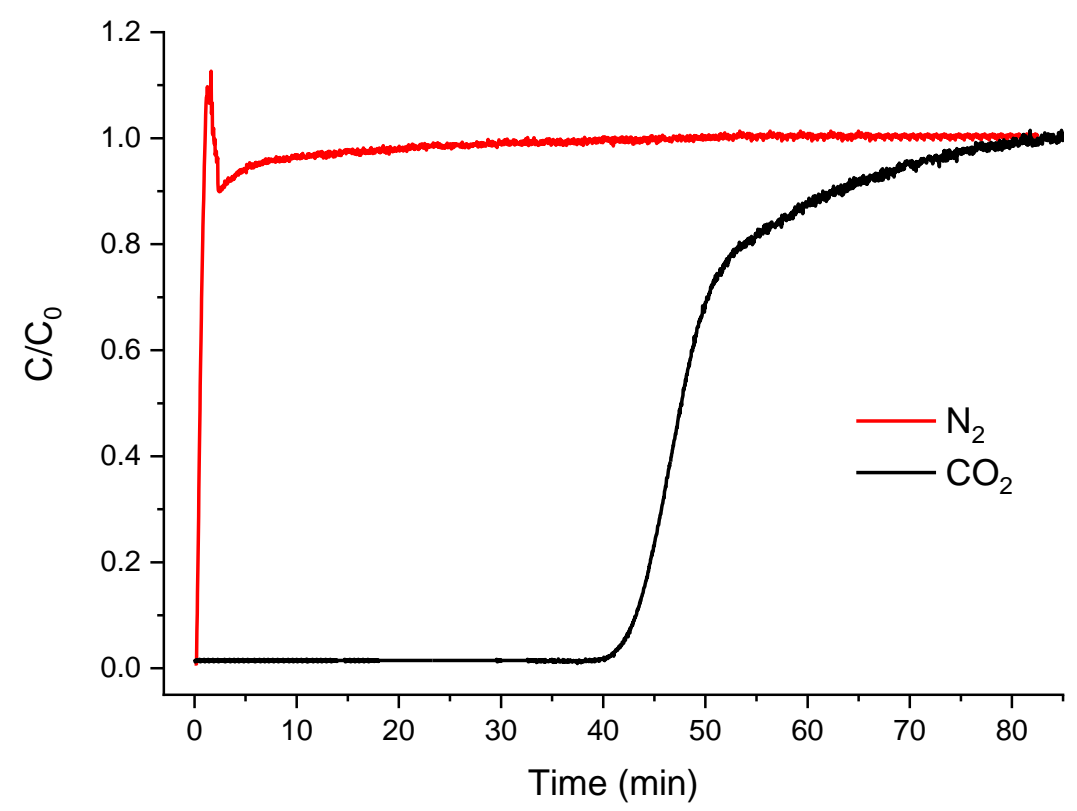

Figure S53. Experimental breakthrough curves for a mixture of $1 / 99 \mathrm{CO}_{2} / \mathrm{N}_{2}$ at 1.1 bar and $293 \mathrm{~K}$ in an adsorption column packed with MUF-16. 


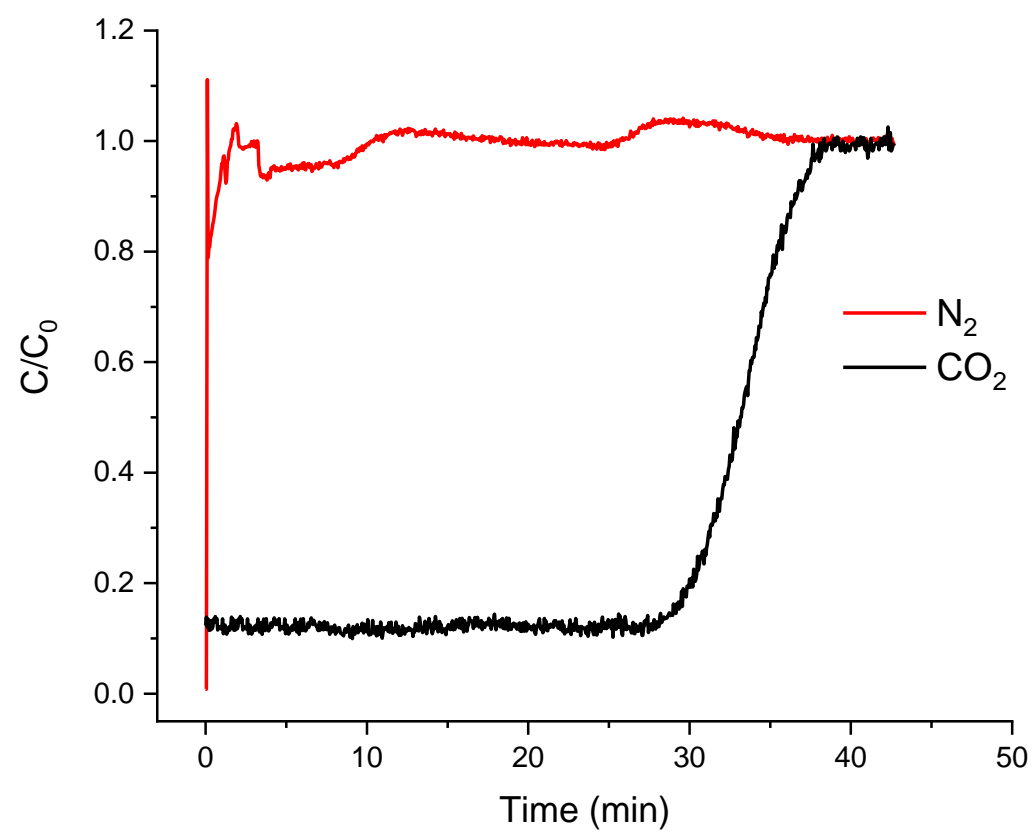

Figure S54. Experimental breakthrough curves for a mixture of $0.4 / 99.6 \mathrm{CO}_{2} / \mathrm{N}_{2}$ at 1.1 bar and $293 \mathrm{~K}$ in an adsorption column packed with MUF-16.

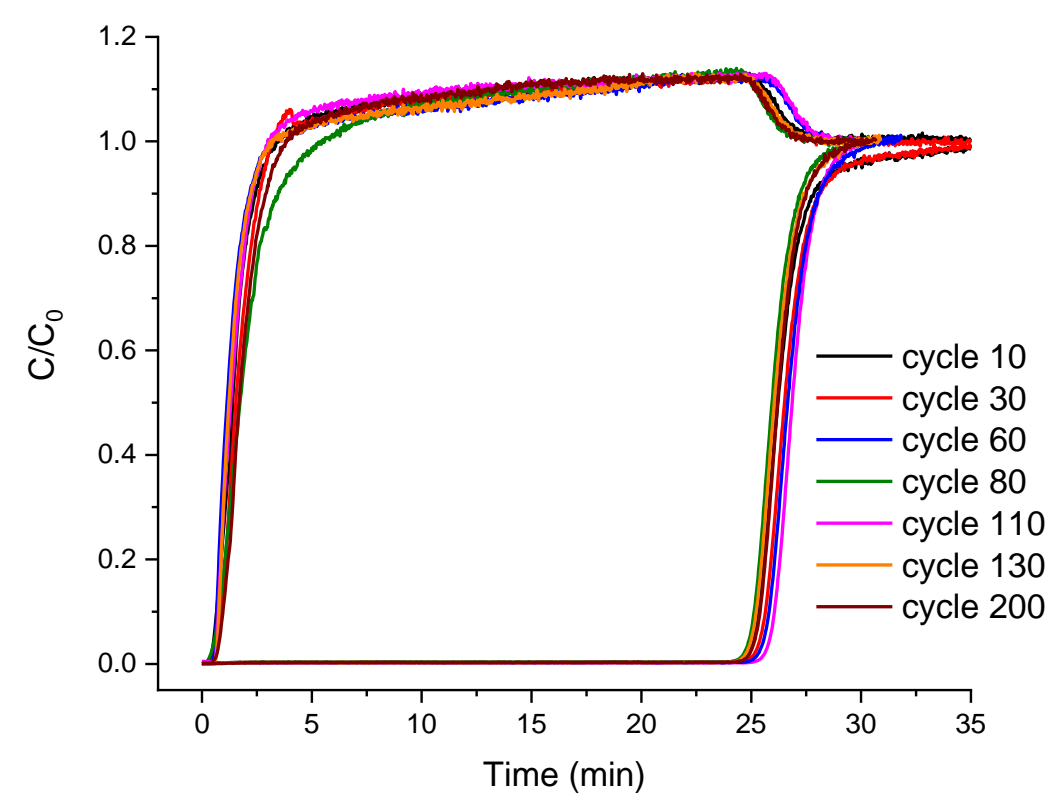

Figure S55. Breakthrough curves of $\mathrm{CO}_{2} / \mathrm{N}_{2}(15 / 85)$ mixture at different cycles at $293 \mathrm{~K}$ and 1.1 bar for MUF-16. 


\subsubsection{Separation of $\mathrm{CO}_{2} / \mathrm{H}_{2}$}

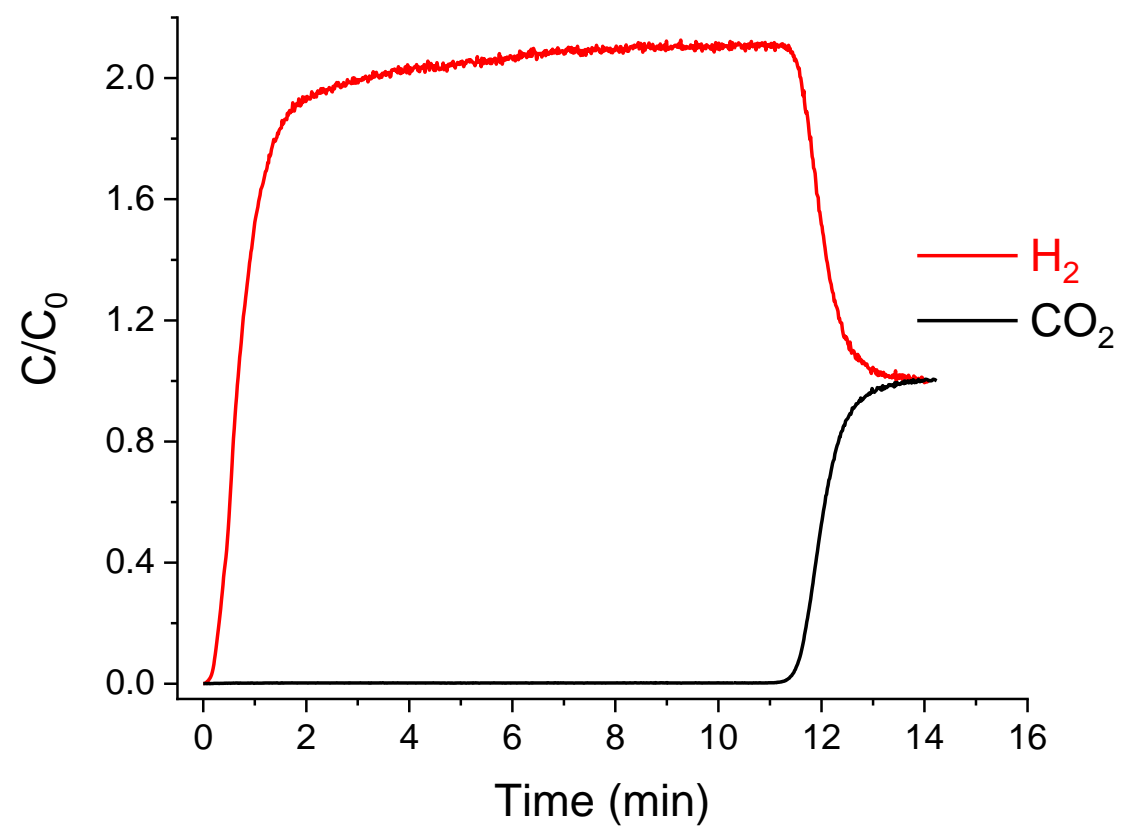

Figure S56. Experimental breakthrough curves for a mixture of $50 / 50 \mathrm{CO}_{2} / \mathrm{H}_{2}$ at 1.1 bar and $293 \mathrm{~K}$ in an adsorption column packed with MUF-16.

\subsubsection{Separation of $\mathrm{CO}_{2} / \mathrm{CH}_{4}$ and $\mathrm{CO}_{2} / \mathrm{CH}_{4}+\mathrm{C}_{2} \mathrm{H}_{6}+\mathrm{C}_{3} \mathrm{H}_{8}$}

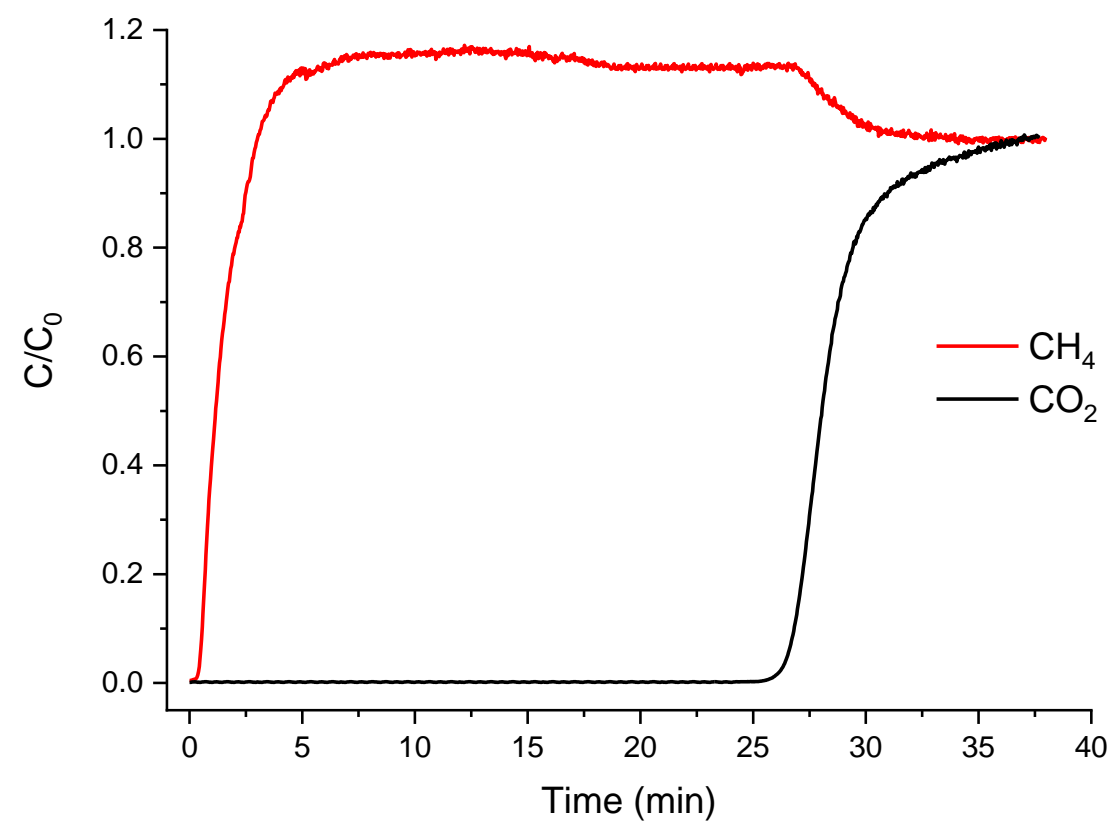

Figure S57. Experimental breakthrough curves for a mixture of $15 / 85 \mathrm{CO}_{2} / \mathrm{CH}_{4}$ at 1.1 bar and $293 \mathrm{~K}$ in an adsorption column packed with MUF-16. 


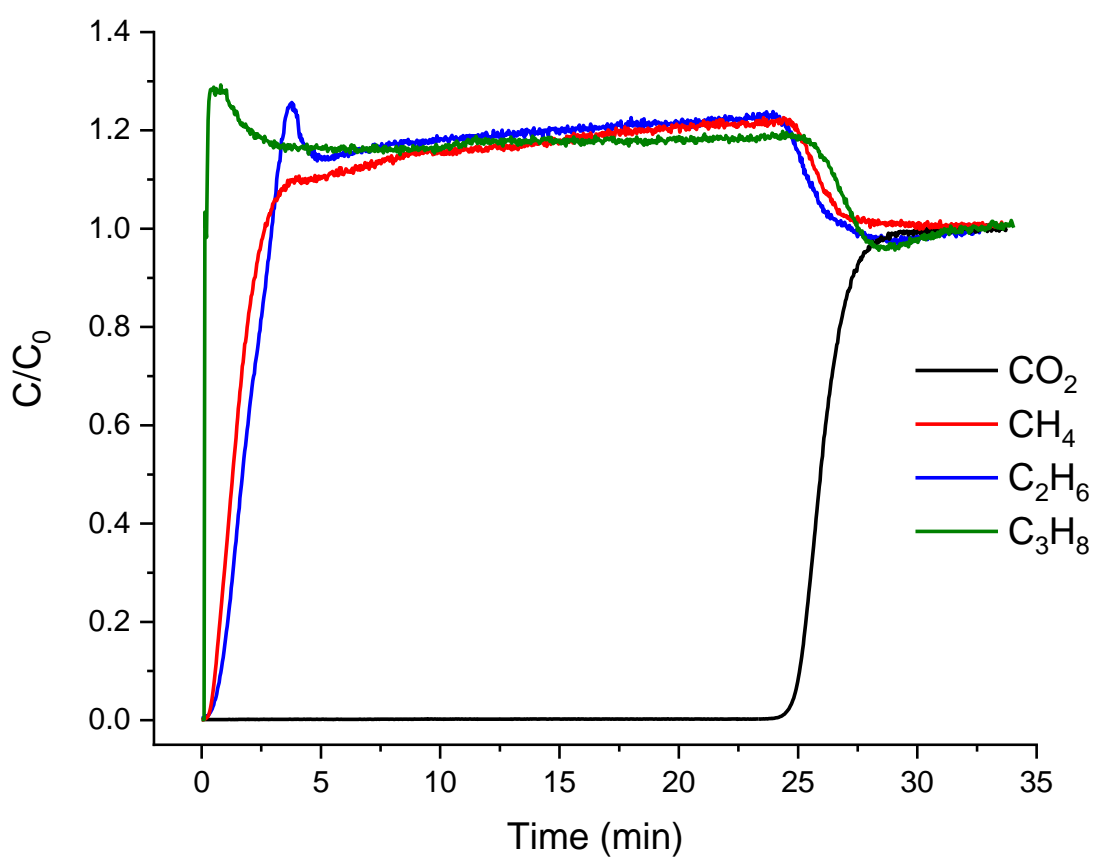

Figure S58. Experimental breakthrough curves for a mixture of $15 / 80 / 4 / 1 \mathrm{CO}_{2} / \mathrm{CH}_{4} / \mathrm{C}_{2} \mathrm{H}_{6} / \mathrm{C}_{3} \mathrm{H}_{8}$ at 1.1 bar and $293 \mathrm{~K}$ in an adsorption column packed with MUF-16.

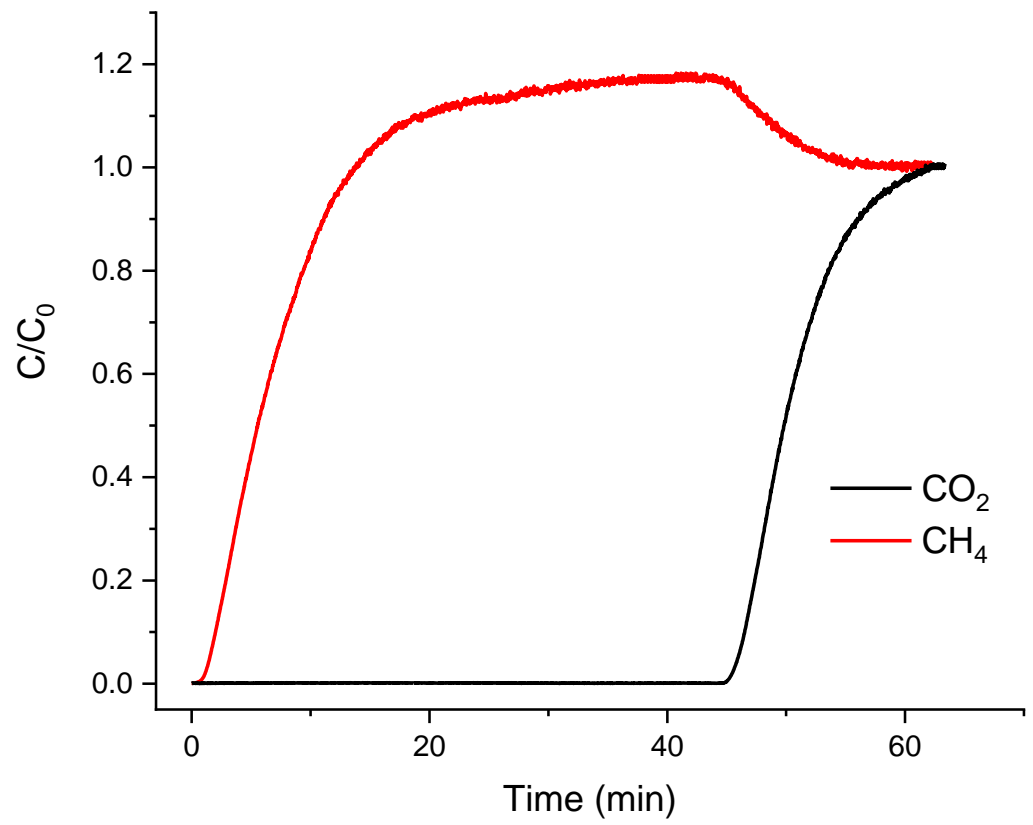

Figure S59. Experimental breakthrough curves for a mixture of $15 / 85 \mathrm{CO}_{2} / \mathrm{CH}_{4}$ at 9 bar and $293 \mathrm{~K}$ in an adsorption column packed with MUF-16. 


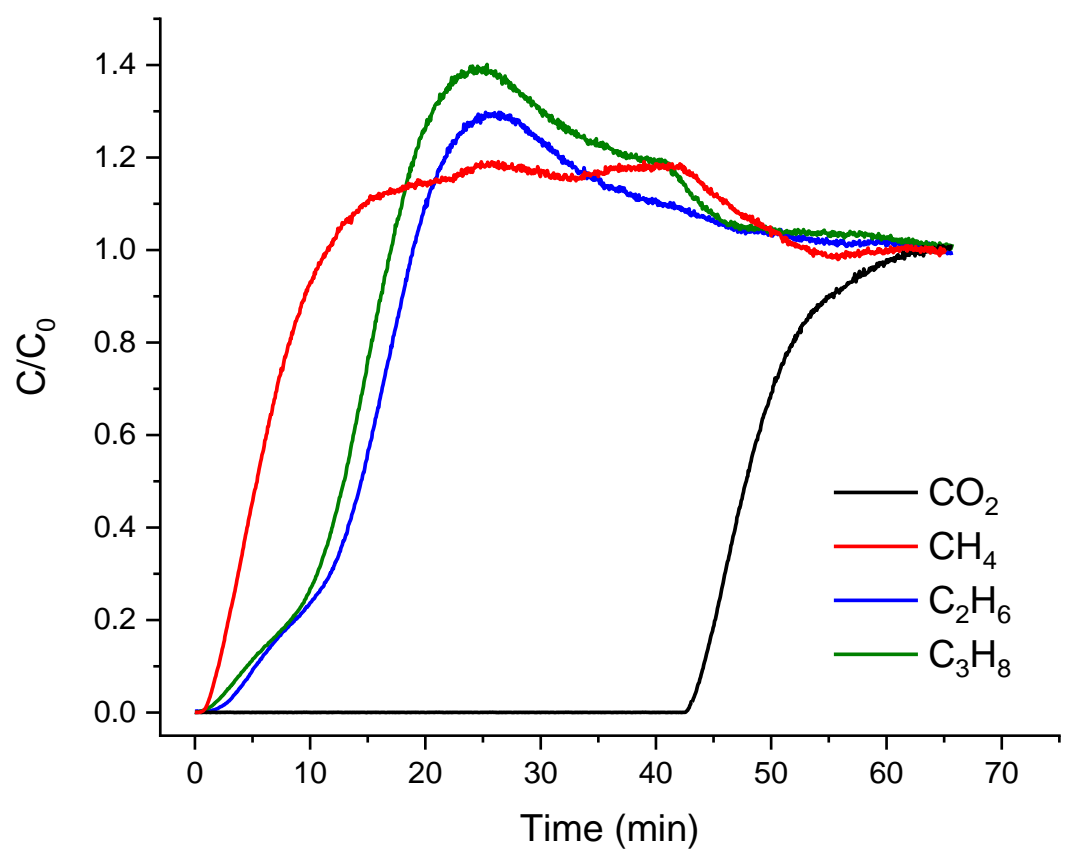

Figure S60. Experimental breakthrough curves for a mixture of $15 / 80 / 4 / 1 \mathrm{CO}_{2} / \mathrm{CH}_{4} / \mathrm{C}_{2} \mathrm{H}_{6} / \mathrm{C}_{3} \mathrm{H}_{8}$ at 9 bar and $293 \mathrm{~K}$ in an adsorption column packed with MUF-16. 


\subsubsection{Simulations of $\mathrm{CO}_{2} / \mathrm{CH}_{4}$ breakthrough curves}

The simulation of breakthrough curves was carried out using a previously reported method. ${ }^{12-13} \mathrm{~A}$ value for the mass transfer coefficient $(\mathrm{k})$ was obtained by empirical tuning the steepness of the predicted breakthrough curves to match the experimental curve. The mass transfer coefficient tuned in this way was later used to predict breakthrough curves for other feed mixtures and operating pressures. A summary of adsorption column parameters and feed characterizations are presented in Table S8.

Table S8. Adsorption column parameters and feed characterizations used for the simulations for MUF16.

\begin{tabular}{ll}
\hline Adsorption bed & Feed \\
Length: $110 \mathrm{~mm}$ & Flow rate: $6 \mathrm{~mL}_{\mathrm{N}} / \mathrm{min}$ \\
Diameter: $6.4 \mathrm{~mm}$ & Temperature: $293 \mathrm{~K}$ \\
Amount of adsorbent in the bed: $0.9 \mathrm{~g}$ & Pressure: $1.1 \mathrm{bar}$ \\
Adsorbent density: $1.674 \mathrm{~g} / \mathrm{cm}^{3}$ & Carrier gas flow rate: No carrier gas was used \\
Adsorbent average radius: $0.2 \mathrm{~mm}$ & \\
$\mathrm{k}_{\mathrm{CO} 2: 0.029 \mathrm{~s}^{-1}}$ & \\
$\mathrm{k}_{\mathrm{CH} 4: 0.00021 \mathrm{~s}^{-1}}$ & \\
\hline
\end{tabular}

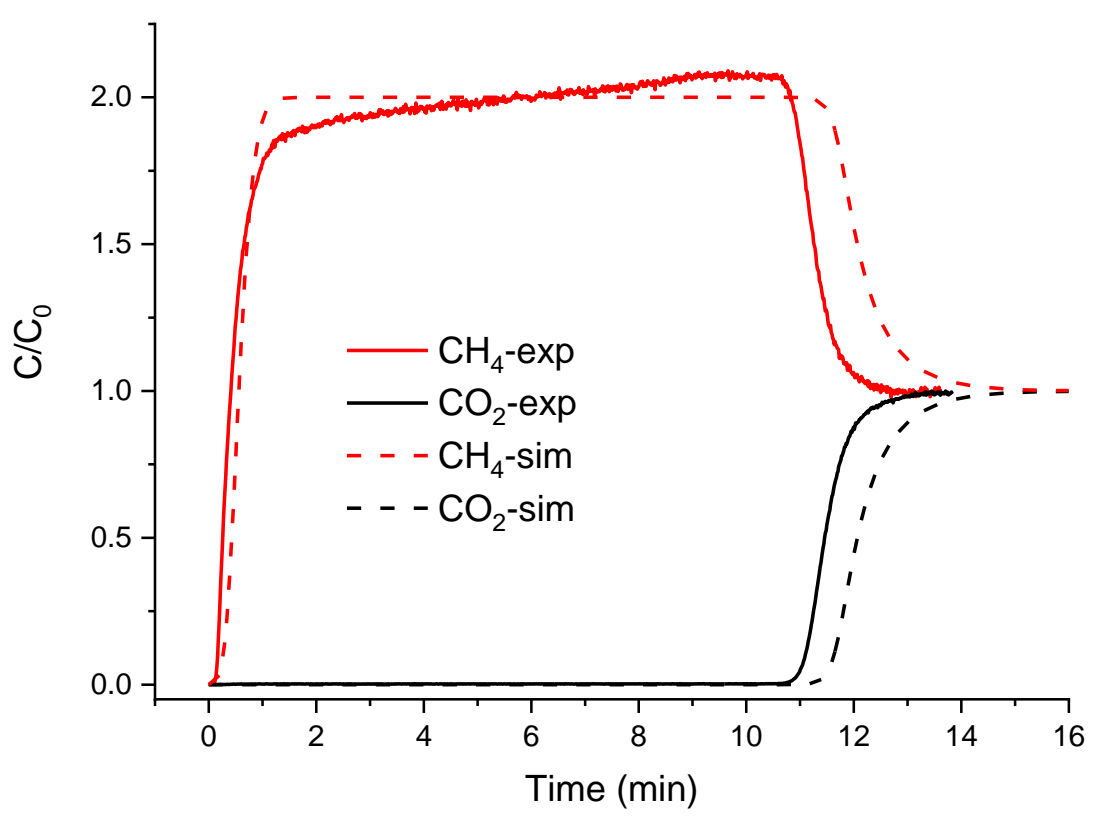

Figure S61. Experimental breakthrough curves in comparison to simulated one for a mixture of 50/50 $\mathrm{CO}_{2} / \mathrm{CH}_{4}$ at 1.1 bar and $293 \mathrm{~K}$ in an adsorption column packed with MUF-16. 


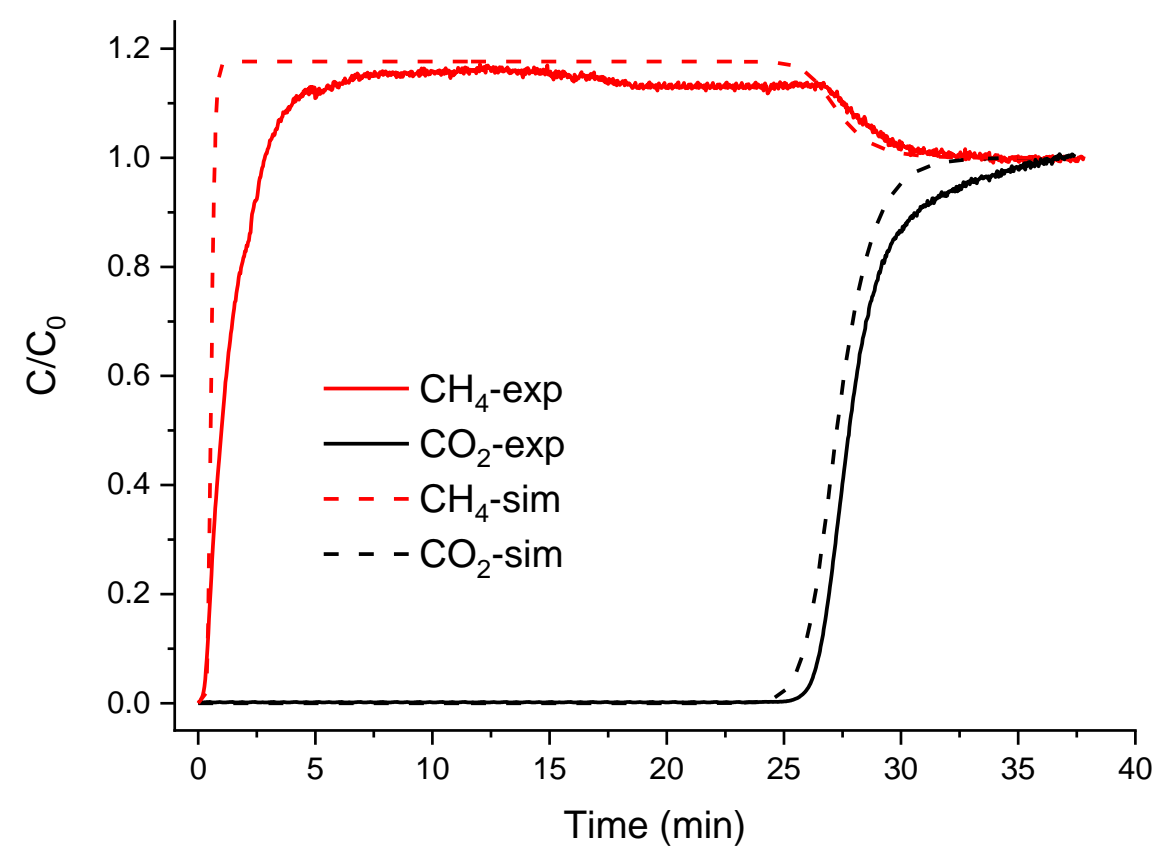

Figure S62. Experimental breakthrough curves in comparison to simulated one for a mixture of 15/85 $\mathrm{CO}_{2} / \mathrm{CH}_{4}$ at 1.1 bar and $293 \mathrm{~K}$ in an adsorption column packed with MUF-16.

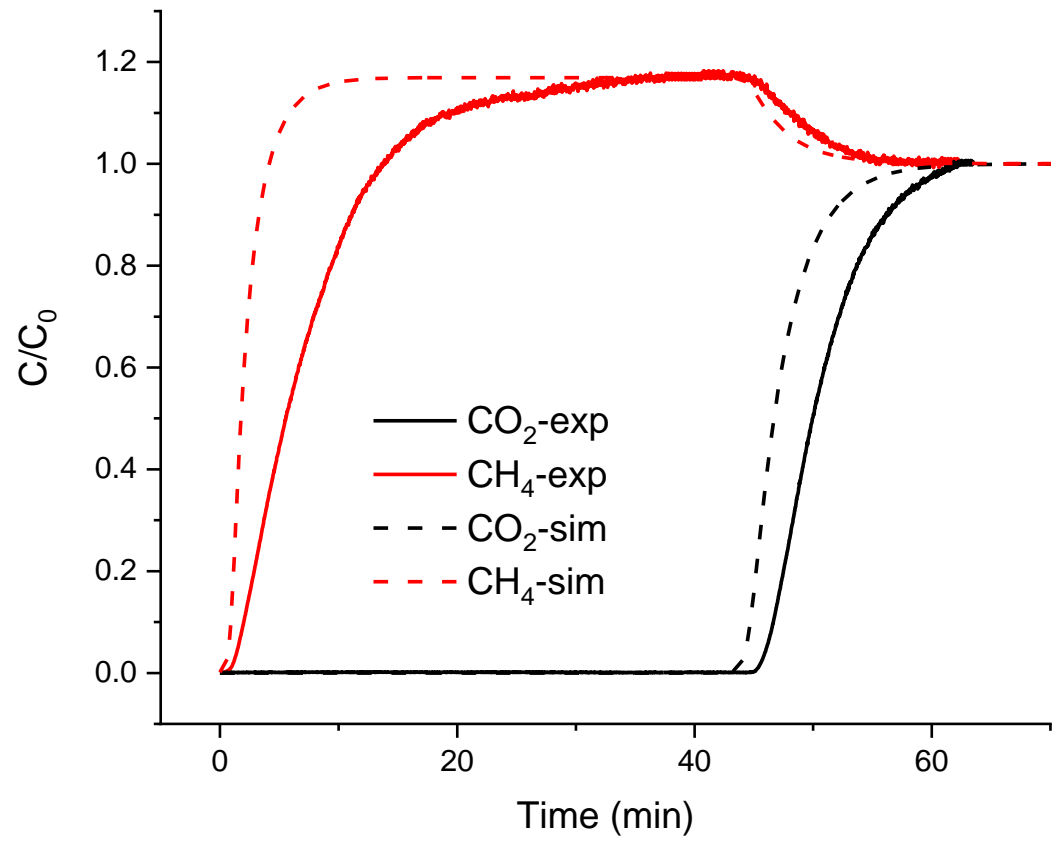

Figure S63. Experimental breakthrough curves in comparison to simulated one for a mixture of $15 / 85$ $\mathrm{CO}_{2} / \mathrm{CH}_{4}$ at 9 bar and $293 \mathrm{~K}$ in an adsorption column packed with MUF-16. 


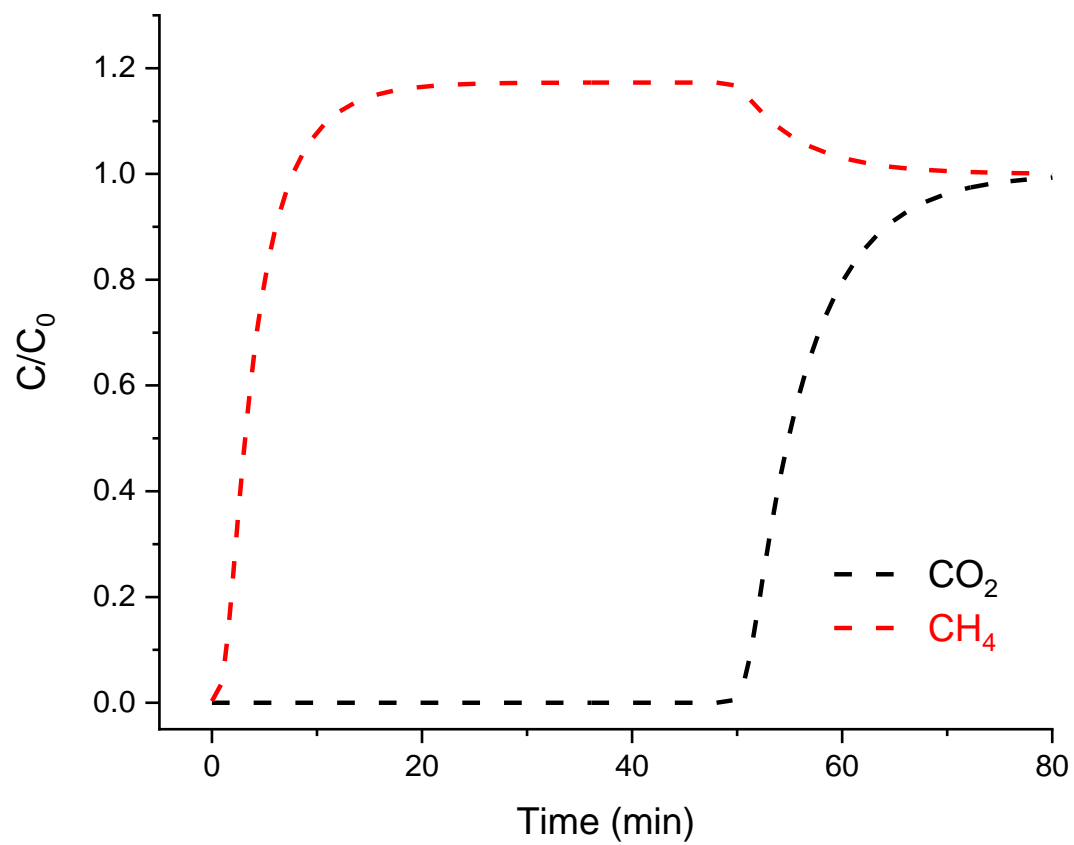

Figure S64. Simulated breakthrough curves for a mixture of $15 / 85 \mathrm{CO}_{2} / \mathrm{CH}_{4}$ at 50 bar and $293 \mathrm{~K}$ in an adsorption column packed with MUF-16.

\section{$9.2 \mathrm{CO}_{2} / \mathrm{C} 2$ hydrocarbon separations}

In a typical breakthrough experiment, $0.9 \mathrm{~g}$ of activated MUF-16 was placed in an adsorption column (6.4 $\mathrm{mm}$ in diameter $\times 11 \mathrm{~cm}$ in length) to form a fixed bed. The adsorbent was activated at $130{ }^{\circ} \mathrm{C}$ under high vacuum for 7 hours and then the column was left under vacuum for another 3 hours while being cooled to $20^{\circ} \mathrm{C}$. The column was then purged under a $20 \mathrm{~mL} / \mathrm{min}$ flow of He gas for $1 \mathrm{hr}$ at $1.1 \mathrm{bar}$ prior to the breakthrough experiment. A gas mixture containing different gas pairs of $\mathrm{CO}_{2}$ and $\mathrm{C}_{2} \mathrm{H}_{2}$, $\mathrm{C}_{2} \mathrm{H}_{6}$ or $\mathrm{C}_{2} \mathrm{H}_{4}$ along with $\mathrm{He}$ as a carrier gas was introduced to the column at 1.1 bar and $20^{\circ} \mathrm{C}$. A feed flowrate of 6.0 or $6.85 \mathrm{~mL}_{\mathrm{N}} / \mathrm{min}$ (including helium) was set for the experiments with 50/50 and 5/95 mixture of gases, respectively, and the flowrate of He in the feed was kept constant at $2 \mathrm{mLN} / \mathrm{min}$ for all the experiments. The operating pressure was controlled at 1.1 bar with a back-pressure regulator. The outlet composition was continuously monitored by a SRS UGA200 mass spectrometer. The $\mathrm{CO}_{2}$ was deemed to have broken through from the column when its concentration reached $600 \mathrm{ppmv}$. 


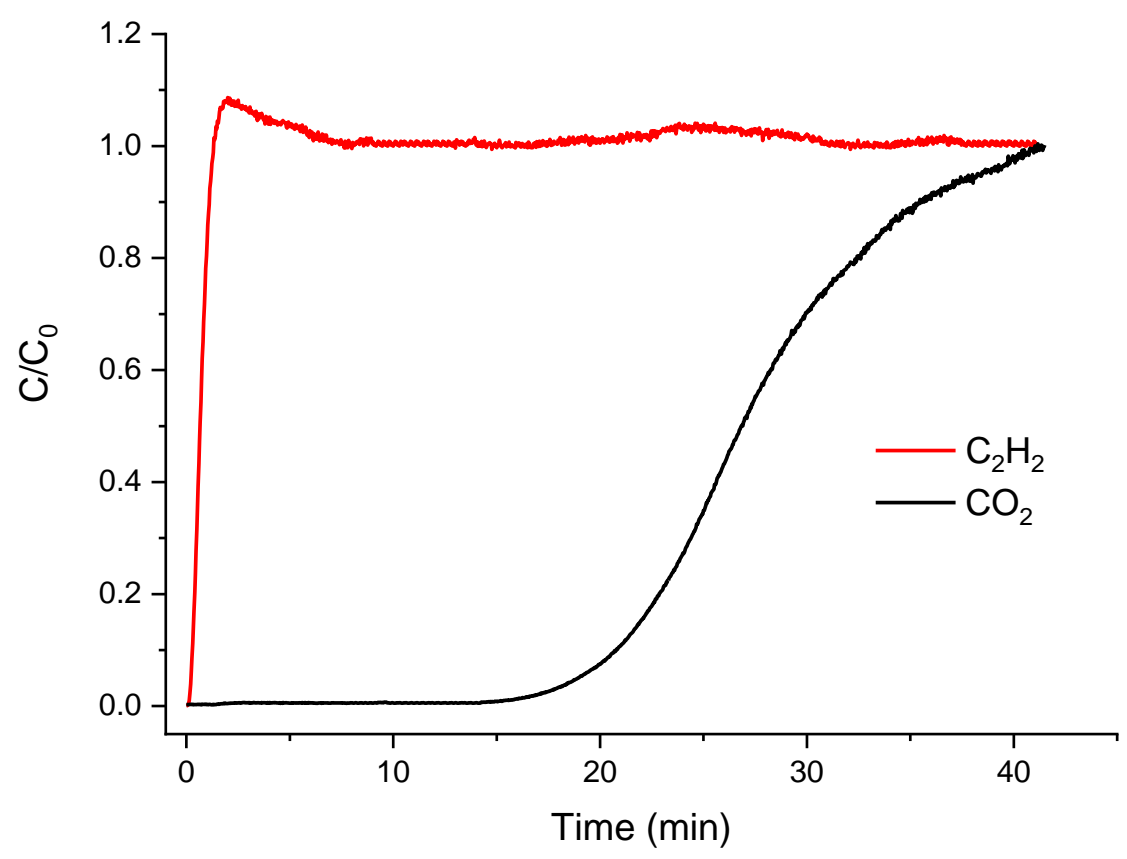

Figure S65. Experimental breakthrough curves for a mixture of $5 / 95 \mathrm{CO}_{2} / \mathrm{C}_{2} \mathrm{H}_{2}$ at 1.1 bar and $293 \mathrm{~K}$ in an adsorption column packed with MUF-16.

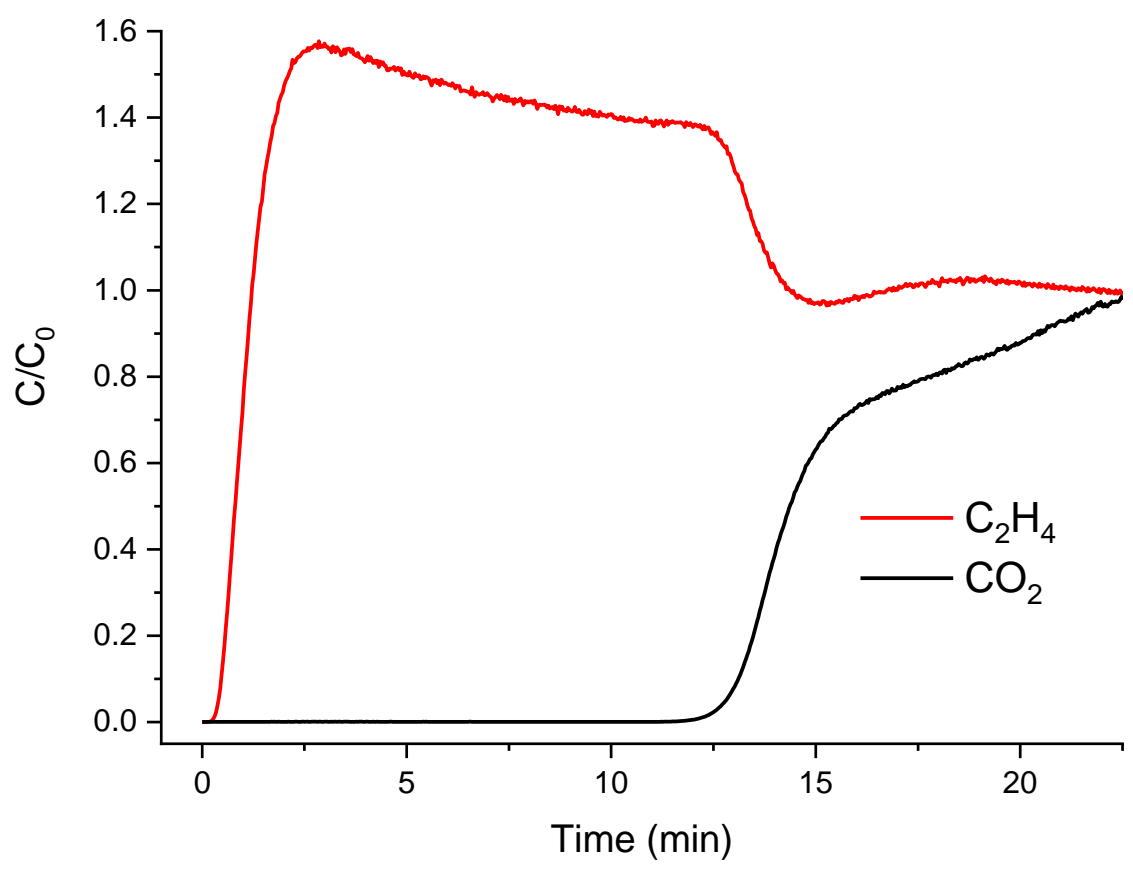

Figure S66. Experimental breakthrough curves for a mixture of $50 / 50 \mathrm{CO}_{2} / \mathrm{C}_{2} \mathrm{H}_{4}$ at 1.1 bar and $293 \mathrm{~K}$ in an adsorption column packed with MUF-16. 


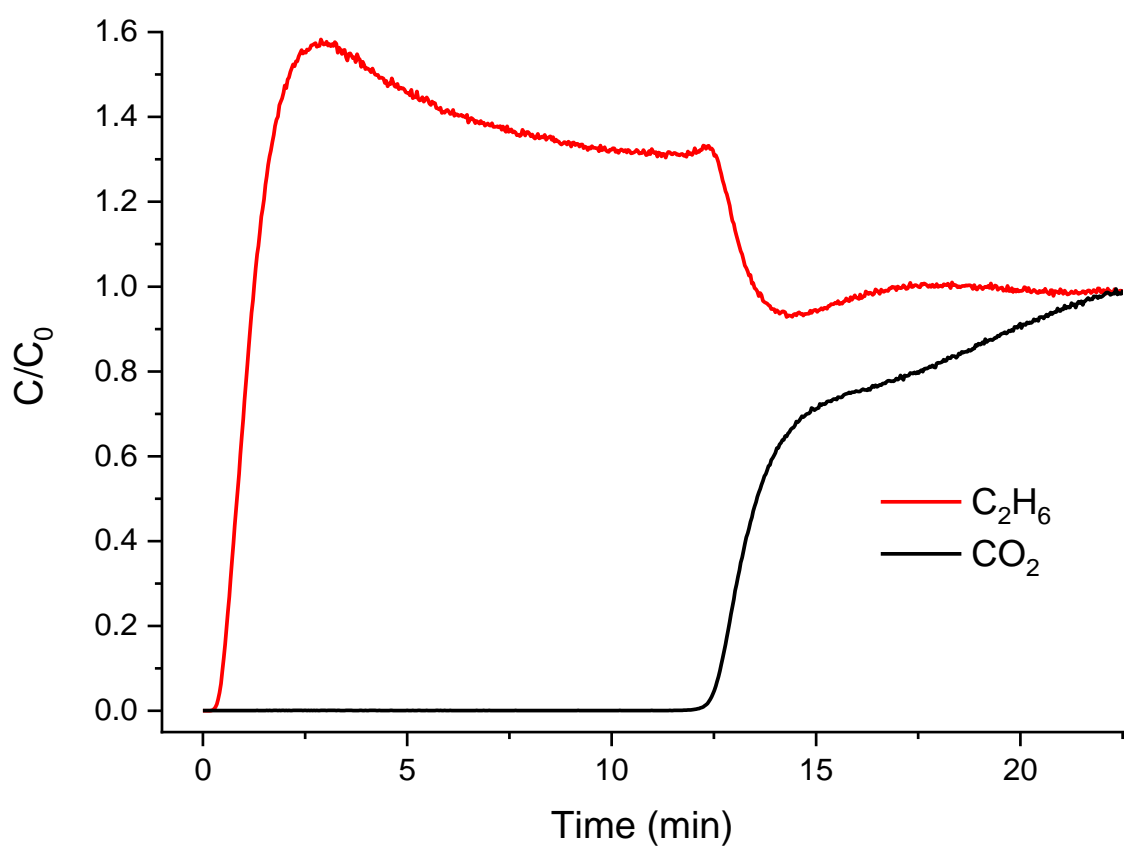

Figure S67. Experimental breakthrough curves for a mixture of $50 / 50 \mathrm{CO}_{2} / \mathrm{C}_{2} \mathrm{H}_{6}$ at 1.1 bar and $293 \mathrm{~K}$ in an adsorption column packed with MUF-16.

\subsubsection{Simulations s of $\mathrm{CO}_{2} / \mathrm{C}_{2} \mathrm{H}_{2}$ breakthrough curves}

The simulation of breakthrough curves for $\mathrm{CO}_{2} / \mathrm{C} 2$ hydrocarbons was carried out using the method reported above. A summary of adsorption column parameters and feed characterizations are presented in Table S9.

Table S9. Adsorption column parameters and feed characterizations used for the simulations for MUF16.

\section{Adsorption bed}

Length: $110 \mathrm{~mm}$

Diameter: $6.4 \mathrm{~mm}$

Amount of adsorbent in the bed: $0.9 \mathrm{~g}$

Bed voidage: 0.84

Adsorbent average radius: $0.2 \mathrm{~mm}$

$\mathrm{k}_{\mathrm{CO} 2}: 0.021 \mathrm{~s}^{-1}$

$\mathrm{k}_{\mathrm{C} 2 \mathrm{H} 2}: 0.024 \mathrm{~s}^{-1}$

\section{Feed}

Flow rates:

$6 \mathrm{~mL} / \mathrm{min}$ for equimolar and $0.1 / 99.9$ mixtures, and 6.85 $\mathrm{mL}_{\mathrm{N}} / \mathrm{min}$ for the $5 / 95$ mixture.

Temperature: $293 \mathrm{~K}$

Pressure: 1.1 bar

Carrier gas $(\mathrm{He})$ flow rate: $2 \mathrm{~mL} / \mathrm{min}$. 


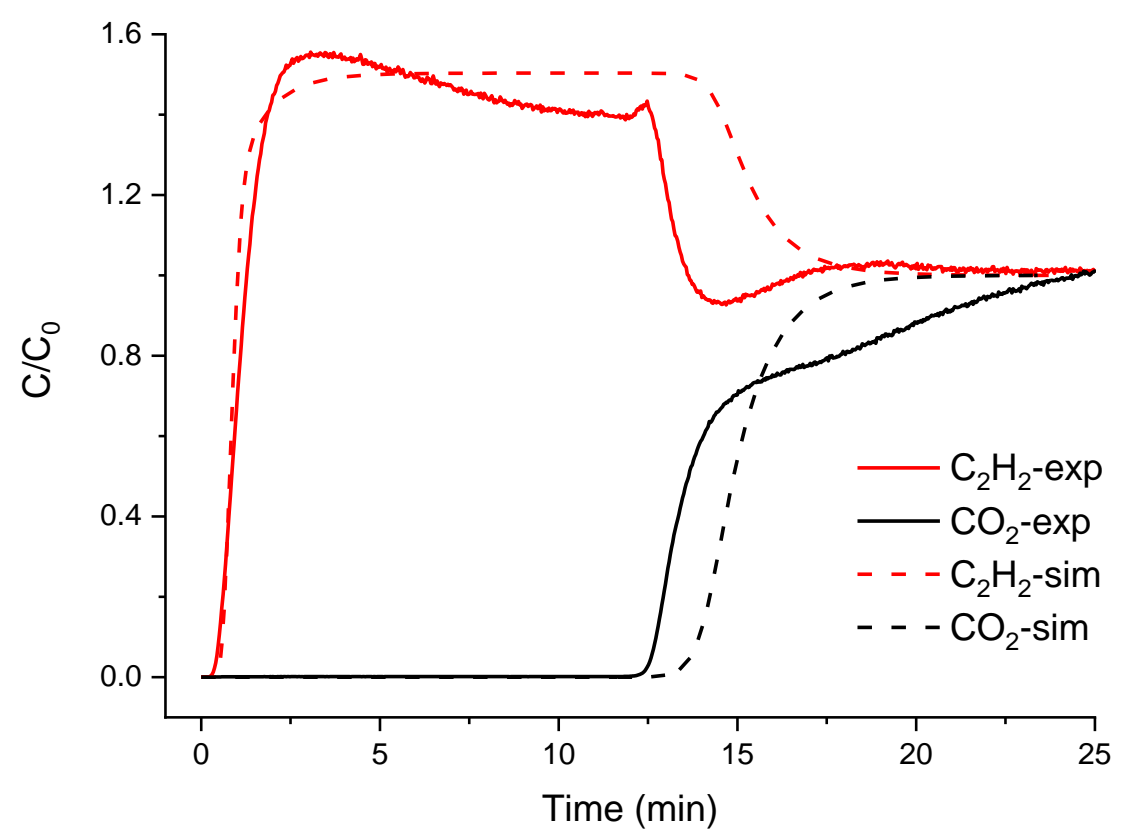

Figure S68. Experimental breakthrough curves in comparison to simulated one for a mixture of 50/50 $\mathrm{CO}_{2} / \mathrm{C}_{2} \mathrm{H}_{2}$ at 1.1 bar and $293 \mathrm{~K}$ in an adsorption column packed with MUF-16.

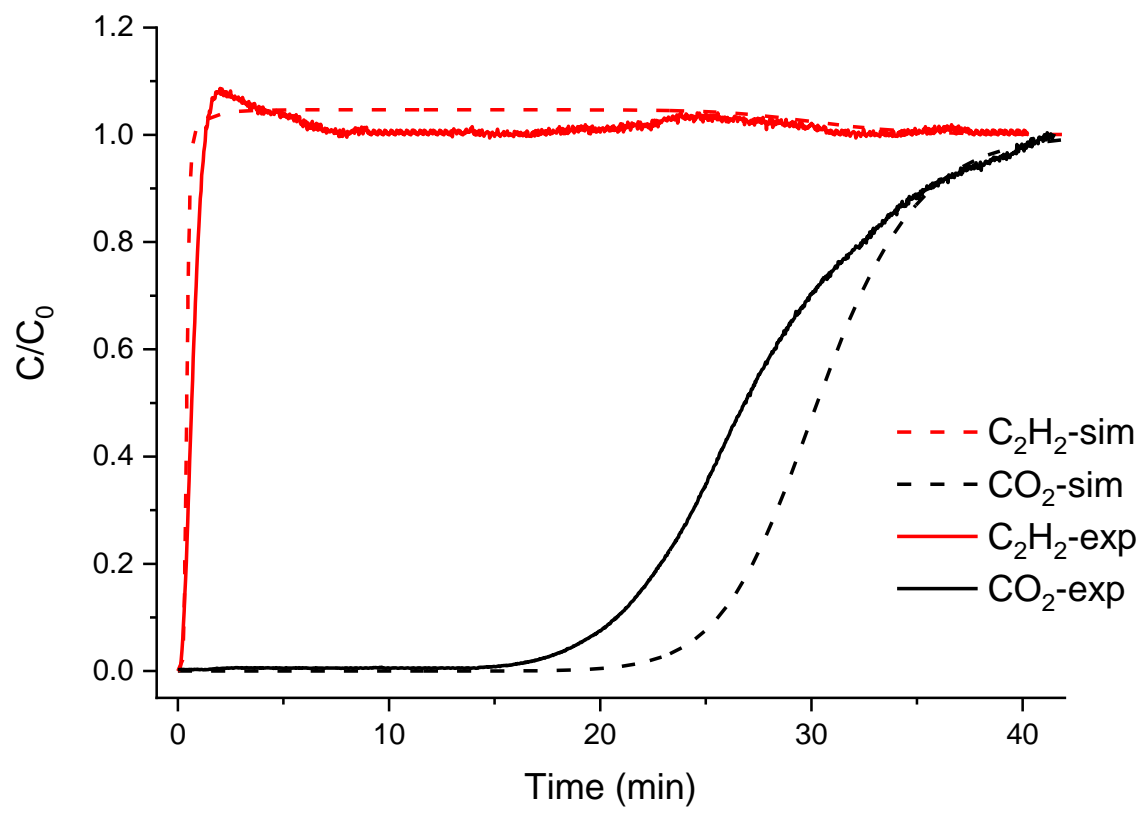

Figure S69. Experimental breakthrough curves in comparison to simulated one for a mixture of 5/95 $\mathrm{CO}_{2} / \mathrm{C}_{2} \mathrm{H}_{2}$ at 1.1 bar and $293 \mathrm{~K}$ in an adsorption column packed with MUF-16. 


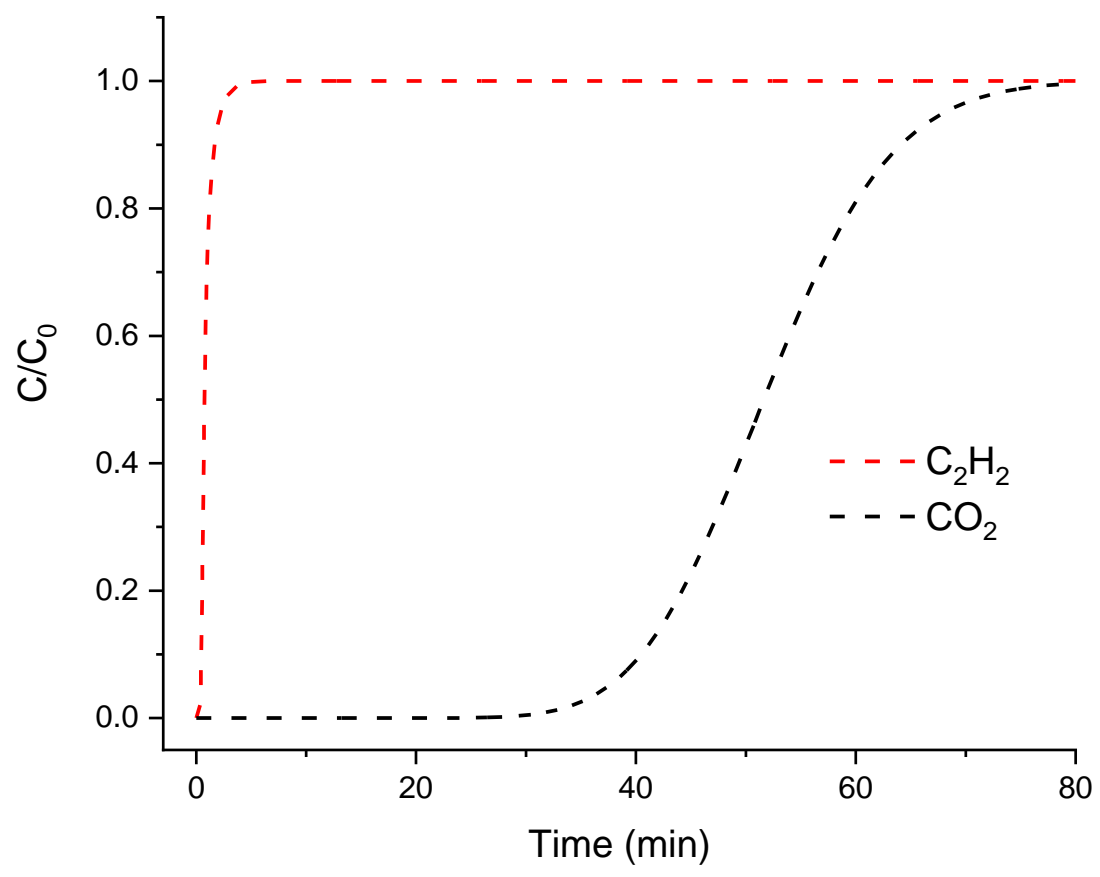

Figure S70. Simulated breakthrough curves for a mixture of $0.1 / 99.9 \mathrm{CO}_{2} / \mathrm{C}_{2} \mathrm{H}_{2}$ at 1.1 bar and $293 \mathrm{~K}$ in an adsorption column packed with MUF-16.

\section{Heat of adsorption}

Isosteric heat of adsorption $\left(\mathrm{Q}_{\mathrm{st}}\right)^{14}$ values were calculated from isotherms measured at $293 \mathrm{~K}, 298 \mathrm{~K}$ and $303 \mathrm{~K}$ for $\mathrm{CO}_{2}$. The isotherms were first fit to a viral equation:

$\ln P=\ln N+\frac{1}{T} \sum_{i=0}^{m} a_{i} N^{i}+\sum_{i=0}^{n} b_{i} N^{i}$

Where $N$ is the amount of gas adsorbed at the pressure $P, a$ and $b$ are virial coefficients, $m$ and $n$ are the number of coefficients require to adequately describe the isotherm. To calculate $\mathrm{Q}_{\mathrm{st}}$, the fitting parameters from the above equation were used for the following equation:

$Q_{s t}=-R \sum_{i=0}^{m} a_{i} N^{i}$ 


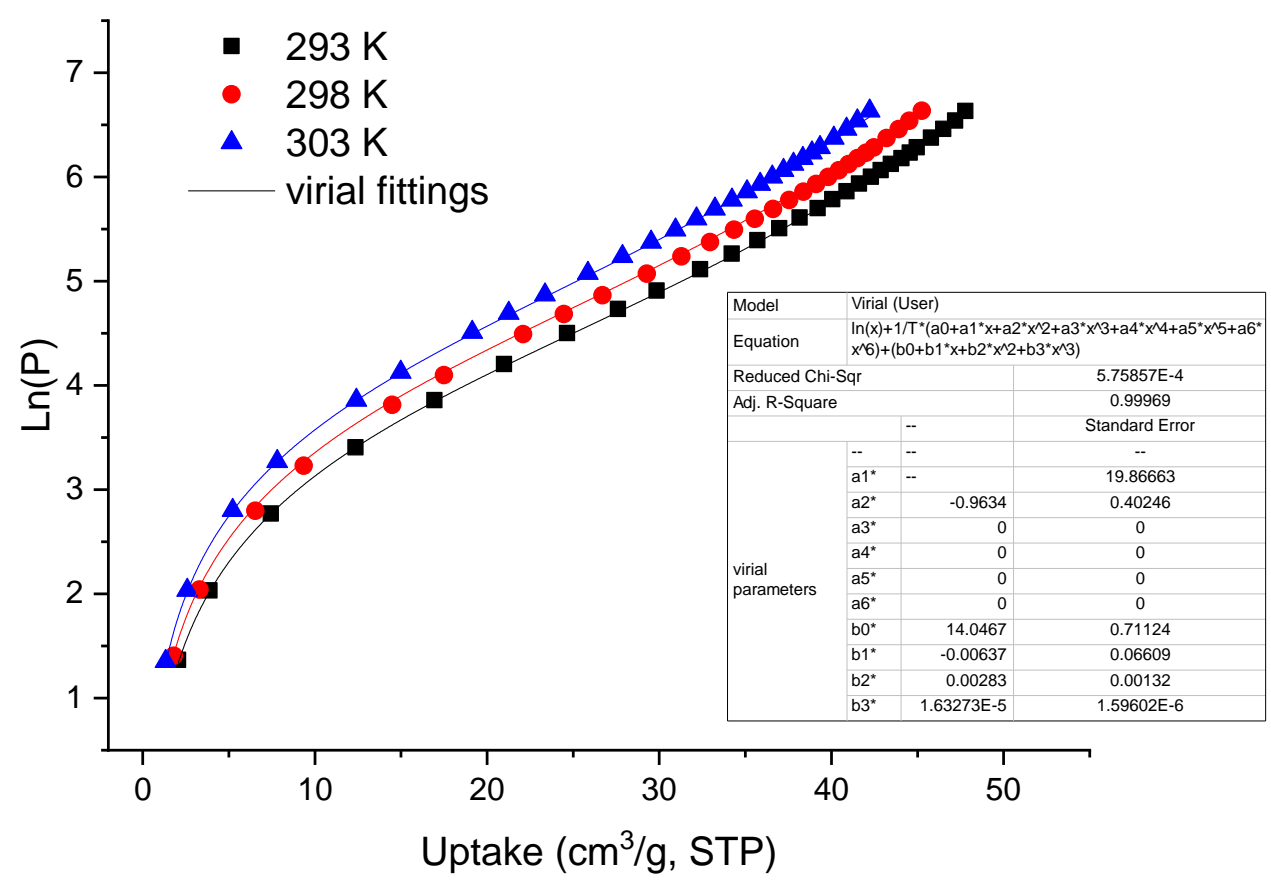

Figure S71. Virial equation fits for $\mathrm{CO}_{2}$ adsorption isotherms of MUF-16.

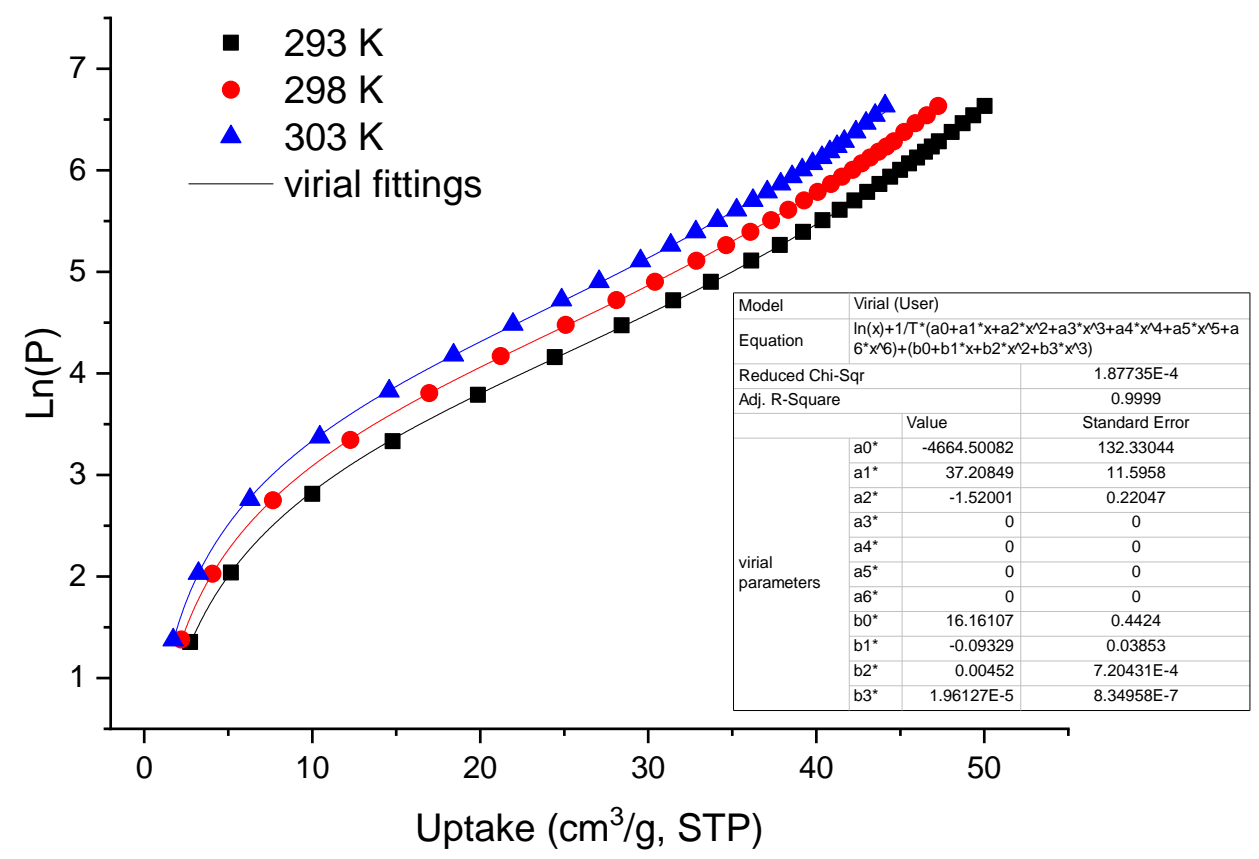

Figure S72. Virial equation fits for $\mathrm{CO}_{2}$ adsorption isotherms of MUF-16(Mn). 


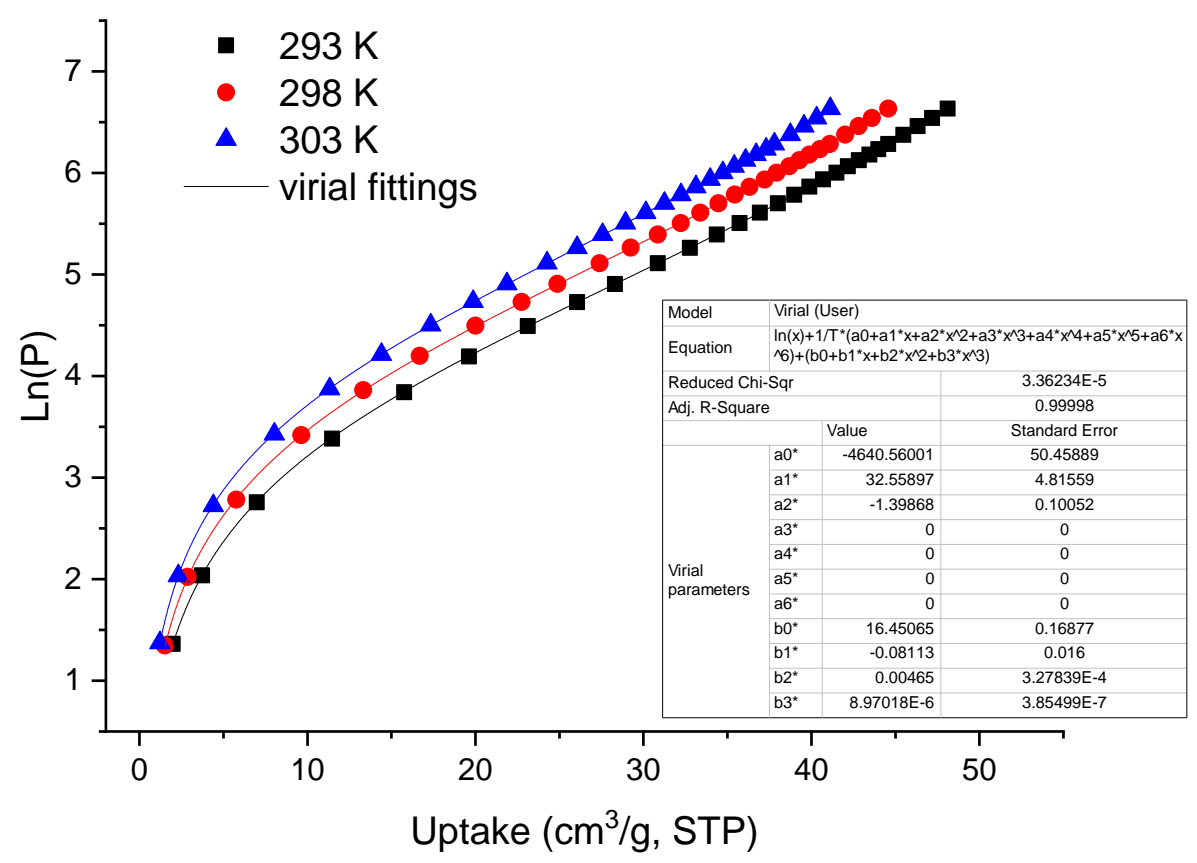

Figure S73. Virial equation fits for $\mathrm{CO}_{2}$ adsorption isotherms of MUF-16(Ni).

\section{Pelletization}

MOF pellets were fabricated based on the following procedure:

1. MUF-16 ( 1 g) was gently ground using mortar and pestle.

2. The ground sample was transferred to a $20 \mathrm{~mL}$ vial and $1 \mathrm{~mL}$ of DMF was added. A viscous suspension was obtained after sonicating for half an hour. The suspension was stirred for another 30 mins.

3. PVDF powder $(50 \mathrm{mg})$ was gradually added over the course of 1 hour and the mixture was stirred overnight to make a viscous paste.

4. The paste was transferred into a plastic syringe and squeezed it out into a thin noodle on a glass slide.

5. The noodle was cut into small pellets and dried under vacuum at $140{ }^{\circ} \mathrm{C}$ for 6 hours.

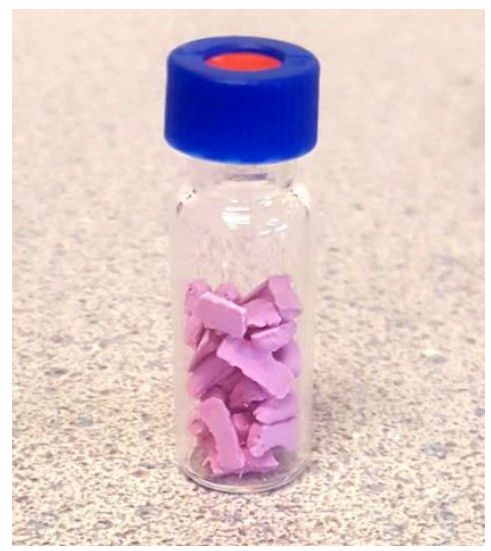

Figure S74. A photograph of MUF-16/PVDF pellets. 


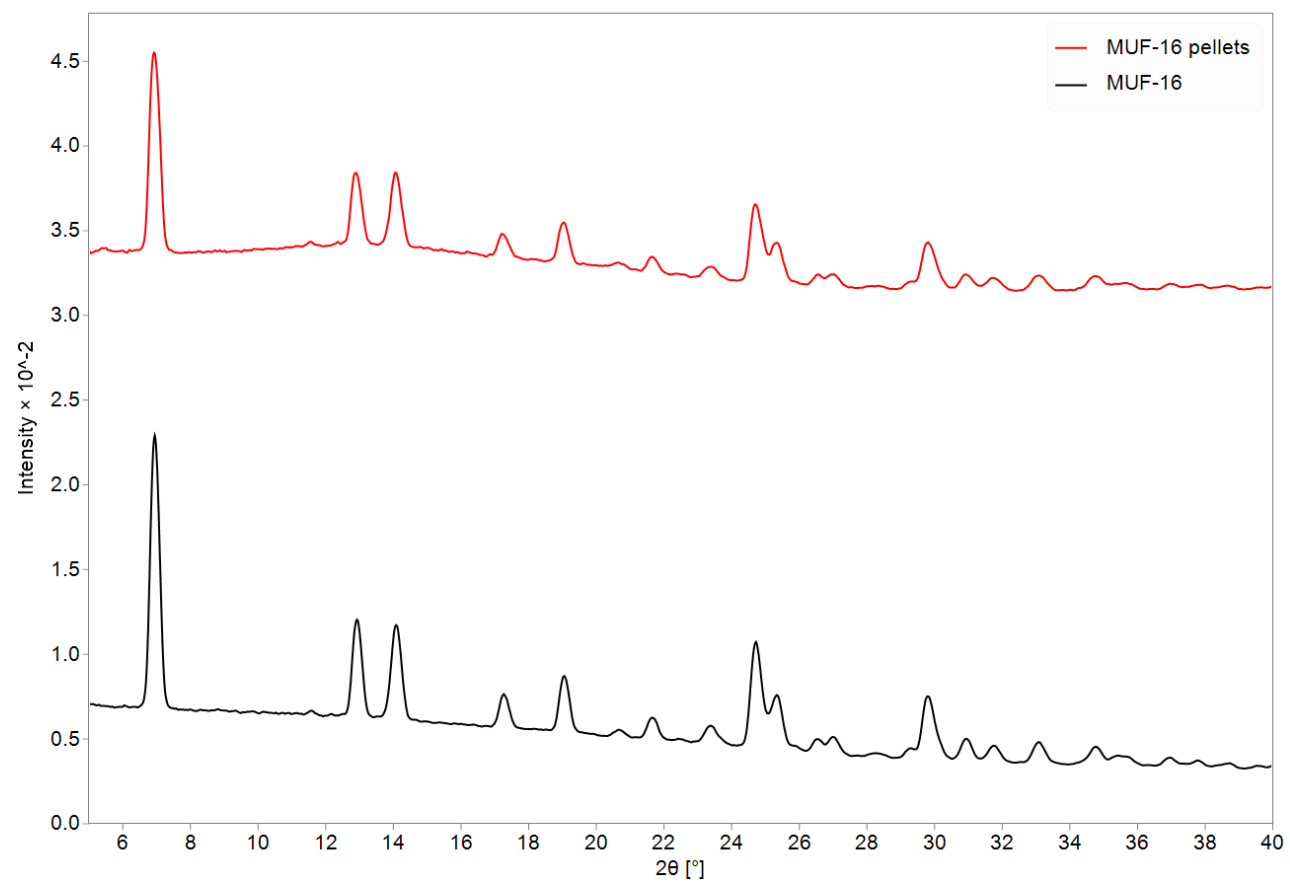

Figure S75. PXRD patterns of MUF-16 showing that its structure remains unchanged after making it into pellet with a PVDF binder.

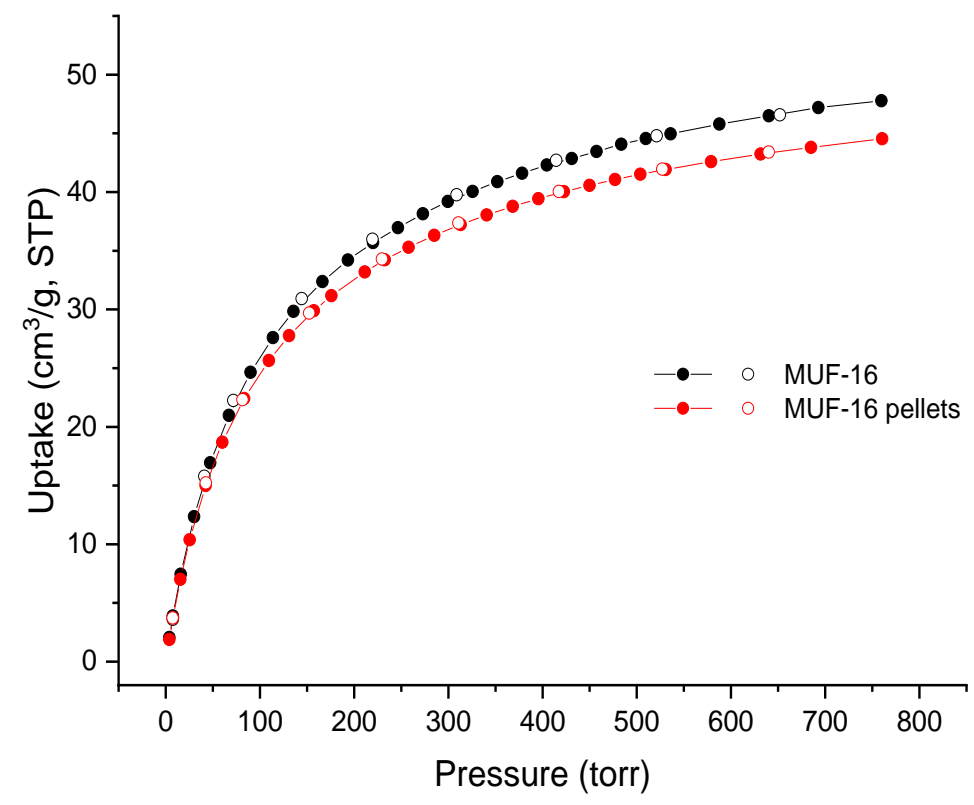

Figure S76. $\mathrm{CO}_{2}$ adsorption isotherm of MUF-16 at $293 \mathrm{~K}$ showing that the inherent adsorption performance of the MOF toward $\mathrm{CO}_{2}$ remains unchanged after making it into pellet with a PVDF binder. The observed drop in capacity for the pellets arises from the $5 \mathrm{wt} \%$ PVDF, which is nonadsorbing. 


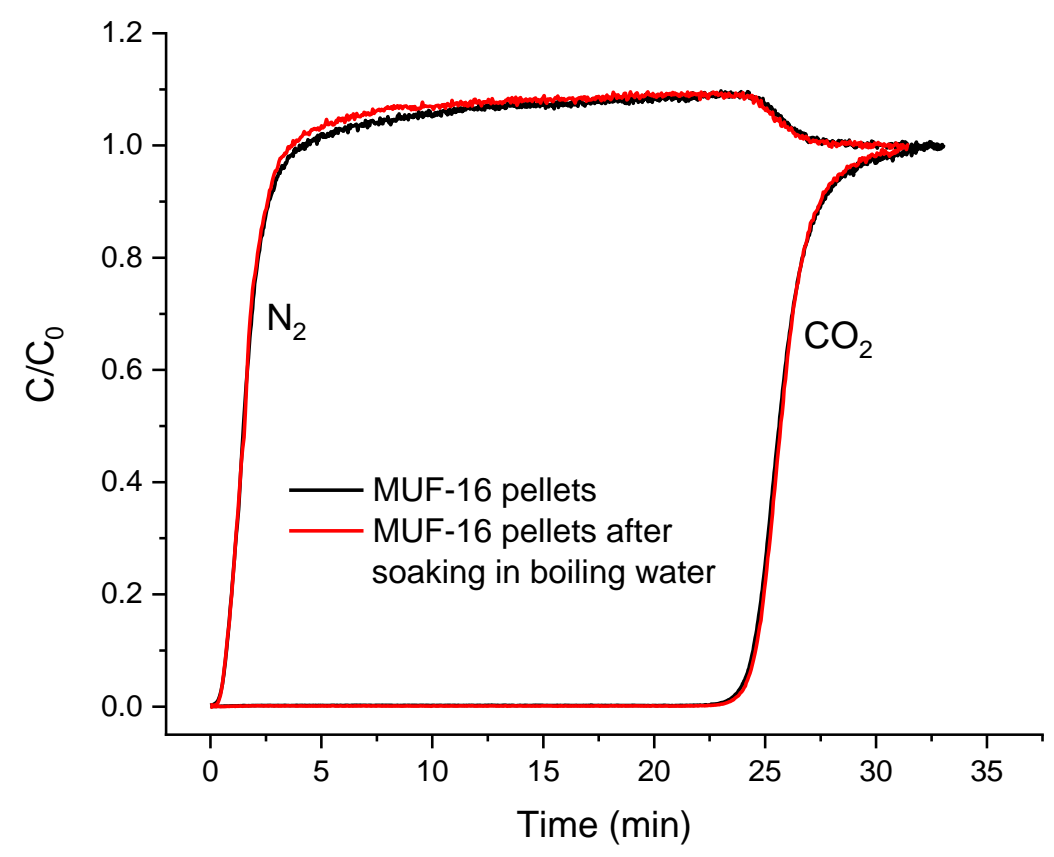

Figure S77. Experimental breakthrough curves for a mixture of $\mathrm{CO}_{2} / \mathrm{N}_{2} 15 / 85$ at $293 \mathrm{~K}$ and 1.1 bar in an adsorption column packed with MUF-16/PVDF pellets before and after being soaked in boiling water.

\section{Tabulated separation metrics}

The $\mathrm{CO}_{2} / \mathrm{N}_{2}, \mathrm{CO}_{2} / \mathrm{CH}_{4}, \mathrm{CO}_{2} / \mathrm{H}_{2}$ and $\mathrm{CO}_{2} / \mathrm{C}_{2} \mathrm{H}_{2}$ separation parameters of MUF-16 in comparison to topperforming MOFs are presented in Table S10 and S11. IAST selectivities are presented for a 15/85 mixture of $\mathrm{CO}_{2} / \mathrm{N}_{2}, 50 / 50 \mathrm{CO}_{2} / \mathrm{CH}_{4}, 20 / 80 \mathrm{CO}_{2} / \mathrm{H}_{2}$ and $50 / 50 \mathrm{CO}_{2} / \mathrm{C}_{2} \mathrm{H}_{2}$ at 1 bar, unless otherwise stated. $Q_{s t}$ values are reported at low loading, unless otherwise stated. Uptake ratios are calculated by dividing the uptake of $\mathrm{CO}_{2}$ by that of $\mathrm{N}_{2}, \mathrm{CH}_{4}$ or $\mathrm{C}_{2} \mathrm{H}_{2}$ (all at 1 bar and the specified temperature in the Table $\mathrm{S} 10$ and S11). These were taken from either a direct statement of relevant details in the manuscript or were extracted from figures by a digitizer software. 
Table S10. Metrics relevant to $\mathrm{CO}_{2} / \mathrm{N}_{2} / \mathrm{CH}_{4}$ separations for MUF-16 in comparison to other top-performing materials reported in the literature.

\begin{tabular}{|c|c|c|c|c|c|c|c|c|c|c|}
\hline & \multirow[t]{2}{*}{ Material } & \multirow[t]{2}{*}{$\mathbf{T}\left({ }^{\circ} \mathbf{C}\right)$} & \multirow{2}{*}{$\begin{array}{c}\mathbf{P} \\
\text { (bar) }\end{array}$} & \multirow{2}{*}{$\begin{array}{l}\mathrm{CO}_{2}\left|\mathrm{~N}_{2}\right| \mathrm{CH}_{4} \\
\text { uptakes }(\mathrm{cc} / \mathrm{g})\end{array}$} & \multirow{2}{*}{$\begin{array}{l}Q_{s t}\left(\mathrm{CO}_{2}\right) \\
(\mathrm{kJ} / \mathrm{mol})\end{array}$} & \multicolumn{2}{|c|}{ Uptake ratio } & \multicolumn{3}{|c|}{ IAST selectivity } \\
\hline & & & & & & $\mathrm{CO}_{2} / \mathrm{N}_{2}$ & $\mathrm{CO}_{2} / \mathrm{CH}_{4}$ & $\begin{array}{l}\mathrm{CO}_{2} / \mathrm{N}_{2} \\
(15 / 85)\end{array}$ & $\begin{array}{c}\mathrm{CO}_{2} / \mathrm{CH}_{4} \\
(50 / 50) \\
\end{array}$ & $\begin{array}{l}\mathrm{CO}_{2} / \mathrm{H}_{2} \\
(20 / 80)\end{array}$ \\
\hline \multirow{3}{*}{.} & MUF-16 & 20 & 1 & $\begin{array}{l}47.8|1.3| \\
\mid 1.2\end{array}$ & 33 & 36.2 & 39.8 & 631 & 6686 & 9695 \\
\hline & MUF-16(Mn) & 20 & 1 & $50.5|2.9| 3.1$ & 38 & 17.6 & 16.3 & 256 & 470 & 301 \\
\hline & MUF-16(Ni) & 20 & 1 & \begin{tabular}{l|l|l|}
48.0 & 2.3 & 2.8 \\
\end{tabular} & 37 & 20.8 & $\mathbf{1 7 . 3}$ & 281 & 1215 & 6828 \\
\hline \multirow{31}{*}{ 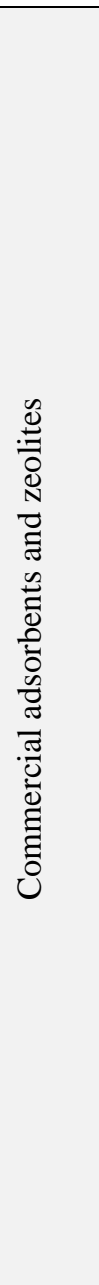 } & Zeolite $13 X^{15-16}$ & 25 & 1 & \begin{tabular}{l|l|l|}
112 & 6.0 & 13
\end{tabular} & $44-54$ & 18.7 & 8.6 & $420^{\#}$ & 103 & $250^{\# \#}$ \\
\hline & Zeolite $5 \mathrm{~A}^{17-18}$ & 30 & 1 & $75.5|5.2| 11.8$ & $23^{c}$ & 14.5 & 6.4 & $\mathrm{n} / \mathrm{a}$ & $\mathrm{n} / \mathrm{a}$ & $\mathrm{n} / \mathrm{a}$ \\
\hline & Zeolite $4 \mathrm{~A}^{19-20}$ & $30-32$ & 1 & $105.3|7.4| 15$ & 39 & 14.2 & 7 & $\mathrm{n} / \mathrm{a}$ & $\mathrm{n} / \mathrm{a}$ & $\mathrm{n} / \mathrm{a}$ \\
\hline & $\begin{array}{l}\text { BPL Activated carbon } \\
22-\end{array}$ & 25 & 1 & $46.2|6.5| 20.2$ & $21^{\mathrm{c}}$ & 7.1 & 2.3 & $23 *$ & 4 & $\mathrm{n} / \mathrm{a}$ \\
\hline & SIFSIX-3-Cu ${ }^{23}$ & 25 & 1 & $58|4.3| \mathrm{n} / \mathrm{a}$ & 54 & 13.5 & $\mathrm{n} / \mathrm{a}$ & $15500^{\#}$ & $\mathrm{n} / \mathrm{a}$ & $\mathrm{n} / \mathrm{a}$ \\
\hline & SGU-2924 & 25 & 1 & $79.2|\mathrm{n} / \mathrm{a}| \mathrm{n} / \mathrm{a}$ & 50 & $\mathrm{n} / \mathrm{a}$ & $\mathrm{n} / \mathrm{a}$ & $3510^{\#}$ & $\mathrm{n} / \mathrm{a}$ & $\mathrm{n} / \mathrm{a}$ \\
\hline & IISERP-MOF $2^{25}$ & 30 & 1 & $88.5|5.1| \mathrm{n} / \mathrm{a}$ & 33 & 17.3 & $\mathrm{n} / \mathrm{a}$ & 1860 & $\mathrm{n} / \mathrm{a}$ & $\mathrm{n} / \mathrm{a}$ \\
\hline & SIFSIX-3-Zn ${ }^{16}$ & 25 & 1 & $57|5.1| 17.6$ & 45 & 11.2 & 3.2 & $1820^{\#}$ & 230 & $\mathrm{n} / \mathrm{a}$ \\
\hline & {$\left[\mathrm{Cd}_{2} \mathrm{~L}\left(\mathrm{H}_{2} \mathrm{O}\right)\right]_{2} .5 \mathrm{H}_{2} \mathrm{O}^{26}$} & 20 & 1 & $47.2|1.3| 1.1$ & 37 & 36.3 & 42.9 & $\mathrm{n} / \mathrm{a}$ & $\mathrm{n} / \mathrm{a}$ & $\mathrm{n} / \mathrm{a}$ \\
\hline & UTSA- $120^{27}$ & 23 & 1 & $112|5.6| 20.8$ & 27 & 20.0 & 5.4 & 600 & 96 & $\mathrm{n} / \mathrm{a}$ \\
\hline & {$\left[\mathrm{Cu}(\mathrm{bcppm}) \mathrm{H}_{2} \mathrm{O}\right]^{28}$} & 20 & 1 & $33.6|1.5| \mathrm{n} / \mathrm{a}$ & 29 & 22.4 & $\mathrm{n} / \mathrm{a}$ & 590 & $\mathrm{n} / \mathrm{a}$ & $\mathrm{n} / \mathrm{a}$ \\
\hline & bio-MOF- $11^{29}$ & 25 & 1 & $92|2.9| \mathrm{n} / \mathrm{a}$ & 45 & 31.7 & $\mathrm{n} / \mathrm{a}$ & $75^{\mathrm{b}}$ & $\mathrm{n} / \mathrm{a}$ & $\mathrm{n} / \mathrm{a}$ \\
\hline & PPN-6- $\mathrm{CH}_{2} \mathrm{DETA}^{30}$ & 22 & 1 & $98.6|0.7| \mathrm{n} / \mathrm{a}$ & 63 & 140.0 & $\mathrm{n} / \mathrm{a}$ & 442 & $\mathrm{n} / \mathrm{a}$ & $\mathrm{n} / \mathrm{a}$ \\
\hline & Cu-BTTri & 40 & 1 & $\mathrm{n} / \mathrm{a}|\mathrm{n} / \mathrm{a}| \mathrm{n} / \mathrm{a}$ & $\mathrm{n} / \mathrm{a}$ & $\mathrm{n} / \mathrm{a}$ & $\mathrm{n} / \mathrm{a}$ & $\mathrm{n} / \mathrm{a}$ & $\mathrm{n} / \mathrm{a}$ & $25^{\# \#}$ \\
\hline & mmen-Cu-BTTri ${ }^{31}$ & 25 & 1 & $90|2.35| \mathrm{n} / \mathrm{a}$ & 96 & 38.3 & $\mathrm{n} / \mathrm{a}$ & $330 *$ & $\mathrm{n} / \mathrm{a}$ & $\mathrm{n} / \mathrm{a}$ \\
\hline & $\mathrm{Ni}-4 \mathrm{PyC}^{32}$ & 40 & 1 & $\mathrm{n} / \mathrm{a}|\mathrm{n} / \mathrm{a}| \mathrm{n} / \mathrm{a}$ & $\mathrm{n} / \mathrm{a}$ & $\mathrm{n} / \mathrm{a}$ & $\mathrm{n} / \mathrm{a}$ & $\mathrm{n} / \mathrm{a}$ & $\mathrm{n} / \mathrm{a}$ & 190 \\
\hline & UTSA-16 $6^{33-34}$ & 23 & 1 & $96|4.5| 13.2$ & 33 & 21.3 & 7.3 & 314 & 38 & $\mathrm{n} / \mathrm{a}$ \\
\hline & en-Mg-dobpdc ${ }^{35}$ & 25 & 1 & $103|2.2| \mathrm{n} / \mathrm{a}$ & 50 & 47.0 & $\mathrm{n} / \mathrm{a}$ & $230^{\mathrm{a}}$ & $\mathrm{n} / \mathrm{a}$ & $\mathrm{n} / \mathrm{a}$ \\
\hline & HKUST-1 ${ }^{34,36-37}$ & 25 & 1 & $103|4.5| 18.7$ & $35^{\mathrm{c}}$ & $\mathrm{n} / \mathrm{a}$ & 7.4 & 23 & 5.5 & $\mathrm{n} / \mathrm{a}$ \\
\hline & Mg-dobdc $11,16,34,38$ & 23 & 1 & $190|24.6| 25$ & $47-52$ & 7.7 & 7.6 & 180 & 130 & $1530^{\# \#}$ \\
\hline & IITKGP-5a & 22 & 1 & $49|4| 13.6$ & 23 & 12.3 & 3.6 & 150 & 24 & $\mathrm{n} / \mathrm{a}$ \\
\hline & DICRO-3-Cu-i ${ }^{40}$ & 20 & 1 & $40.3|0.51| \mathrm{n} / \mathrm{a}$ & 37 & 79.0 & $\mathrm{n} / \mathrm{a}$ & $150^{\mathrm{a}}$ & $\mathrm{n} / \mathrm{a}$ & $\mathrm{n} / \mathrm{a}$ \\
\hline & DICRO-3-Ni-i ${ }^{40}$ & 20 & 1 & $49.8|1.95| \mathrm{n} / \mathrm{a}$ & 37 & 25.5 & $\mathrm{n} / \mathrm{a}$ & $79^{a}$ & $\mathrm{n} / \mathrm{a}$ & $\mathrm{n} / \mathrm{a}$ \\
\hline & WOFOUR-1-Ni ${ }^{41}$ & 25 & 1 & $52|3.5| 11.5$ & 66 & 14.8 & 4.5 & $180^{\#}$ & $26^{\#}$ & $\mathrm{n} / \mathrm{a}$ \\
\hline & SIFSIX-2-Cu-i ${ }^{16}$ & 25 & 1 & $121.2|3.4| 10.5$ & 32 & 35.6 & 11.5 & $140^{\#}$ & 33 & $\mathrm{n} / \mathrm{a}$ \\
\hline & CAU $-1^{42}$ & 0 & 1 & $165|5.6| 27$ & 48 & 29.5 & 6.1 & $100^{\mathrm{b}}$ & $28^{\mathrm{b}}$ & $\mathrm{n} / \mathrm{a}$ \\
\hline & NbOFFIVE-Ni ${ }^{43}$ & 25 & 1 & $51.7|\mathrm{n} / \mathrm{a}| 2.2$ & 54 & $\mathrm{n} / \mathrm{a}$ & 23.1 & $\mathrm{n} / \mathrm{a}$ & 370 & $\mathrm{n} / \mathrm{a}$ \\
\hline & TIFSIX-3-Ni ${ }^{43}$ & 25 & 1 & $48.6|\mathrm{n} / \mathrm{a}| 4.8$ & 50 & $\mathrm{n} / \mathrm{a}$ & 10.2 & $\mathrm{n} / \mathrm{a}$ & 160 & $\mathrm{n} / \mathrm{a}$ \\
\hline & SIFSIX-3-Ni ${ }^{43}$ & 25 & 1 & $59|\mathrm{n} / \mathrm{a}| 6.6$ & 45 & $\mathrm{n} / \mathrm{a}$ & 8.9 & $\mathrm{n} / \mathrm{a}$ & 130 & $\mathrm{n} / \mathrm{a}$ \\
\hline & SIFSIX-14-Cu-i ${ }^{44}$ & 25 & 1 & $109|\mathrm{n} / \mathrm{a}| 1.1$ & 38 & $\mathrm{n} / \mathrm{a}$ & 116.0 & $\mathrm{n} / \mathrm{a}$ & $\mathrm{n} / \mathrm{a}$ & $\mathrm{n} / \mathrm{a}$ \\
\hline & mmen-Mg-dobdc ${ }^{45}$ & 25 & 1 & $86.3|2.35| \mathrm{n} / \mathrm{a}$ & $71^{\mathrm{c}}$ & 36.7 & $\mathrm{n} / \mathrm{a}$ & $\mathrm{n} / \mathrm{a}$ & $\mathrm{n} / \mathrm{a}$ & $\mathrm{n} / \mathrm{a}$ \\
\hline
\end{tabular}

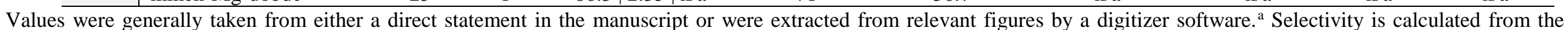

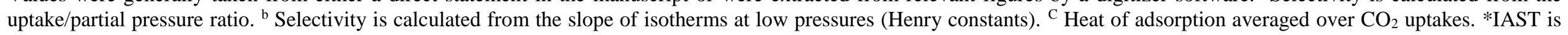




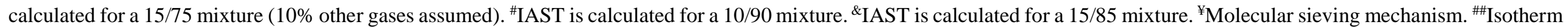
data were taken from the literature for zeolite $13 \mathrm{X}^{10}$ and other materials ${ }^{11}$ to calculate IAST selectivities at 1 bar and $313 \mathrm{~K}$ (see IAST calculation section for fitting parameters).

Table S11. Separation metrics relevant to $\mathrm{C}_{2} \mathrm{H}_{2} / \mathrm{CO}_{2}$ separations for MUF-16 in comparison to other top-performing materials reported in the literature.

\begin{tabular}{|c|c|c|c|c|c|c|c|c|}
\hline MOF & $\mathbf{T}\left({ }^{\circ} \mathbf{C}\right)$ & $\begin{array}{c}\mathbf{P} \\
\text { (bar) }\end{array}$ & $\begin{array}{c}\mathrm{CO}_{2} \\
\text { uptake } \\
(\mathrm{mmol} / \mathrm{g})\end{array}$ & $\begin{array}{c}\mathrm{C}_{2} \mathrm{H}_{2} \\
\text { uptake } \\
(\mathrm{mmol} / \mathrm{g})\end{array}$ & $\begin{array}{c}\mathbf{Q}_{\text {st of }} \\
\mathrm{CO}_{2}{ }^{\mathrm{a}} \\
(\mathrm{kJ} / \mathrm{mol})\end{array}$ & $\begin{array}{c}\mathbf{Q}_{\text {st of }} \\
\mathbf{C}_{2} \mathbf{H}_{2}{ }^{a} \\
(\mathbf{k J} / \mathbf{m o l})\end{array}$ & $\begin{array}{l}\text { Uptake } \\
\text { ratio* }\end{array}$ & $\begin{array}{c}\text { IAST } \\
\text { selectivity } \\
(50 / 50)^{*}\end{array}$ \\
\hline \multicolumn{9}{|c|}{$\mathrm{CO}_{2}$-selective MOFs } \\
\hline MUF-16 & 20 & 1 & 2.14 & 0.18 & 34 & $¥$ & 12.0 & 510 \\
\hline$[\mathrm{Mn}(\mathrm{bdc})(\mathrm{dpe})]^{46}$ & 0 & 1 & 2.08 & 0.32 & 29.5 & 27.8 & 6.4 & 9.0 \\
\hline SIFSIX-3-Ni ${ }^{47}$ & 25 & 1 & 2.80 & 3.30 & 51 & 36.5 & 0.8 & $7.5^{\&}$ \\
\hline $\mathrm{K}_{2}\left[\mathrm{Cr}_{3} \mathrm{O}(\mathrm{OOCH})_{6}{ }^{4}\right.$ & 5 & 1 & 0.50 & 0.10 & 38 & 30 & 4.5 & $5.6^{\# \#}$ \\
\hline CD-MOF-1 ${ }^{48}$ & 25 & 1 & 2.87 & 2.23 & 41 & 17 & 1.3 & $3.4^{\&}$ \\
\hline CD-MOF-2 ${ }^{48}$ & 25 & 1 & 2.67 & 2.03 & 67.5 & 25 & 1.3 & $6.1^{\&}$ \\
\hline \multicolumn{9}{|c|}{$\mathrm{C}_{2} \mathrm{H}_{2}$-selective MOFs } \\
\hline UTSA-300a $a^{49}$ & 25 & 1 & 0.15 & 3.10 & - & 57 & 20.6 & 700 \\
\hline NKMOF-1-Ni ${ }^{50}$ & 25 & 1 & 2.27 & 2.67 & 41 & 60 & 1.2 & 22 \\
\hline $\mathrm{HOF}-3 \mathrm{a}^{51}$ & 23 & 1 & 0.93 & 2.14 & 42 & 19.5 & 2.3 & 21 \\
\hline$\left[\mathrm{Ni}_{3}(\mathrm{HCOO})_{6}\right]^{52}$ & 25 & 1 & 3.00 & 4.20 & 24.5 & 41 & 1.4 & 21 \\
\hline SNNU-45 53 & 25 & 1 & 4.34 & 5.98 & 27.1 & 40 & 1.37 & 4.5 \\
\hline ZJU-196a ${ }^{54}$ & 25 & 1 & 0.35 & 3.70 & - & 39 & 10.6 & 18 \\
\hline $\mathrm{JCM}-1^{55}$ & 25 & 1 & 1.69 & 3.34 & 33 & 36.5 & 2.0 & 14 \\
\hline DICRO-4-Ni-i ${ }^{56}$ & 25 & 1 & 1.02 & 1.91 & 34 & 38 & 1.9 & 13.5 \\
\hline UTSA-74a $a^{57}$ & 25 & 1 & 3.00 & 4.80 & 25.5 & 31.5 & 1.6 & 8 \\
\hline TIFSIX-2-Cu-i ${ }^{\mathbf{4}}$ & 25 & 1 & 4.20 & 4.10 & 36 & 46 & 0.97 & 6 \\
\hline $\mathrm{Cu}-\mathrm{BTC}^{\mathbf{3 4}, \mathbf{5 1}, \mathbf{5 8}}$ & 25 & 1 & 5.10 & 8.90 & 26.9 & 30 & 1.7 & 5.5 \\
\hline MAF- $2^{59}$ & 25 & 1 & 0.82 & 3.90 & 27 & 33 & 4.7 & 5 \\
\hline UTSA-50a $a^{51}$ & 23 & 1 & 3.10 & 4.10 & 27.8 & 32 & 1.3 & 5 \\
\hline FJU-90a ${ }^{60}$ & 25 & 1 & 4.92 & 8.03 & 21 & 25 & 1.6 & 4.3 \\
\hline ZJU-60a ${ }^{61}$ & 23 & 1 & 3.12 & 6.69 & 15.5 & 17.5 & 2.1 & 4 \\
\hline ZJU-10a ${ }^{62}$ & 25 & 1 & 3.66 & 7.58 & 26 & 39 & 2.1 & 4 \\
\hline MFM-188 ${ }^{63}$ & 25 & 1 & 5.35 & 10.20 & 20.8 & 32.5 & 1.9 & 3.7 \\
\hline
\end{tabular}

作 are given with respect to the ratio of the highly adsorbed component to the weakly adsorbed component from an equimolar mixture. \& Fitting parameters were taken from the literature for SIFSIX-3- $\mathrm{Ni}^{47}$ and for CD-MOFs ${ }^{48}$ and to calculate IAST selectivity for an equimolar mixture. ${ }^{\# \#}$ Isotherm data were extracted from ${ }^{4}$ using a digitizer software and so we could calculate IAST selectivity for an equimolar mixture. ${ }^{\ddagger}$ Adsorption amount is too low to reliably calculate $\mathrm{Q}_{\text {st }}$ 


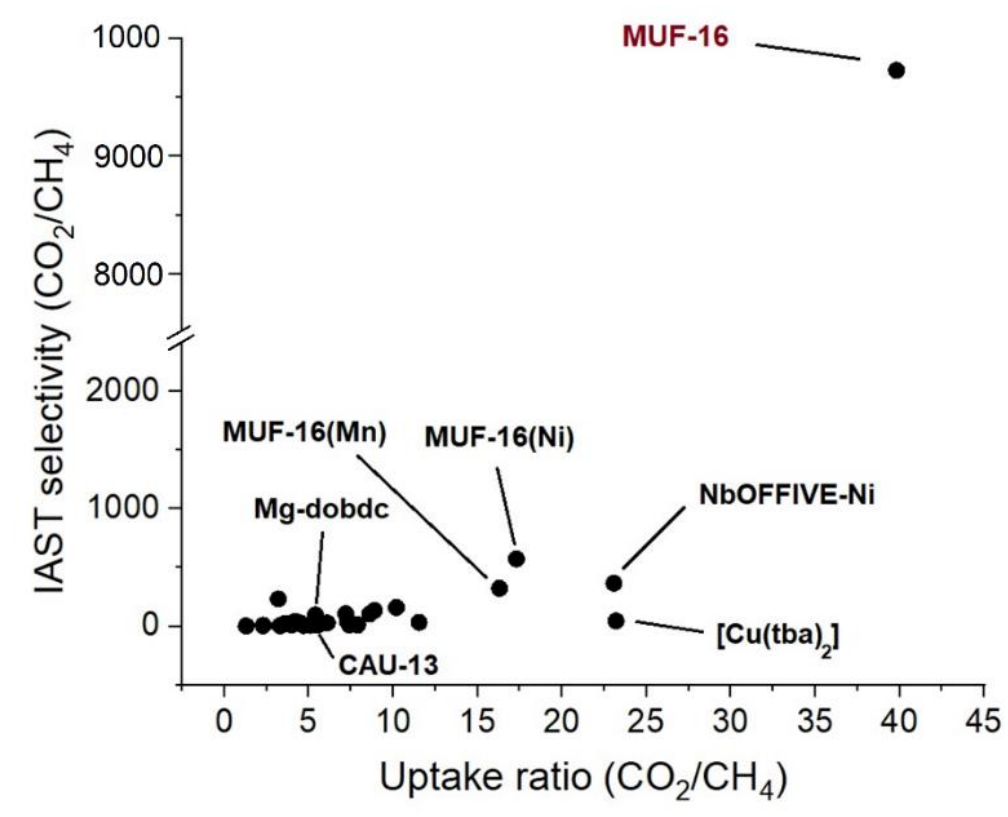

Figure S78. IAST selectivity of MUF-16 family for an equimolar mixture of $\mathrm{CO}_{2} / \mathrm{CH}_{4}$ in comparison to top top-performing MOFs at 1 bar and ambient temperature versus their uptake ratio at 1 bar.

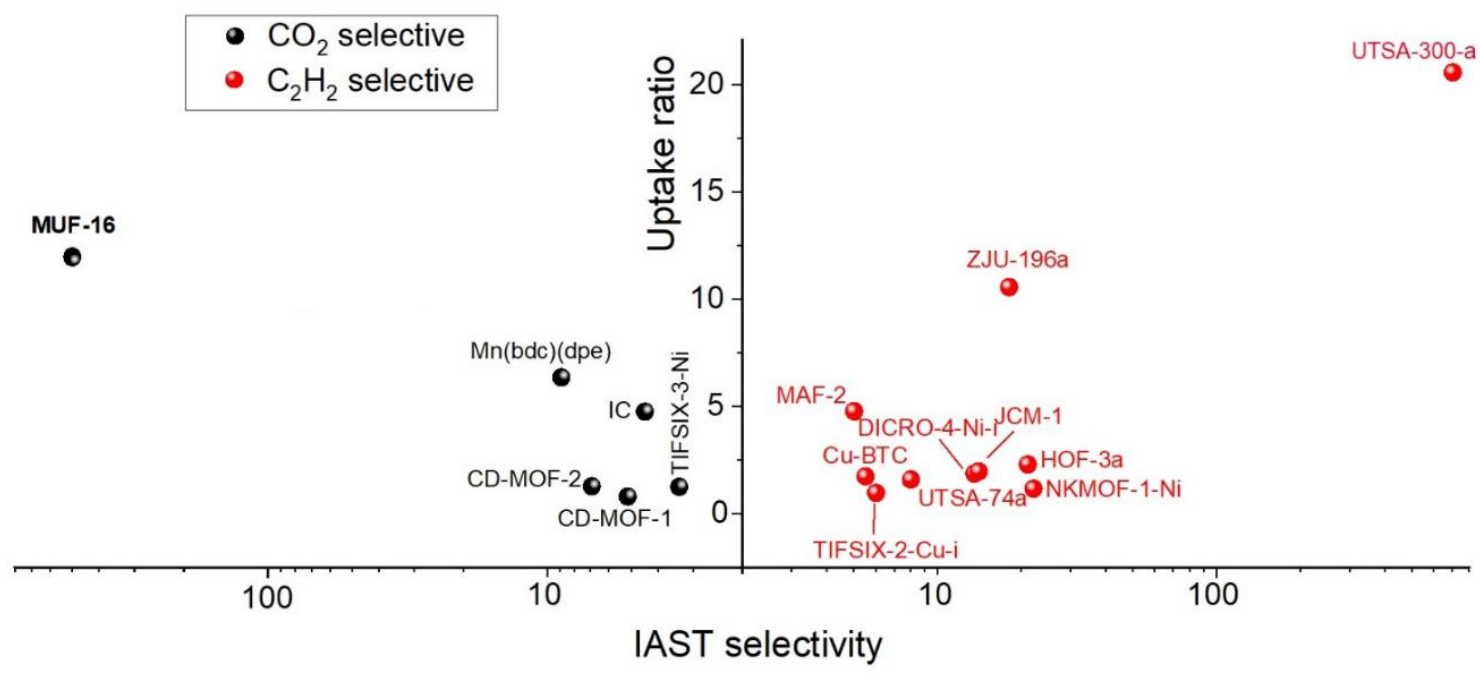

Figure S79. Predicted IAST selectivity (log scale) from an equimolar mixture of $\mathrm{CO}_{2} / \mathrm{C}_{2} \mathrm{H}_{2}$ plotted against uptake ratio at 1 bar and 293-298 K (except for IC (278 K) and

[Mn(bdc)(dpe)] (273 K)) for MUF-16 in comparison to the best materials reported to date. Selectivity and uptake ratios are defined as $\mathrm{CO}_{2} / \mathrm{C}_{2} \mathrm{H}_{2}$ and $\mathrm{C}_{2} \mathrm{H}_{2} / \mathrm{CO}_{2}$ for $\mathrm{CO}_{2}$-selective and $\mathrm{C}_{2} \mathrm{H}_{2}$-selective materials, respectively. 


\section{References}

1. Willems, T. F.; Rycroft, C. H.; Kazi, M.; Meza, J. C.; Haranczyk, M., Algorithms and tools for high-throughput geometry-based analysis of crystalline porous materials. Microporous Mesoporous Mater. 2012, 149 (1), 134-141.

2. Dubbeldam, D.; Calero, S.; Ellis, D. E.; Snurr, R. Q., RASPA: molecular simulation software for adsorption and diffusion in flexible nanoporous materials. Mol. Simul. 2016, 42 (2), 81-101.

3. Li, J.-R.; Kuppler, R. J.; Zhou, H.-C., Selective gas adsorption and separation in metalorganic frameworks. Chem. Soc. Rev. 2009, 38 (5), 1477-1504.

4. Eguchi, R.; Uchida, S.; Mizuno, N., Inverse and High CO2/C2H2 Sorption Selectivity in Flexible Organic-Inorganic Ionic Crystals. Angew. Chem., Int. Ed. 2012, 51 (7), 16351639.

5. Reid, C. R.; Thomas, K. M., Adsorption Kinetics and Size Exclusion Properties of Probe Molecules for the Selective Porosity in a Carbon Molecular Sieve Used for Air Separation. J. Phys. Chem. B 2001, 105 (43), 10619-10629.

6. Li, L.; Lin, R.-B.; Wang, X.; Zhou, W.; Jia, L.; Li, J.; Chen, B., Kinetic separation of propylene over propane in a microporous metal-organic framework. Chem. Eng. J. 2018, 354, 977-982.

7. Walton, K. S.; Snurr, R. Q., Applicability of the BET Method for Determining Surface Areas of Microporous Metal-Organic Frameworks. J. Am. Chem. Soc. 2007, 129, 85528558.

8. Myers, A.; Prausnitz, J. M., Thermodynamics of mixed-gas adsorption. AIChE J. 1965, $11(1), 121-127$.

9. Simon, C. M.; Smit, B.; Haranczyk, M., pyIAST: Ideal adsorbed solution theory (IAST) Python package. Comput. Phys. Commun. 2016, 200, 364-380.

10. Belmabkhout, Y.; Pirngruber, G.; Jolimaitre, E.; Methivier, A., A complete experimental approach for synthesis gas separation studies using static gravimetric and column breakthrough experiments. Adsorption 2007, 13 (3-4), 341-349.

11. Herm, Z. R.; Swisher, J. A.; Smit, B.; Krishna, R.; Long, J. R., Metal-Organic Frameworks as Adsorbents for Hydrogen Purification and Precombustion Carbon Dioxide Capture. J. Am. Chem. Soc. 2011, 133 (15), 5664-5667.

12. Qazvini, O. T.; Babarao, R.; Shi, Z.-L.; Zhang, Y.-B.; Telfer, S. G., A Robust EthaneTrapping Metal-Organic Framework with a High Capacity for Ethylene Purification. $J$. Am. Chem. Soc. 2019.

13. Qazvini, O. T.; Babarao, R.; Telfer, S. G., Multipurpose Metal-Organic Framework for the Adsorption of Acetylene: Ethylene Purification and Carbon Dioxide Removal. Chem. Mater. 2019, 31 (13), 4919-4926.

14. Dincă, M.; Dailly, A.; Liu, Y.; Brown, C. M.; Neumann, D. A.; Long, J. R., Hydrogen Storage in a Microporous Metal-Organic Framework with Exposed Mn2+ Coordination Sites. J. Am. Chem. Soc. 2006, 128 (51), 16876-16883.

15. Cavenati, S.; Grande, C. A.; Rodrigues, A. E., Adsorption Equilibrium of Methane, Carbon Dioxide, and Nitrogen on Zeolite 13X at High Pressures. J. Chem. Eng. Data 2004, 49 (4), 1095-1101.

16. Nugent, P.; Belmabkhout, Y.; Burd, S. D.; Cairns, A. J.; Luebke, R.; Forrest, K.; Pham, T.; Ma, S.; Space, B.; Wojtas, L.; Eddaoudi, M.; Zaworotko, M. J., Porous materials with optimal adsorption thermodynamics and kinetics for CO2 separation. Nature 2013, 495, 80 . 
17. Saha, D.; Bao, Z.; Jia, F.; Deng, S., Adsorption of CO2, CH4, N2O, and N2 on MOF-5, MOF-177, and Zeolite 5A. Environ. Sci. Technol. 2010, 44 (5), 1820-1826.

18. Nam, G.-M.; Jeong, B.-M.; Kang, S.-H.; Lee, B.-K.; Choi, D.-K., Equilibrium Isotherms of $\mathrm{CH} 4, \mathrm{C} 2 \mathrm{H} 6, \mathrm{C} 2 \mathrm{H} 4, \mathrm{~N} 2$, and $\mathrm{H} 2$ on Zeolite 5A Using a Static Volumetric Method. J. Chem. Eng. Data 2005, 50 (1), 72-76.

19. Shao, W.; Zhang, L.; Li, L.; Lee, R. L., Adsorption of CO2 and N2 on synthesized NaY zeolite at high temperatures. Adsorption 2009, 15 (5), 497.

20. Ahmed, M. J.; Theydan, S. K., Equilibrium isotherms studies for light hydrocarbons adsorption on 4A molecular sieve zeolite. J. Pet. Sci. Eng. 2013, 108, 316-320.

21. McEwen, J.; Hayman, J.-D.; Ozgur Yazaydin, A., A comparative study of CO2, CH4 and N2 adsorption in ZIF-8, Zeolite-13X and BPL activated carbon. Chem. Phys. 2013, 412, $72-76$.

22. Delgado, J. A.; Águeda, V. I.; Uguina, M. A.; Sotelo, J. L.; Brea, P.; Grande, C. A., Adsorption and Diffusion of $\mathrm{H} 2, \mathrm{CO}, \mathrm{CH} 4$, and $\mathrm{CO} 2$ in BPL Activated Carbon and 13X Zeolite: Evaluation of Performance in Pressure Swing Adsorption Hydrogen Purification by Simulation. Ind. Eng. Chem. Res. 2014, 53 (40), 15414-15426.

23. Shekhah, O.; Belmabkhout, Y.; Chen, Z.; Guillerm, V.; Cairns, A.; Adil, K.; Eddaoudi, M., Made-to-order metal-organic frameworks for trace carbon dioxide removal and air capture. Nat. Commun. 2014, 5, 4228.

24. Datta, S. J.; Khumnoon, C.; Lee, Z. H.; Moon, W. K.; Docao, S.; Nguyen, T. H.; Hwang, I. C.; Moon, D.; Oleynikov, P.; Terasaki, O.; Yoon, K. B., CO2 capture from humid flue gases and humid atmosphere using a microporous coppersilicate. Science 2015, 350 (6258), 302-306.

25. Nandi, S.; Collins, S.; Chakraborty, D.; Banerjee, D.; Thallapally, P. K.; Woo, T. K.; Vaidhyanathan, R., Ultralow parasitic energy for postcombustion $\mathrm{CO} 2$ capture realized in a nickel isonicotinate metal-organic framework with excellent moisture stability. J. Am. Chem. Soc. 2017, 139 (5), 1734-1737.

26. Hou, L.; Shi, W.-J.; Wang, Y.-Y.; Guo, Y.; Jin, C.; Shi, Q.-Z., A rod packing microporous metal-organic framework: unprecedented ukv topology, high sorption selectivity and affinity for CO2. Chem. Commun. 2011, 47 (19), 5464-5466.

27. Wen, H.-M.; Liao, C.; Li, L.; Alsalme, A.; Alothman, Z.; Krishna, R.; Wu, H.; Zhou, W.; $\mathrm{Hu}$, J.; Chen, B., A metal-organic framework with suitable pore size and dual functionalities for highly efficient post-combustion CO2 capture. J. Mater. Chem. A 2019.

28. Bloch, W. M.; Babarao, R.; Hill, M. R.; Doonan, C. J.; Sumby, C. J., Post-synthetic Structural Processing in a Metal-Organic Framework Material as a Mechanism for Exceptional CO2/N2 Selectivity. J. Am. Chem. Soc. 2013, 135 (28), 10441-10448.

29. An, J.; Geib, S. J.; Rosi, N. L., High and Selective CO2 Uptake in a Cobalt Adeninate Metal-Organic Framework Exhibiting Pyrimidine- and Amino-Decorated Pores. J. Am. Chem. Soc. 2010, 132 (1), 38-39.

30. Lu, W.; Sculley, J. P.; Yuan, D.; Krishna, R.; Wei, Z.; Zhou, H.-C., Polyamine-Tethered Porous Polymer Networks for Carbon Dioxide Capture from Flue Gas. Angew. Chem., Int. Ed. 2012, 51 (30), 7480-7484.

31. McDonald, T. M.; D'Alessandro, D. M.; Krishna, R.; Long, J. R., Enhanced carbon dioxide capture upon incorporation of $\mathrm{N}, \mathrm{N}^{\prime}$-dimethylethylenediamine in the metal-organic framework CuBTTri. Chem. Sci. 2011, 2 (10), 2022.

32. Nandi, S.; De Luna, P.; Daff, T. D.; Rother, J.; Liu, M.; Buchanan, W.; Hawari, A. I.; Woo, T. K.; Vaidhyanathan, R., A single-ligand ultra-microporous MOF for precombustion CO2 capture and hydrogen purification. Sci. Adv. 2015, 1 (11), e1500421. 
33. Masala, A.; Vitillo, J. G.; Mondino, G.; Grande, C. A.; Blom, R.; Manzoli, M.; Marshall, M.; Bordiga, S., CO2 Capture in Dry and Wet Conditions in UTSA-16 Metal-Organic Framework. ACS Appl. Mater. Interfaces 2017, 9 (1), 455-463.

34. Xiang, S.; He, Y.; Zhang, Z.; Wu, H.; Zhou, W.; Krishna, R.; Chen, B., Microporous metal-organic framework with potential for carbon dioxide capture at ambient conditions. Nat. Commun. 2012, 3, 954.

35. Lee, W. R.; Hwang, S. Y.; Ryu, D. W.; Lim, K. S.; Han, S. S.; Moon, D.; Choi, J.; Hong, C. S., Diamine-functionalized metal-organic framework: exceptionally high $\mathrm{CO} 2$ capacities from ambient air and flue gas, ultrafast $\mathrm{CO} 2$ uptake rate, and adsorption mechanism. Energy Environ. Sci. 2014, 7 (2), 744-751.

36. Liang, Z.; Marshall, M.; Chaffee, A. L., CO2 Adsorption-Based Separation by Metal Organic Framework (Cu-BTC) versus Zeolite (13X). Energy Fuels 2009, 23 (5), 27852789.

37. Liu, B.; Smit, B., Comparative Molecular Simulation Study of CO2/N2 and CH4/N2 Separation in Zeolites and Metal-Organic Frameworks. Langmuir 2009, 25 (10), 59185926.

38. Mason, J. A.; Sumida, K.; Herm, Z. R.; Krishna, R.; Long, J. R., Evaluating metal-organic frameworks for post-combustion carbon dioxide capture via temperature swing adsorption. Energy Environ. Sci. 2011, 4 (8), 3030-3040.

39. Pal, A.; Chand, S.; Elahi, S. M.; Das, M. C., A microporous MOF with a polar pore surface exhibiting excellent selective adsorption of $\mathrm{CO} 2$ from $\mathrm{CO} 2-\mathrm{N} 2$ and $\mathrm{CO} 2-\mathrm{CH} 4$ gas mixtures with high CO2 loading. Dalton Trans. 2017, 46 (44), 15280-15286.

40. Scott, H. S.; Ogiwara, N.; Chen, K.-J.; Madden, D. G.; Pham, T.; Forrest, K.; Space, B.; Horike, S.; Perry Iv, J. J.; Kitagawa, S.; Zaworotko, M. J., Crystal engineering of a family of hybrid ultramicroporous materials based upon interpenetration and dichromate linkers. Chem. Sci. 2016, 7 (8), 5470-5476.

41. Mohamed, M. H.; Elsaidi, S. K.; Pham, T.; Forrest, K. A.; Tudor, B.; Wojtas, L.; Space, B.; Zaworotko, M. J., Pillar substitution modulates $\mathrm{CO} 2$ affinity in "mmo" topology networks. Chem. Commun. 2013, 49 (84), 9809-9811.

42. Si, X.; Jiao, C.; Li, F.; Zhang, J.; Wang, S.; Liu, S.; Li, Z.; Sun, L.; Xu, F.; Gabelica, Z.; Schick, C., High and selective CO2 uptake, H2storage and methanol sensing on the aminedecorated 12-connected MOF CAU-1. Energy Environ. Sci. 2011, 4 (11), 4522-4527.

43. Madden, D. G.; O’Nolan, D.; Chen, K.-J.; Hua, C.; Kumar, A.; Pham, T.; Forrest, K. A.; Space, B.; Perry, J. J.; Khraisheh, M., Highly selective CO 2 removal for one-step liquefied natural gas processing by physisorbents. Chem. Commun. 2019, 55 (22), 3219-3222.

44. Jiang, M.; Li, B.; Cui, X.; Yang, Q.; Bao, Z.; Yang, Y.; Wu, H.; Zhou, W.; Chen, B.; Xing, H., Controlling Pore Shape and Size of Interpenetrated Anion-Pillared Ultramicroporous Materials Enables Molecular Sieving of CO2 Combined with Ultrahigh Uptake Capacity. ACS Appl. Mater. Interfaces 2018, 10 (19), 16628-16635.

45. McDonald, T. M.; Lee, W. R.; Mason, J. A.; Wiers, B. M.; Hong, C. S.; Long, J. R., Capture of Carbon Dioxide from Air and Flue Gas in the Alkylamine-Appended MetalOrganic Framework mmen- $\mathrm{Mg}_{2}$ (dobpdc). J. Am. Chem. Soc. 2012, 134 (16), 7056-7065.

46. Foo, M. L.; Matsuda, R.; Hijikata, Y.; Krishna, R.; Sato, H.; Horike, S.; Hori, A.; Duan, J.; Sato, Y.; Kubota, Y.; Takata, M.; Kitagawa, S., An Adsorbate Discriminatory Gate Effect in a Flexible Porous Coordination Polymer for Selective Adsorption of $\mathrm{CO} 2$ over C2H2. J. Am. Chem. Soc. 2016, 138 (9), 3022-3030.

47. Chen, K.-J.; Scott, Hayley S.; Madden, David G.; Pham, T.; Kumar, A.; Bajpai, A.; Lusi, M.; Forrest, Katherine A.; Space, B.; Perry, John J.; Zaworotko, Michael J., Benchmark $\mathrm{C} 2 \mathrm{H} 2 / \mathrm{CO} 2$ and $\mathrm{CO} 2 / \mathrm{C} 2 \mathrm{H} 2$ Separation by Two Closely Related Hybrid Ultramicroporous Materials. Chem 2016, 1 (5), 753-765. 
48. Li, L.; Wang, J.; Zhang, Z.; Yang, Q.; Yang, Y.; Su, B.; Bao, Z.; Ren, Q., Inverse Adsorption Separation of $\mathrm{CO} 2 / \mathrm{C} 2 \mathrm{H} 2$ Mixture in Cyclodextrin-Based Metal-Organic Frameworks. ACS Appl. Mater. Interfaces 2019, 11 (2), 2543-2550.

49. Lin, R.-B.; Li, L.; Wu, H.; Arman, H.; Li, B.; Lin, R.-G.; Zhou, W.; Chen, B., Optimized separation of acetylene from carbon dioxide and ethylene in a microporous material. $J$. Am. Chem. Soc. 2017, 139 (23), 8022-8028.

50. Peng, Y.-L.; Pham, T.; Li, P.; Wang, T.; Chen, Y.; Chen, K.-J.; Forrest, K. A.; Space, B.; Cheng, P.; Zaworotko, M. J.; Zhang, Z., Robust Ultramicroporous Metal-Organic Frameworks with Benchmark Affinity for Acetylene. Angew. Chem., Int. Ed. 2018, 57 (34), 10971-10975.

51. Li, P.; He, Y.; Zhao, Y.; Weng, L.; Wang, H.; Krishna, R.; Wu, H.; Zhou, W.; O'Keeffe, M.; Han, Y.; Chen, B., A Rod-Packing Microporous Hydrogen-Bonded Organic Framework for Highly Selective Separation of C2H2/CO2 at Room Temperature. Angew. Chem., Int. Ed. 2015, 54 (2), 574-577.

52. Zhang, L.; Jiang, K.; Zhang, J.; Pei, J.; Shao, K.; Cui, Y.; Yang, Y.; Li, B.; Chen, B.; Qian, G., Low-Cost and High-Performance Microporous Metal-Organic Framework for Separation of Acetylene from Carbon Dioxide. ACS Sustainable Chemistry \& Engineering 2019, 7 (1), 1667-1672.

53. Li, Y.-P.; Wang, Y.; Xue, Y.-Y.; Li, H.-P.; Zhai, Q.-G.; Li, S.-N.; Jiang, Y.-C.; Hu, M.$\mathrm{C} . ; \mathrm{Bu}, \mathrm{X}$., Ultramicroporous Building Units as a Path to Bi-microporous Metal-Organic Frameworks with High Acetylene Storage and Separation Performance. Angew. Chem. Int. Ed. O (0).

54. Zhang, L.; Jiang, K.; Li, L.; Xia, Y.-P.; Hu, T.-L.; Yang, Y.; Cui, Y.; Li, B.; Chen, B.; Qian, G., Efficient separation of $\mathrm{C} 2 \mathrm{H} 2$ from $\mathrm{C} 2 \mathrm{H} 2 / \mathrm{CO} 2$ mixtures in an acid-base resistant metal-organic framework. Chem. Commun. 2018, 54 (38), 4846-4849.

55. Lee, J.; Chuah, C. Y.; Kim, J.; Kim, Y.; Ko, N.; Seo, Y.; Kim, K.; Bae, T. H.; Lee, E., Separation of Acetylene from Carbon Dioxide and Ethylene by a Water-Stable Microporous Metal-Organic Framework with Aligned Imidazolium Groups inside the Channels. Angew. Chem., Int. Ed. 2018, 57 (26), 7869-7873.

56. Scott, H. S.; Shivanna, M.; Bajpai, A.; Madden, D. G.; Chen, K.-J.; Pham, T.; Forrest, K. A.; Hogan, A.; Space, B.; Perry Iv, J. J.; Zaworotko, M. J., Highly Selective Separation of $\mathrm{C} 2 \mathrm{H} 2$ from $\mathrm{CO} 2$ by a New Dichromate-Based Hybrid Ultramicroporous Material. ACS Appl. Mater. Interfaces 2017, 9 (39), 33395-33400.

57. Luo, F.; Yan, C.; Dang, L.; Krishna, R.; Zhou, W.; Wu, H.; Dong, X.; Han, Y.; Hu, T.-L.; O'Keeffe, M.; Wang, L.; Luo, M.; Lin, R.-B.; Chen, B., UTSA-74: A MOF-74 Isomer with Two Accessible Binding Sites per Metal Center for Highly Selective Gas Separation. J. Am. Chem. Soc. 2016, 138 (17), 5678-5684.

58. Xiang, S.; Zhou, W.; Gallegos, J. M.; Liu, Y.; Chen, B., Exceptionally High Acetylene Uptake in a Microporous Metal-Organic Framework with Open Metal Sites. J. Am. Chem. Soc. 2009, 131 (34), 12415-12419.

59. Zhang, J.-P.; Chen, X.-M., Optimized Acetylene/Carbon Dioxide Sorption in a Dynamic Porous Crystal. J. Am. Chem. Soc. 2009, 131 (15), 5516-5521.

60. Ye, Y.; Ma, Z.; Lin, R.-B.; Krishna, R.; Zhou, W.; Lin, Q.; Zhang, Z.; Xiang, S.; Chen, B., Pore Space Partition within a Metal-Organic Framework for Highly Efficient C2H2/CO2 Separation. J. Am. Chem. Soc. 2019, 141 (9), 4130-4136.

61. Duan, X.; Zhang, Q.; Cai, J.; Yang, Y.; Cui, Y.; He, Y.; Wu, C.; Krishna, R.; Chen, B.; Qian, G., A new metal-organic framework with potential for adsorptive separation of methane from carbon dioxide, acetylene, ethylene, and ethane established by simulated breakthrough experiments. J. Mat. Chem. A 2014, 2 (8), 2628-2633. 
62. Duan, X.; Wang, H.; Ji, Z.; Cui, Y.; Yang, Y.; Qian, G., A novel metal-organic framework for high storage and separation of acetylene at room temperature. J. Solid State Chem. 2016, 241, 152-156.

63. Moreau, F.; da Silva, I.; Al Smail, N. H.; Easun, T. L.; Savage, M.; Godfrey, H. G. W.; Parker, S. F.; Manuel, P.; Yang, S.; Schröder, M., Unravelling exceptional acetylene and carbon dioxide adsorption within a tetra-amide functionalized metal-organic framework. Nat. Commun. 2017, 8, 14085. 